\title{
A reevaluation of the evidence supporting an unorthodox hypothesis on the origin of extant amphibians
}

\author{
David Marjanović, Michel Laurin \\ UMR 7179, Équipe 'Squelette des Vertébrés', CNRS/Université Paris 6, 4 place Jussieu, case 19, 75005 Paris, \\ France,david.marjanovic@gmx.at
}

Key words: Albanerpetontidae, Brachydectes, coding, continuous characters, data matrix, Gerobatrachus, Gymnophioniformes, Gymnophionomorpha, Lissamphibia, Lysorophia, morphology, ontogeny, paleontology, phylogeny, scoring, stepmatrix gap-weighting

\begin{abstract}
The origin of frogs, salamanders and caecilians is controversial. McGowan published an original hypothesis on lissamphibian origins in 2002 (McGowan, 2002, Zoological Journal of the Linnean Society, 135: 1-32), stating that Gymnophiona was nested inside the 'microsaurian' lepospondyls, this clade was the sister-group of a caudate-salientian-albanerpetontid clade, and both were nested inside the dissorophoid temnospondyls. We have investigated McGowan's data matrix and disagree with the scoring of $35 \%$ of the cells. All taxa and all but two characters are affected. In some cases, we have a different interpretation about correspondence between morphology and character states, or we delimit states differently (or use information that was unknown in 2002). In others, we report probable typographic errors. When these cells and characters are revised, the most parsimonious trees - now longer by almost $64 \%$ - support one of the three commonly advocated hypotheses, namely a monophyletic Lissamphibia nested, together with its sister-group Albanerpetontidae, within the temnospondyls (next to Doleserpeton) - even though we did not add any characters or taxa to the very small data matrix. This exemplifies the impact of errors in data matrices on the results of phylogenetic analyses. Adding the lysorophian Brachydectes, however, results in the Lissamphibia-Albanerpetontidae clade becoming the sister-group of Brachydectes and settling within the lepospondyls rather than the temnospondyls, thus supporting another of the previously published three hypotheses. This latter finding does not change if the recently described Gerobatrachus is also added. Finally, when Doleserpeton is interpreted as morphologically immature (which means scoring three characters as unknown instead of known), Lissamphibia and Albanerpetontidae are again nested within the 'microsaurian' lepospondyls, even though Brachydectes is not included in this analysis. This, too, does not change if Gerobatrachus is added and likewise treated as morphologically immature. Bootstrap supports are rather low under all assumptions. Such lability was to be expected from the small size of the data matrix.
\end{abstract}

\section{Contents}

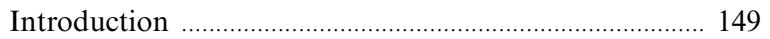

Nomenclatural remarks ..................................................... 152

Phylogenetic nomenclature …………………………..... 152

Rank-based nomenclature …….............................. 154

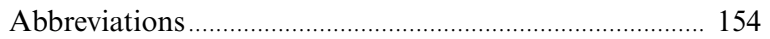

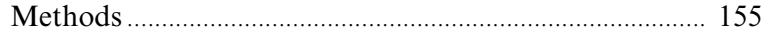

Addition of Brachydectes and homology of its

dermal skull bones..................................................... 155

Ontogeny and phylogenetic position of Doleserpeton. 157

Ontogeny and phylogenetic position of Brachydectes.. 157

Addition of Gerobatrachus and its ontogeny and

phylogenetic position ................................................. 158

Phylogenetic analysis ................................................. 159

Rooting the tree

Interpretation of the OTUs .......................................... 160

Revision of the matrix ................................................... 163

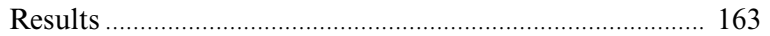

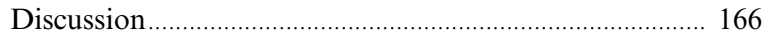

Implications of the size of the matrix .......................... 166

Implications of the quality of the matrix ................... 167

Analyses without Gerobatrachus................................... 168

Interpretation of Gerobatrachus and effects

of its addition to our analysis ...................................... 168

'Microsaur' phylogeny ................................................... 169

The phylogenetic position of Albanerpetontidae ...... 169

Acknowledgments .......................................................... 169

References $\quad 170$

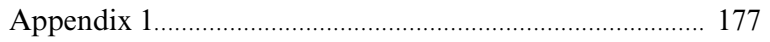

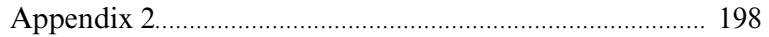

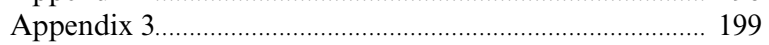

\section{Introduction}

The origin of lissamphibians remains highly contentious, despite decades of intensive research (Vallin 
and Laurin, 2004; Pawley, 2006: appendix 16; Anderson, 2007; Ruta and Coates, 2007; Marjanović and Laurin, 2007; Anderson et al., 2008a). Our hypotheses about the relationships between the relevant extinct taxa (from the late Paleozoic and early Mesozoic) have been fairly stable in phylogenetic analyses over the last two decades (the various groups of 'lepospondyls' are the obvious exception), while widely divergent opinions persist on where to insert the anurans, urodeles and gymnophionans into this tree. Part of the problem is a stratigraphic gap between the oldest known representatives of the lissamphibians on the one hand and the first appearance of most or all of their proposed sistergroups on the other, as noted by Schoch and Milner (2004).

Early phylogenetic analyses of paleontological data divided most early limbed vertebrates into an amphibian clade composed of temnospondyls and lepospondyls, and a reptiliomorph clade composed of embolomeres, seymouriamorphs, diadectomorphs and amniotes (Gauthier et al., 1988; Trueb and Cloutier, 1991; Lombard and Sumida, 1992; Ahlberg and Milner, 1994; Fig. 1a, b). However, nearly all recent paleontological studies indicate that the lepospondyls are closer to the amniotes than the temnospondyls and the seymouriamorphs are, and this topology is now nearly consensual (Carroll, 1995, 2007: fig. 77; Laurin and Reisz, 1997, 1999; Laurin, 1998a, b; Anderson, 2001, 2007; Ruta et al., 2003; Vallin and Laurin, 2004; Pawley, 2006; Ruta and Coates, 2007; Anderson et al., 2008a; see Fig. 1c-e, g-h) - only the position of the extant amphibians within this tree is not. This latter question has not yet been resolved, even though it has been assessed using anatomical data on extant (Carroll and Currie, 1975; Carroll and Holmes, 1980) and extinct (Milner, 1988, 1993; Laurin and Reisz, 1997, 1999; Laurin, 1998a, b; Anderson, 2001, 2007; Ruta et al., 2003; Carroll et al., 2004; Schoch and Milner, 2004; Vallin and Laurin, 2004; Pawley, 2006; Ruta and Coates, 2007; Anderson et al., 2008a) forms, as well as developmentary (Schoch and Carroll, 2003; Schoch, 2006; Anderson, 2007) and molecular data (Laurin, 2002; Zhang et al., 2005; Lee and Anderson, 2006; Marjanović and Laurin, 2007). All molecular analyses (including those which did not have an investigation of lissamphibian origins as their main purpose: e.g., San Mauro et al., 2005; Frost et al., 2006; Roelants et al., 2007) suggest that the extant amphibians are more closely related to each other than to Amniota, as do all morphological analyses based on extant taxa, but paleontological analyses suggest several incompatible hypotheses about lissamphibian origins.

Currently, three main hypotheses (all with variants) on lissamphibian origins are discussed based on morphological data. The first hypothesis (Fig. 1a-d) advocates a single origin within dissorophoid temnospondyls (Bolt, 1969 [with reservations], 1977; Milner, 1988, 1993; Panchen and Smithson, 1988; Trueb and Cloutier, 1991; Lombard and Sumida, 1992; Ahlberg and Milner, 1994; Ruta et al., 2003; Ruta and Coates, 2007; Jenkins and Walsh in Jenkins et al., 2007). The second hypothesis (Fig. 1e) advocates a single origin within lepospondyls (Laurin and Reisz, 1997, 1999; Laurin, 1998a, b; Vallin and Laurin, 2004; see also Pawley, 2006: 239 and appendix 16). In the third hypothesis (Fig. 1f, g), the extant amphibians are deemed to have originated from at least two, but usually three groups of Paleozoic stegocephalians (Carroll and Currie, 1975; Carroll and Holmes, 1980; Schoch and Carroll, 2003; Carroll et al., 2004; Carroll, 2007; Carroll in Jenkins et al., 2007; Anderson, 2007; Anderson et al., 2008a), once or twice within lepospondyls (gymnophionans and sometimes urodeles), and once or twice within dissorophoid temnospondyls (anurans and sometimes urodeles). Unlike the two monophyly hypotheses, it is not compatible with the results of the molecular analyses cited above, and has so far only been supported by two very similar published data matrices (Anderson, 2007; Anderson et al., 2008a) (Fig. 1g).

The phylogenetic analysis by McGowan (2002) supports a fourth hypothesis (Fig. 2): the extant amphibians are diphyletic, the ('microsaurian') lepospondyls are stem gymnophionans, and the lepospondyls including the extant amphibians are nested within the (dissorophoid) temnospondyls, contradicting the consensus that Temnospondyli and Lepospondyli form mutually exclusive clades (Carroll, 1995; Vallin and Laurin, 2004; Pawley, 2006; Ruta and Coates, 2007; Anderson, 2007; Anderson et al., 2008a). This highly unorthodox hypothesis is relevant because another, more recent and more comprehensive, study has obtained similar results (Carroll, 2007: fig. 77; see Fig. 1h). The present study was undertaken solely to determine whether or not the suggestions that the lepospondyls are nested within the temnospondyls, and whether or not the extant amphibians are diphyletic, are supported by 

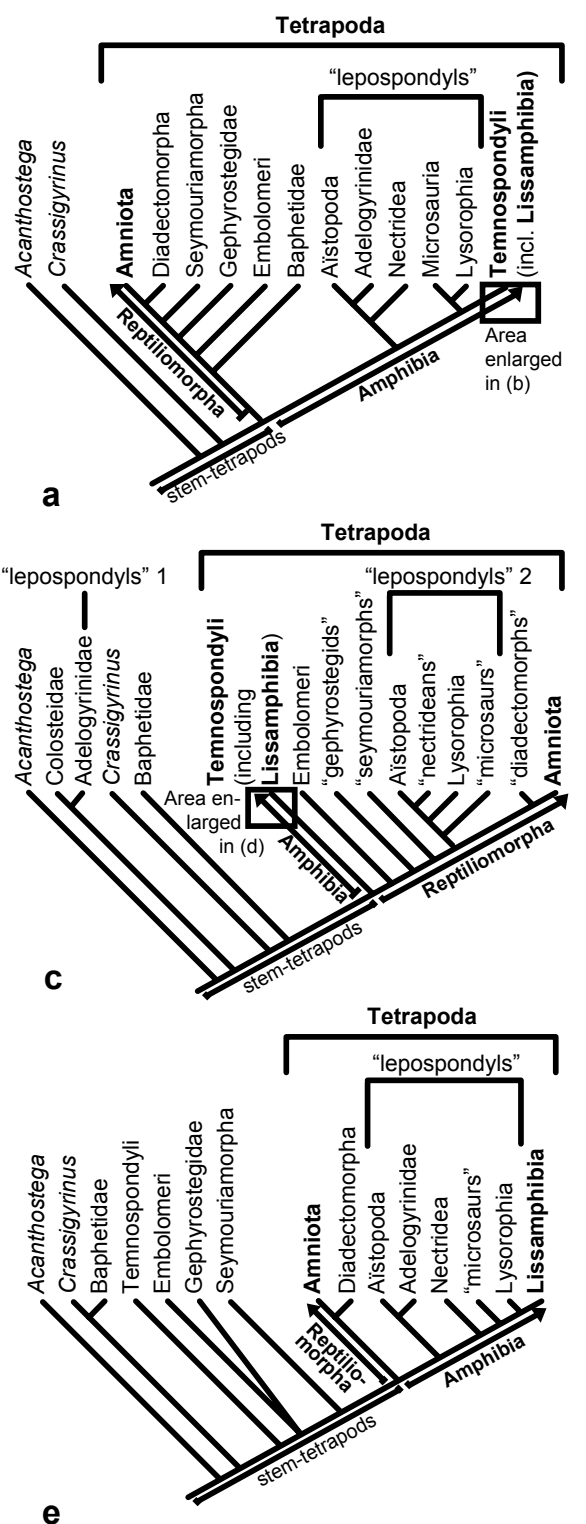

e

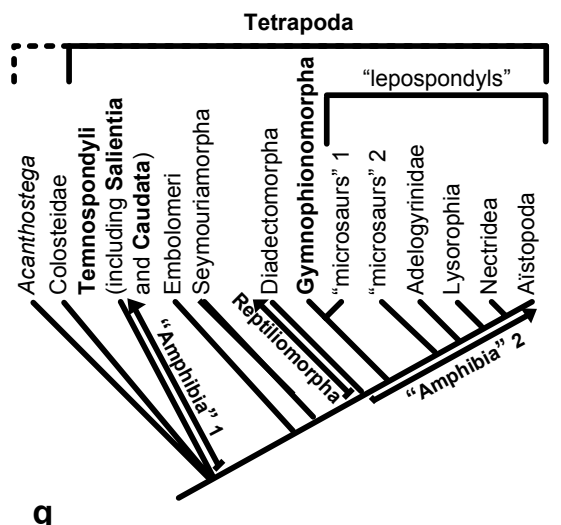

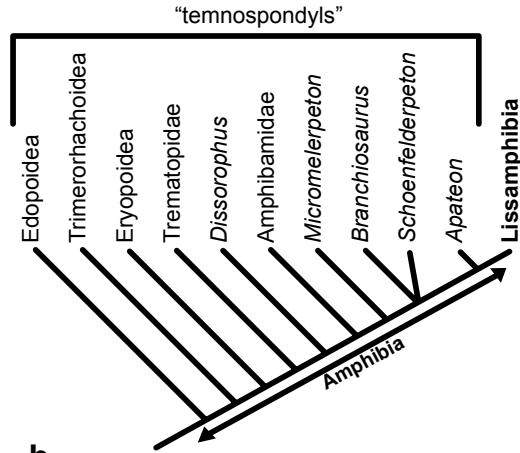

b

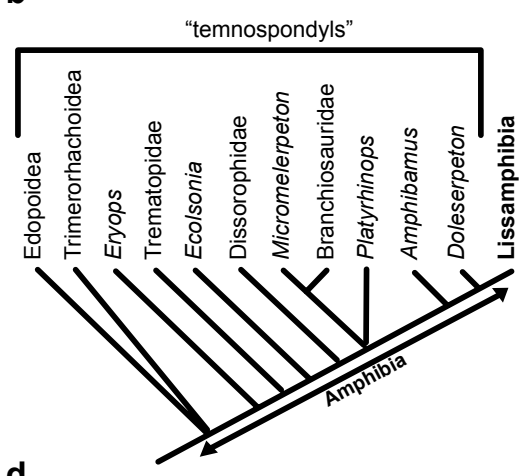

d
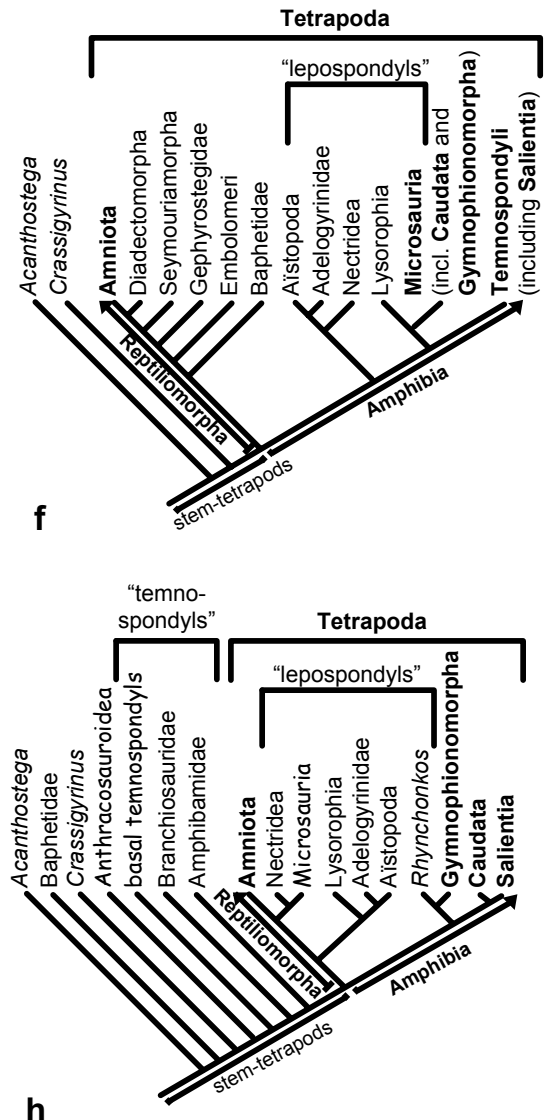

Fig. 1. The currently discussed hypotheses on the origin of the extant amphibians. Extant taxa in bold, paraphyletic taxa in quotation marks. (a, b) Monophyletic origin within the temnospondyls as suggested by Panchen and Smithson (1988), Trueb and Cloutier (1991), Lombard and Sumida (1992), and Ahlberg and Milner (1994); lepospondyls form the basalmost part of the amphibian stem. ((b) is simplified from Trueb and Cloutier, 1991; Amphibamidae contains the topology ('Tersomius' (Doleserpeton, Amphibamus)).) (c, d) Monophyletic origin within the temnospondyls, most lepospondyls are reptiliomorphs; simplified from Ruta and Coates (2007; see also Ruta et al., 2003). (e) Monophyletic origin within the lepospondyls, simplified from Vallin and Laurin (2004; see also Laurin and Reisz, 1997, 1999; Pawley, 2006: 239 and appendix 16). (f) Diphyletic origin in which frogs are temnospondyls, caecilians are lepospondyls, and salamanders may be one or the other (Carroll and Currie, 1975; Carroll and Holmes, 1980; Carroll et al., 2004). (g) Diphyletic origin in which frogs and salamanders are temnospondyls and caecilians are lepospondyls - note that the name Amphibia ceases to apply to any clade; the solid line shows the minimum content of Tetrapoda, the stippled line the maximum content; simplified from Anderson (2007; see also Anderson et al., 2008a). (h) Monophyletic origin in which Rhynchonkos is a lissamphibian, amniotes are lepospondyls, and all of these together are temnospondyls; simplified from the result of Carroll's (2007) analysis (fig. 77), not from his preferred tree (fig. 78) which is 36 steps longer. In (h), 'Anthracosauroidea' is an OTU that includes Embolomeri, Gephyrostegidae and Seymouriamorpha; 'basal temnospondyls' is an OTU composed of Dendrerpeton and Balanerpeton; the 'Microsauria' OTU consists of all 'microsaurs' except Rhynchonkos - Carroll did not test the monophyly of any of these assemblages and in fact believes (Carroll and Currie, 1975, through Carroll, 2007) that the 'Microsauria' OTU is paraphyletic with respect to Rhynchonkos (and Gymnophionomorpha). 
a
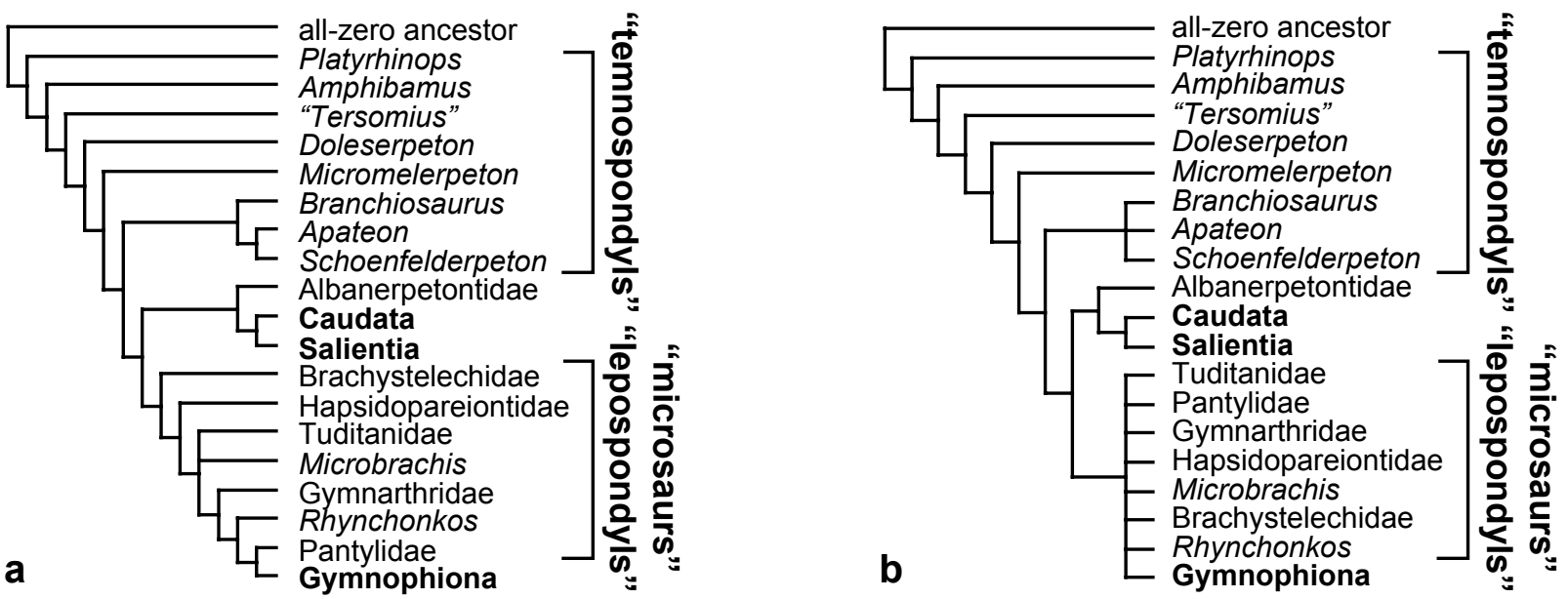

Fig. 2. The impact of ordering characters in McGowan's (2002) matrix. (a) McGowan's (2002: fig. 15) result (strict consensus of the two most parsimonious trees; length $=95$ steps, $\mathrm{CI}=0.4947, \mathrm{RI}=0.7513, \mathrm{RC}=0.3717$ ) obtained by leaving all characters unordered: the microsaurian lepospondyls are closer to Gymnophionomorpha than Batrachia is, and Lissamphibia including the microsaurs is monophyletic within the dissorophoid temnospondyls. (b) Strict and majority-rule consensus (identical) of the 8 most parsimonious trees (length $=97$ steps, $\mathrm{CI}=0.4845, \mathrm{RI}=0.7608, \mathrm{RC}=0.3686$ ) which result when all multistate characters in McGowan's (2002) matrix are ordered according to their state numbers $(0>1>2>3)$. This consensus tree was described but not illustrated by McGowan (2002: 20). Note that, in the present case, ordering the multistate characters reveals additional character conflict and therefore decreases the resolution. Extant taxa are in boldface.

the data which were originally used to advocate them (McGowan, 2002) when these data are subjected to a detailed revision; Carroll's (2007) work will be addressed elsewhere, as will be that of Ruta and Coates (2007), Anderson (2007), and Anderson et al. (2008a).

\section{Nomenclatural remarks}

\section{Phylogenetic nomenclature}

Phylogenetic nomenclature is used throughout this work, in a way that would be compatible with the ICPN (International Code for Phylogenetic Nomenclature: Cantino and de Queiroz, 2007; earlier drafts were called PhyloCode) if the ICPN were already implemented.

We discontinue our previous usage (Marjanović and Laurin, 2007) and instead follow Cannatella and Hillis (1993), Frost et al. (2006), Wilkinson and Nussbaum (2006) and Jenkins et al. (2007: 358) in using the name Gymnophiona for the caecilian crown group. The name Apoda Oppel 1810 has often (e.g., Trueb and Cloutier, 1991; Ruta and Coates, 2007) been used for the crown group (and Gymnophiona for the total group) in paleontologi- cal literature, but it is a junior homonym of the moth genus Apoda Haworth 1809 (Dundee, 1989; Wilkinson and Nussbaum, 2006; Naish, 2008) and should therefore not be used for an amphibian clade.

To facilitate discussion of gymnophionans and their relatives, we introduce the new clade names Gymnophioniformes and Gymnophionomorpha. (Because the ICPN will not be retroactive, and because these names are not registered, they are not hereby established and will need to be published anew once the ICPN is in effect.) Fig. 3 serves as the reference phylogeny (required by the ICPN in Article 9.6) for both, but note that both names can be applied to any phylogeny, not only to the reference phylogeny; the reference phylogeny merely serves to clarify our intent (ICPN Note 9.6.1). Gymnophioniformes has a node-based definition with Caecilia tentaculata L. 1758 and Rubricacaecilia monbaroni Evans and Sigogneau-Russell 2001 as internal specifiers. Gymnophionomorpha has a branch-based definition with Caecilia tentaculata L. 1758 as the internal specifier and Rana temporaria L. 1758, Salamandra salamandra (L. 1758), Albanerpeton inexpectatum Estes and Hoffstetter 1976, Brachydectes newberryi Cope 1868, Rhynchonkos stovalli (Olson 1970), Batropetes fritschi 


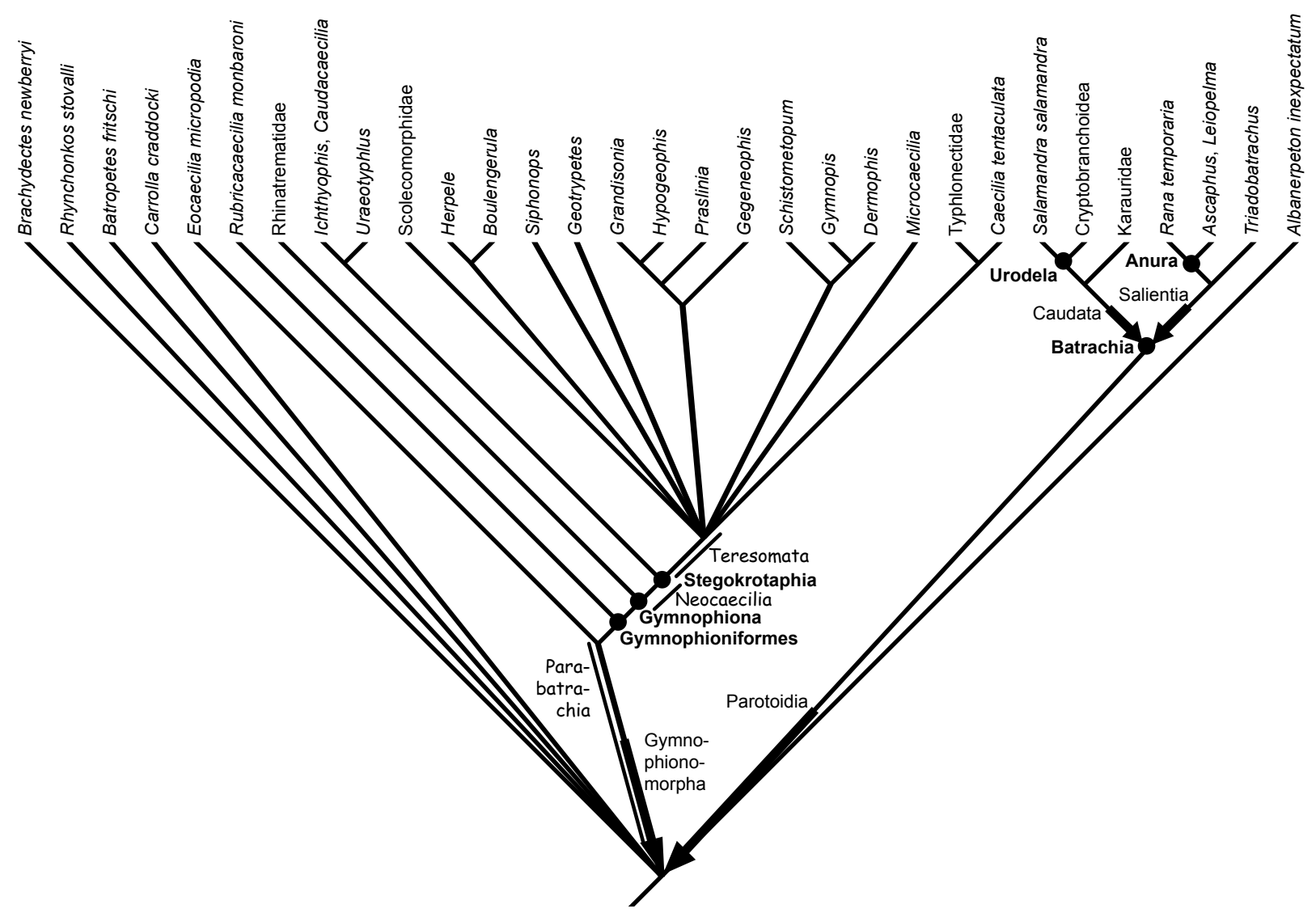

Fig. 3. Reference phylogeny for Gymnophioniformes and Gymnophionomorpha (new clade names) which additionally shows our usage of several other taxon names. Of these, those with node-based definitions are in boldface, those with branch-based definitions in regular typeface, and those without definitions in the font Comic Sans MS. The topology is a strict consensus of the opinions and results of Anderson (2001, 2007 except for Batrachia), Anderson et al. (2008a) except for the position of Albanerpetontidae, Evans and Sigogneau-Russell (2001), Vallin and Laurin (2004), Wilkinson and Nussbaum (2006), Jenkins et al. (2007), Ruta and Coates (2007) and Carroll (2007 and references therein) and fully compatible with McGowan's (2002; see Fig. 2) and our own results (Fig. 6), as well as with those of the molecular analysis by Frost et al. (2006) (except for the position of Siphonops), and even with Moodie's (1909) and Eaton's (1959) opinion that Brachydectes is a close relative of Gymnophiona. Dots mark the first member of clades whose names have node-based definitions, arrows point to the first member of clades whose names have branch-based definitions (the first member lying at the tip of the arrow, not beyond). Teresomata, Neocaecilia and Parabatrachia lack phylogenetic definitions; their first members could lie anywhere in the indicated ranges and still be compatible with the usage by Wilkinson and Nussbaum (2006) respectively Frost et al. (2006).

(Geinitz and Deichmüller 1882), and Carrolla craddocki Langston and Olson 1986 as external specifiers. The first three external specifiers serve to prevent Gymnophionomorpha from including any of the other three large lissamphibian (or possibly lissamphibian) clades, taking account of the conflicting hypotheses that exist on their interrelationships. The other four prevent it from including all or many 'lepospondyls' in the event of extant amphibian polyphyly: Brachydectes was considered a close relative of Gymnophiona as used here by Moodie
(1909) and Eaton (1959); Rhynchonkos has been hypothesized to be the sister-group of Gymnophionomorpha by Carroll (Carroll and Currie, 1975, through Carroll, 2007, and Carroll in Jenkins et al., 2007); and Eocaecilia, the only lissamphibian in the data matrix of Anderson (2001), is the sister-group of Batropetes + (Carrolla + Quasicaecilia) in his most parsimonious tree (Anderson, 2001: fig. 6), while it forms a polytomy with Rhynchonkos, (Batropetes + Quasicaecilia), and Carrolla in the Adams consensus of all trees that are one step less 
parsimonious (Anderson, 2001: fig. 7) as well as in the strict consensus of the most parsimonious trees found by Vallin and Laurin (2004: fig. 7) in their reanalysis of Anderson's (2001) matrix. Anderson (2007) and Anderson et al. (2008a) are congruent with Anderson (2001) in the position of Eocaecilia (the other lissamphibians being found as temnospondyls, i.e., in remote branches of the tree). We deliberately do not use Quasicaecilia as an external specifier because it is known from a single, highly incomplete and immature specimen and because its name implies that it should not be automatically excluded from Gymnophionomorpha by definition.

Ruta and Coates (2007) have found Gymnophionomorpha (represented by Eocaecilia) and Albanerpetontidae as sister-groups; the undefined name Parabatrachia Frost et al. 2006 ("the taxon composed of living caecilians + Eocaecilia"; Frost et al., 2006: 356) might be used for such a clade.

Within Gymnophiona, Wilkinson and Nussbaum (2006: 44) have suggested "the anatomically neutral Neocaecilia" as a replacement for the anatomically misleading name Stegokrotaphia Cannatella and Hillis 1993 (not all stegokrotaphians have a stegokrotaphic [= unfenestrated and unembayed] skull, nor is the stegokrotaphic condition necessarily an apomorphy of any clade within Gymnophionomorpha or even Lissamphibia). We nonetheless retain Stegokrotaphia for "the most recent common ancestor of Caeciliaidae [sic], Ichthyophiidae, Scolecomorphidae, and Uraeotyphlidae, and all of its descendants" (Cannatella and Hillis, 1993: 2) because this name is older and because, unlike Neocaecilia, it has a phylogenetic definition (although none of the specifiers of that definition are 'species, specimens or apomorphies', which is required by the ICPN in Article 11.1). Perhaps Neocaecilia could be used for a slightly more inclusive clade in the future, if extinct taxa closer to Stegokrotaphia than to Rhinatrematidae will be identified, in analogy to the successful resolution of former synonyms such as Salientia and Anura, Caudata and Urodela, Eutheria and Placentalia, Metatheria and Marsupialia, Rhynchocephalia and Sphenodonti(d)a, Ophidia and Serpentes, or Testudinata and Testudines. (Wilkinson and Nussbaum [2006: 45] specify that Neocaecilia is a clade and mention an autapomorphy, but they do not provide information which indicates whether that clade has a node-based, branch-based, or apomorphy-based definition.)

\section{Rank-based nomenclature}

We would like to provide a few comments about the status and correct spelling of a few relevant taxon names (discussed in other sections of this paper) in the context of rank-based ('Linnaean') nomenclature. Contrary to common usage, Boulengerula is feminine (by virtue of not being 'Boulengerulus'), so that B. taitanus Loveridge 1935 is an incorrect original spelling and automatically corrected to $B$. taitana by ICZN Articles 31.2 and 34.2 (International Commission on Zoological Nomenclature, 1999). According to the same articles, no formal emendation is necessary, and the correct spelling must be attributed to Loveridge 1935. All this also holds if the likewise feminine Afrocaecilia (of which $B$. taitana is the type species) is recognized.

Likewise, Albanerpeton is neuter, which makes the original spelling of the type species, $A$. inexpectatum, correct and those of A. nexuosus, A. gracilis and $A$. pannonicus incorrect; the correct spellings (which again must be attributed to the original authors) are $A$. nexuosum, A. gracile and A. pannonicum. Anoualerpeton, Chunerpeton, Pangerpeton and Sinerpeton, too, are neuter, so that $A$. unicus, $A$. priscus, $C$. tianyiensis, $P$. sinensis and $S$. fengshanensis are correctly spelled $A$. unicum, $A$. priscum, $C$. tianyiense, $P$. sinense and $S$. fengshanense.

Finally, Heyler (1994) appears to be wrong in claiming that only the International Commission on Zoological Nomenclature has the authority to designate neotypes and that therefore the designation of a neotype for Apateon pedestris by Boy (1986) is invalid: whenever "no name-bearing type specimen (i.e. holotype, lectotype, syntype or prior neotype) is believed extant and an author considers that a name-bearing type is necessary to define the nominal taxon objectively", that author has the right to designate a neotype (ICZN Article 75.1). Boy's (1986) designation of a neotype for A. pedestris fulfills all requirements of Article 75 and is therefore, to the best of our knowledge, valid.
Abbreviations
CI, RI, RC: consistency index, retention index, res- caled consistency index (see Swofford and Begle, 1993: 54).
MPT: most parsimonious tree.
OTU: Operational Taxonomic Unit. 


\section{Methods}

Addition of Brachydectes and homology of its dermal skull bones

In trying to test whether McGowan's (2002) matrix supports his phylogenetic hypothesis, we are logically bound to McGowan's choices of characters and taxa. However, we have decided to deviate from this principle in one respect: McGowan included in his matrix all temnospondyls that have been considered (at one time or another, alone or together with others in the list) particularly close relatives of some or all of the lissamphibian OTUs: Doleserpeton, Amphibamus, Platyrhinops, 'Tersomius', Schoenfelderpeton, Apateon, and Branchiosaurus. On the lepospondyl side, however, McGowan restricted himself to Rhynchonkos, the likely sister-group of the caecilians according to Carroll and Currie (1975) and Carroll (2000, 2007), and (in hindsight) the brachystelechids, which occupy more or less the same position according to Anderson $(2001,2007)$ and Anderson et al. (2008a). He did not include any lysorophians, even though Lysorophia has been identified as the sister-group of Lissamphibia in all published phylogenetic analyses that support the lepospondyl hypothesis (Laurin and Reisz, 1997, 1999; Laurin, 1998a; Vallin and Laurin, 2004; see also Pawley, 2006: appendix 16). To examine the effects of McGowan's decision not to include any lysorophian, we have coded Brachydectes as an OTU (as a composite of its two species, B. newberryi and B. elongatus) and performed analyses with and without Brachydectes (see below).

The skull roof and cheek region of Brachydectes (the only sufficiently well known lysorophian) have proven difficult to interpret in that the identities of their component bones are unclear. This makes it difficult to score Brachydectes for those characters in the present matrix that deal with the presence/ absence of the tabular, postorbital, postfrontal and supratemporal. In lateral view, there is a large T- or 7-shaped bone that overlies the squamosal laterally and extends ventrally almost to the jaw articulation. On the occiput and the caudal part of the skull roof, a narrow dumbbell-shaped median bone forms the dorsal margin of the foramen magnum and contacts the parietal as well as the exoccipital.

Traditionally (Sollas, 1920; Romer, 1966; Bolt and Wassersug, 1975), the T-shaped bone was con- sidered the supratemporal, and the median bone the suproccipital (Fig. 4). It follows that the square bone that lies on each side between the 'suproccipital', parietal, 'supratemporal' and exoccipital and participates in skull roof and occiput represents the tabular, and that the postparietals are absent (at least as separate bones), as are the postorbitals and postfrontals. However, among the microsaurs, generally considered the closest known relatives (mono- or paraphyletic) of Lysorophia, a supratemporal is never present (see Appendix I, character 13), and wherever a supratemporal is present in other lepospondyls, it is always a long, narrow strip of bone that lies on the skull roof between the tabular and the squamosal, unlike the ' $\mathrm{T}$ bone' of Brachydectes.

In his review of the Lysorophia, Wellstead (1991) agrees with the identification of the 'suproccipital' and the absence of postorbital and postfrontal, but he considers the ' $\mathrm{T}$ bone' the tabular and the square bone between it and the 'suproccipital' the postparietal. It follows that the supratemporal is absent. The latter fact agrees with the situation in the microsaurs, but under this interpretation the tabular has a strange shape and extends lateroventrally much farther than in any other taxon, and the postparietals are separated from each other by the suproccipital, an autapomorphic configuration.

We suggest a third interpretation that is possibly more parsimonious. In the brachystelechid "microsaur' Batropetes (Carroll, 1991: fig. 5), the postorbital (plus the caudal half of the postfrontal) has a shape and position very similar to those of the ' $T$ bone' in Brachydectes (Wellstead, 1991: figs 2, 3). Thus, we propose that the ' $\mathrm{T}$ bone' is the postorbital, an interpretation consistent with the ventral extent of this bone. The 'square bone' would then be the tabular, as suggested by its position in the caudolateral corner of the skull table and as in the traditional interpretation. The postparietal is a small, median bone in the 'microsaur' Odonterpeton (Carroll and Gaskill, 1978) and absent in the brachystelechid 'microsaurs'. Our interpretation is coherent with our view that the lysorophians and at least some 'microsaurs' form a clade (Vallin and Laurin, 2004), since there is no discrete postparietal in Brachydectes (according to our interpretation). This absence, together with the plesiomorphically small size of the parietals, explains why the suproccipital participates in the skull roof, which it does not do in any other lepospondyl. 

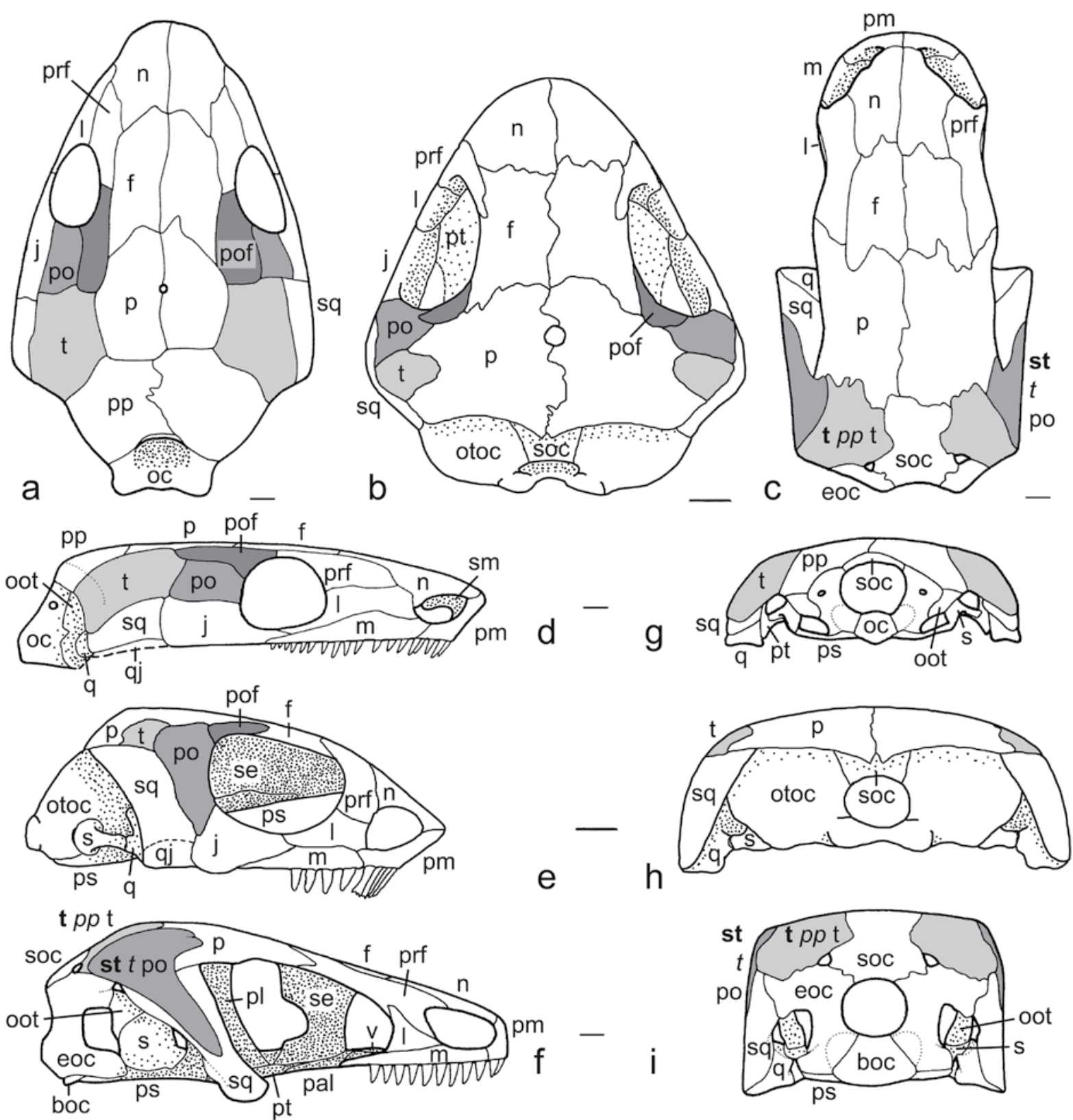

Fig. 4. Our interpretation of the homologies between the dermal skull bones of three 'lepospondyls': (a, d, g) Rhynchonkos (reproduced from Laurin and Reisz, 1997, and Laurin, 1998a), (b, e, h) Batropetes (redrawn from Carroll, 1991), and (c, f, i) Brachydectes (reproduced from Laurin and Reisz, 1997, and Laurin, 1998a). (a, b, c) Dorsal view; (d, e, f) right lateral view; (g, h, i) occipital view. Abbreviations: boc, basioccipital; eoc, exoccipital; f, frontal; j, jugal; 1, lacrimal; m, maxilla; $n$, nasal; oc, fusion of exoccipital and basioccipital; oot, opisthotic; otoc, fusion of prootic, opisthotic, exoccipital, and basioccipital; p, parietal; pal, palatine; pl, pleurosphenoid; pm, premaxilla; po, postorbital; pof, postfrontal; pp, postparietal; prf, prefrontal; ps, parasphenoid; pt, pterygoid; q, quadrate; qj, quadratojugal; s, stapes; se, sphenethmoid; sm, septomaxilla; soc, suproccipital; sq, squamosal; st, supratemporal; t, tabular; v, vomer. Where interpretations of Brachydectes differ, those by Sollas (1920), Romer (1966) and Bolt and Wassersug (1975) are in bold, those by Wellstead (1991) are in italics, and ours are in regular typeface; they are always given in this order. The shaded bones are the tabular (light), the postorbital (intermediate), and the postfrontal (dark) according to our interpretation. Bones at the bottom of fenestrae or of skull roof emarginations are stippled. 
We have scored the tabular as present, because all three interpretations agree on its presence, even though only two of them agree on which bone is the tabular. We have also scored the supratemporal as absent, because two of the three interpretations agree on its absence. We have furthermore scored the postfrontal as absent, because the two published interpretations agree on its absence and because there is no evidence of its presence. However, unlike all analyses which have found Lysorophia and Lissamphibia as sister-groups (Laurin and Reisz, 1997, 1999; Laurin, 1998a; Vallin and Laurin, 2004; Pawley, 2006), we have scored the postorbital as present, because of the similarity of the 'T bone' to the postorbital of brachystelechids in general and Batropetes in particular. Both the postorbital and the postfrontal are absent in all known lissamphibians, except for the probable presence of the postfrontal ancestrally in Gymnophionomorpha (discussed below), and present in all other taxa in our data matrix.

\section{Ontogeny and phylogenetic position of Doleserpeton}

Ever since its preliminary description (Bolt, 1969), Doleserpeton has commonly been considered the sister-group of Salientia, Batrachia, or Lissamphibia as a whole (e.g., Bolt 1977, 1979; Milner, 1993 [with reservations]; Roček and Rage, 2000; Ruta and Coates, 2007). However, Bolt (1979: 554, 557; see also Bolt, 1969, 1977) considered the specimens postmetamorphic but juvenile, like all known postmetamorphic specimens of Amphibamus (except YPM 794, which is more mature: Daly, 1994: 27). Some of the character states that Doleserpeton shares with the extant amphibians and which have been argued in the literature as indicating a close relationship between the latter and Doleserpeton are also found in juveniles but not adults of Amphibamus, Platyrhinops and 'Tersomius' (Milner, 1982; Clack and Milner, 1993; Daly, 1994; Schoch, 2001, 2002). This opens up the possibility that some or all of the supposed synapomorphies of Doleserpeton and extant amphibians that are not found in adults of amphibamids other than Doleserpeton are juvenile features of unknown phylogenetic distribution that may occur widely among (at least) dissorophoids - for most of which growth series are unknown - rather than indicating a close relationship between extant amphibians and specifically Doleserpeton. This holds regardless of whether some or all of the extant amphibians are themselves paedo- morphic dissorophoids (an opinion shared by all of the references cited above in this paragraph). To evaluate the impact of the general assumption that Doleserpeton is morphologically adult, we have run one of our analyses (see below) twice, once with all characters scored as if the described material of Doleserpeton were adult, and once with the potentially juvenile features (characters 7, 35, and 40; see Appendices 1 and 2) scored as unknown, as recommended by Wiens et al. (2005) for the phylogenetic analysis of juvenile or paedomorphic OTUs (in order to avoid the confounding effects of correlated characters and those of the absence of character states that appear late in non-truncated ontogenies).

Unfortunately, the plentiful and well-preserved but often disarticulated material of Doleserpeton (M. L., pers. obs. January 1996) has never been thoroughly described in a publication.

\section{Ontogeny and phylogenetic position of Brachydectes}

On a similar note, it has been suggested that the apparently obligatorily aquatic lysorophians (of which only Brachydectes is adequately known) are "heavily paedomorphic" (Schoch, 2002: 294), and that this is manifested not only in their well-developed hyobranchial apparatus and (most spectacularly) in the persistent suture between their left and right neural arches, but also in character states like the lack of postfrontal and jugal - which are included in the present matrix and are potential synapomorphies of (at least) Caudata, Salientia, and Brachydectes. However, in the continued absence of any knowledge on ossification sequences of Brachydectes and its closest relatives (Wellstead, 1991: 67), and in view of the fact that other certainly (adelogyrinids, Microbrachis, diplocaulid nectrideans) and probably (some aïstopods) obligatorily aquatic and possibly paedomorphic lepospondyls show no such bone losses, we have not scored such characters as unknown in Brachydectes in any analysis, because we would have had to interpret Brachydectes according to the ontogeny of the phylogenetically far distant dissorophoid temnospondyls. Coding it according to the ontogeny of extant amphibians would mean to assume a close relationship a priori, and it would raise new questions - for example, the arrangement of the vomerine teeth of Brachydectes is identical to that of larval and paedomorphic salamanders, but never seen in anuran or gymnophionan ontogeny. We hope that lysorophian or at least 'microsaurian' 
ossification sequences will one day come to light.

A partial ossification sequence of the deeply nested aïstopod Phlegethontia, consisting of three stages, has been described by Anderson (2002, 2007). However, the second stage shows a complete jugal as well as the rostrodorsal corner of the postfrontal, while the squamosal is still incomplete and (an autapomorphy of Phlegethontiidae) the parietal never appears at all, as it is unnecessary because of the uniquely hyperossified braincase. These features, along with the full ossification of the prefrontal and the maxilla at the second stage, and that of the entire caudal half of the braincase (except the sagittal and nuchal crests) at the first stage (when cleithra, gastralia, teeth and even ribs are lacking), show that the highly derived ossification sequence of Phlegethontia was not only very different from all known lissamphibian and temnospondyl ossification sequences, but also never led through a stage comparable to the adult condition of Brachydectes. It is therefore unfortunately irrelevant for determining paedomorphosis in the latter.

Comparison of the palate of Brachydectes (especially the width of the cultriform process, the caudal extent of the maxilla relative to that of the palatine, the orientation of the pterygoid, and the lack of interpterygoid vacuities; Fig. 4) to those of larval and paedomorphic lissamphibians (Reiss, 2002) does suggest paedomorphosis in Brachydectes and a close relationship between these taxa, but this latter assumption is one of the very questions the present analysis is meant to test. We have therefore refrained from using this assumption in our coding.

Addition of Gerobatrachus and its ontogeny and phylogenetic position

Gerobatrachus hottoni was recently (Anderson et al., 2008a) described as a temnospondyl that shares apomorphies with batrachians (salientians and caudates) but not with gymnophionomorphs and thus bolsters the polyphyly hypothesis; this hypothesis is indeed supported by the phylogenetic analysis conducted by Anderson et al. (2008a). Therefore, even though it was unknown to McGowan in 2002, this animal is as relevant to the present work as Brachydectes; we have included it in two of our five analyses.

Gerobatrachus was described as juvenile, based on the very large relative size of its pineal foramen (Anderson et al., 2008a: 515) and presumably on the tiny size of the only known specimen $(11 \mathrm{~cm}$ total length, less than $2 \mathrm{~cm}$ skull length). Further features compatible with a young ontogenetic age are the poor ossification of the tail, the extremely short ribs, the absence of pubis, scapulocoracoid, and most of the braincase in the specimen, the very large orbits and nares, and the lack of vomerine fangs (whether palatine fangs were present is, as far as we can tell, unknown, and not mentioned in the description). The shapes and relative sizes of lacrimal and prefrontal, as far as they can be seen in ventral view, are most similar to those of late larval and metamorphosing specimens of Apateon gracilis (Schoch and Fröbisch, 2006: fig. 1B, C).

However, other features conflict with such an assessment and suggest an age much closer to morphological maturity: Anderson et al. (2008a: 516) mention that " $[\mathrm{t}]$ he olecranon process is surprisingly well-ossified [sic] for the inferred young ontogenetic stage of the specimen". All dermal skull bones are ossified, and the contact between maxilla and quadratojugal is established. At least two tarsals are ossified (more may have been present and lost post mortem - the tibiae and fibulae are missing on both sides). The quadrates and the articulars are completely ossified; this generally happened late in temnospondyls, for example no sooner than metamorphosis in Apateon (Schoch and Fröbisch, 2006). The same holds for other endochondral skull bones: the otic capsule is partially ossified, as is the sphenethmoid, and at least the left epipterygoid has likewise been identified in the specimen (Anderson et al., 2008a: 515 and fig. 2). In relation to the intercentra, the pleurocentra are even larger than in the most mature Doleserpeton specimens (see above).

Most of the features that are compatible with immaturity are also compatible with alternative explanations. Disregarding phylogenetic effects, the relative size of the pineal foramen, the orbits and the nares is inversely correlated not directly to ontogeny, but to absolute body size. Of the shoulder girdle, only the cleithra and a part of the right clavicle are present; perhaps the scapulocoracoids were separated from the body together with the interclavicle (of which no trace remains). The missing parts of the braincase may likewise have drifted away prior to fossilization. Finally, the poorly ossified tail, the short ribs, and the absence of the pubis (where applicable) are also found in many or all adult lissamphibians, an observation that has (for the tail at least) not escaped the attention of Anderson et al. 
(2008a); vomerine (and palatine) fangs are absent not only in lissamphibians, but also in all known specimens of Doleserpeton (but see above).

We have therefore treated Gerobatrachus the same way as Doleserpeton (see above), running one analysis with all characters scored as if the described material of Gerobatrachus and Doleserpeton were adult, and one with the potentially juvenile features of both taxa (characters 1, 10, 21, 35, 40, and 41 for Gerobatrachus, characters 7, 35, and 40 for Doleserpeton; see Appendices 1 and 2) scored as unknown.

We do not consider it most likely that the known specimen of Gerobatrachus was fully adult, but treating it as such is the only objective way to assess the potential impact of its ontogenetic stage on its inferred phylogenetic affinities. Coding it as adult means taking several character states at face value that Gerobatrachus shares with lissamphibians in general and batrachians (caudates and salientians) in particular and may thus bias our results toward those of Anderson et al. (2008a).

\section{Phylogenetic analysis}

All analyses were performed in PAUP* $4.0 \mathrm{~b} 10$ (Swofford, 2003) on a Macintosh G5. The data matrix was originally created in MacClade 4.06 (Maddison and Maddison 2003) by copying McGowan's (2002) data matrix by hand, but all modifications of the resulting NEXUS file were carried out in PAUP*. These modifications are based on the literature and personal observations of specimens cited in Appendix-Table 1 and discussed in detail in Appendix 1. Because of the small number of taxa in the datamatrix, wewereabletousethebranch-and-bound algorithm for all analyses. We treated polymorphism differently from uncertainty (PAUP* command: "pset mstaxa = variable"). Inapplicable characters were scored as unknown ('?') because PAUP* (like, as far as we know, all currently available phylogenetics programs) is not capable of treating inapplicable characters in any other way, but are marked with hyphens in Appendix 2 to make our decisions more transparent.

Five analyses were performed: three where Doleserpeton was interpreted as morphologically adult, one of them without Brachydectes and Gerobatrachus, one with Brachydectes and without Gerobatrachus, and one with both; and two where Doleserpeton was interpreted as juvenile or paedomorphic (see above) and Brachydectes was excluded, one with
Gerobatrachus and one without it. Since the latter two analyses recovered the lissamphibians within the 'lepospondyls' as we expected (the possibly paedomorphic characters of Doleserpeton are among the few synapomorphies between this animal and lissamphibians), we did not do additional analyses with Doleserpeton interpreted as juvenile or paedomorphic and with Brachydectes included (addition of Brachydectes is expected to attract lissamphibians into 'lepospondyls').

Bootstrap analyses under the same five settings were conducted using heuristic searches (1000 bootstrap replicates, 20 addition-sequence replicates within each, random addition sequence, 10 trees held at each step, TBR swapping) because branch-andbound analyses soon proved to be too time-consuming, presumably because of the high amount of character conflict in the matrix.

The two NEXUS files (with Doleserpeton and Gerobatrachus interpreted as morphologically adult, and with both interpreted as morphologically immature) are included as an online appendix.

\section{Rooting the tree}

McGowan (2002) rooted his trees on a hypothetical ancestor, requiring him to decide a priori which state of each character was plesiomorphic. (This state he always labeled 0 , even when it was in the middle of a series that should be ordered as in character 37 ; see Appendix 1. This makes the hypothetical ancestor an all-zero ancestor.) Because of the following reasons, it seems to us that McGowan assumed that 'microsaurs' and lissamphibians are temnospondyls (which is also his result: Fig. 2) and therefore modeled his all-zero ancestor on basal temnospondyls:

- various references to "early" or "basal temnospondyls" (e.g., p. 26) or "early primitive tetrapods, e.g. Eryops" (p. 27) to explain the polarization of most characters (it should be noted that Eryops lived in the Permian, later than several of the taxa in the present matrix, and has many apomorphies even if only compared to other temnospondyls);

- the explanation of character 40 in its entirety (p. 29: "Primitively, the orbit of temnospondyls was large; the derived condition of small orbits is seen in gymnophionans and microsaurs".); - wordings like "Trematops and descendents [sic]" (p. 28) or "Amphibamus upwards" (p. 27) that (if we interpret 'descendants' as 'sister-group' 
and 'upwards' as 'and its sister-group') make sense on the tree by Milner (1988) - which McGowan (2002) cites, and where the lissamphibians are temnospondyls (although the 'microsaurs' are not) - but not in the context of most other phylogenetic hypotheses; in this context, we should mention that Milner (1988) did not conduct a cladistic analysis, but only presents a phylogenetic tree (containing only lissamphibians and 'other' temnospondyls) and a list of apomorphies which support each node, without evaluating if other arrangements of the taxa discussed in the paper (various temno- and lepospondyls) would be more parsimonious;

- and the fact that the supposedly plesiomorphic state of character 31 (explained as being present in "e.g., early temnospondyls"; p. 28) is shared only by Platyrhinops and the all-zero ancestor in his matrix - fittingly, McGowan finds Platyrhinops to be the sister-group of the rest of the ingroup.

We prefer to avoid this approach because the assumptions used in the construction of all-zero ancestors are less explicit and testable than the scoring of real outgroups, which can usually be done in more objective ways. Furthermore, if the all-zero ancestor was based on temnospondyls, this is problematic because the latter are part of the ingroup; including temnospondyls in both the ingroup and the outgroup is tantamount to assuming before the analysis is conducted that the temnospondyls are paraphyletic with respect to the rest of the ingroup - even though this is part of what the analysis is supposed to test. Thus, in order to avoid assumptions on whether 'microsaurs' or lissamphibians are temnospondyls, we replaced the all-zero outgroup by Whatcheeria and Crassigyrinus, which clearly (e.g., Ruta and Coates, 2007; Carroll, 2007; Warren, 2007) lie outside the smallest clade that contains all members of the ingroup of McGowan's study, and rooted the tree on Whatcheeria. (Not surprisingly, Crassigyrinus was always found to be the sister-group of the rest of the ingroup.) Both of them show, for a few characters, a state that McGowan (2002) considered derived, highlighting one of the problems that can result from the use of an all-zero outgroup.

\section{Interpretation of the OTUS}

We did not test the monophyly of the supraspecific OTUs, taking the monophyly of the taxa used as
OTUs by McGowan and described by Carroll (1998) at face value (with one or two exceptions, see below). We note, however, that the monophyly of a few of these taxa is poorly supported. Nevertheless, we did not break them down into smaller, clearly monophyletic OTUs because this would have required adding many more characters and would thus have made our analyses difficult to compare with McGowan's.

When characters are not constant in a supraspecific OTU, we scored that OTU as polymorphic, with the exception of Salientia, Caudata and Gymnophionomorpha (whose internal relationships are to a large extent agreed upon), for which we reconstructed the plesiomorphic state using parsimony as shown in Fig. 5. The exception to this exception are the quantitative characters 20 and 40 (see Appendix 1), where such a reconstruction would require a squared-change parsimony analysis, detailed branchlength data, and various tests to ensure that there are no statistical artefacts (Laurin, 2004); to avoid these problems, we scored Salientia, Caudata and Gymnophionomorpha as polymorphic for character 20 and used the representatives with the most plesiomorphic values to code them for character 40 .

In this paper, the term 'amphibamids' refers to the OTUs Platyrhinops, 'Tersomius', Amphibamus, and Doleserpeton; 'branchiosaurids' refers to Branchiosaurus, Apateon, and Schoenfelderpeton; and 'microsaurs' include Tuditanidae, Pantylidae, Gymnarthridae, Hapsidopareiontidae, Microbrachis, Brachystelechidae, and Rhynchonkos. These do not imply an a priori opinion on the monophyly of any of these assemblages (depending on the phylogeny, our use of 'amphibamids' may or may not agree with the phylogenetic definition of Amphibamidae by Anderson et al., 2008b). McGowan (2002) found the amphibamids and the microsaurs to be paraphyletic but the branchiosaurids to be monophyletic.

Trivially, we have changed the OTU name 'Microbrachidae' to 'Microbrachis' because M. pelikani is the only species referred to Microbrachidae by Carroll and Gaskill (1978) and Carroll (1998) and because McGowan (2002) used the name Rhynchonkos instead of the monotypic Rhynchonkidae.

Microsaurs. - Milner (1988: 85) felt that Carrolla was "a juvenile ostodolep[id]id" rather than a brachystelechid as assumed elsewhere in the literature and here. However, Milner (1993) and Carroll (1998) did not mention this suggestion, and Anderson (2001, 


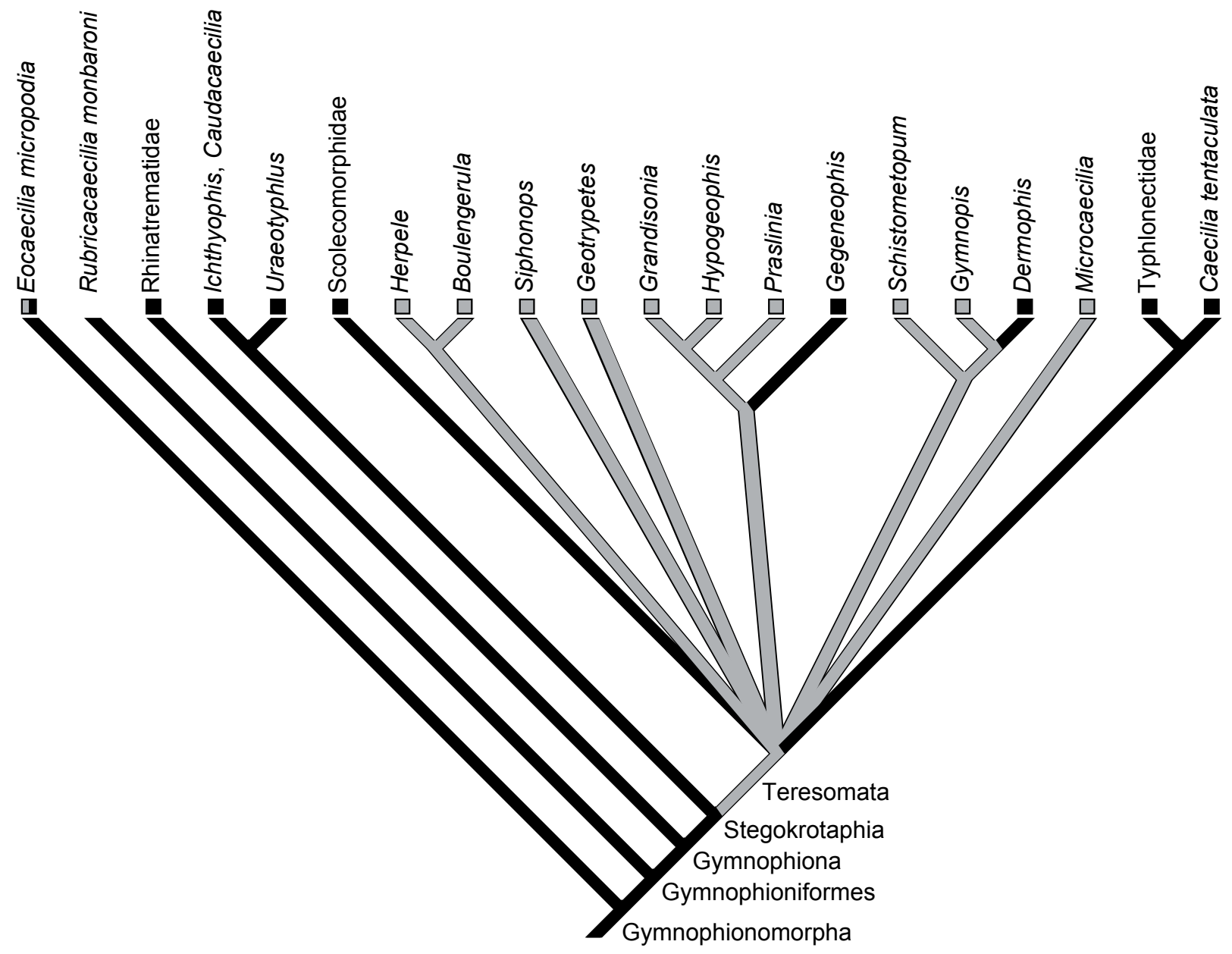

Fig. 5. A demonstration of the method used to score supraspecific OTUs: character 8 (ectopterygoid at least about half as long as the palatine [0], about a third as long or shorter [1], or absent [2]) optimized onto a supertree of Gymnophionomorpha compiled from Evans and Sigogneau-Russell (2001), Jenkins et al. (2007), and Wilkinson and Nussbaum (2006). No gymnophionomorph is known to have state 0 ; state 1 is shown as gray, state 2 as black; Rubricacaecilia is scored as unknown and Eocaecilia as partial uncertainty (state 1 or 2). Even though teresomatans known to lack an ectopterygoid are underrepresented in this tree, the basal node of Gymnophionomorpha is most parsimoniously optimized as possessing state 2. This does not change under any resolution of the teresomatan polytomy (not shown); we have tested this for each character.

2007) found Carrolla nested within Brachystelechidae (although the changes to Anderson's [2001] matrix by Vallin and Laurin [2004: fig. 7] introduce Rhynchonkos and Eocaecilia into the same clade, forming a five-branched polytomy), so we have, like McGowan (2002), used Carrolla (along with other genera, see Table 1) to code Brachystelechidae.

Carroll and Gaskill (1978) reluctantly included Saxonerpeton in Hapsidopareiontidae. Subsequently, Schultze and Foreman (1981) found Saxonerpeton as the sister-group of the (other) gymnarthrids, far away from the hapsidopareiontids. The publica- tion by Carroll (1998), which was McGowan's (2002: table 2) only source for the coding of all microsaurs except Rhynchonkos, did not follow this suggestion and, as far as we have been able to find, neither mentions it nor cites Schultze and Foreman (1981). Subsequently, however, Anderson (2001, 2007) and Anderson et al. (2008a) confirmed Carroll and Gaskill's (1978) opinion (see also Vallin and Laurin, 2004: fig. 7) that Saxonerpeton was more closely related to Hapsidopareion than to the gymnarthrids. Because Anderson's analyses are the most comprehensive analyses of lepospondyl intrarelationships published 
so far, we have followed them and have, like McGowan (2002), used Saxonerpeton to code the Hapsidopareiontidae OTU in spite of the widely divergent findings by Ruta and Coates (2007); however, Anderson $(2001,2007)$ and Anderson et al. (2008a) did not order any of their many multistate characters, not even ones like the number of sacral vertebrae or the number of caudal rib pairs, which casts doubt on the reliability of their results (and the results of the modified version of the 2001 matrix by Vallin and Laurin, 2004: fig. 7).

Stegotretus was described as a pantylid (Berman et al., 1988). Without comment, Carroll (1998) lists it among the gymnarthrids, mentioning a difference from Pantylus in the diagnosis, but none from any 'other' gymnarthrid. We presume an inadvertent error on Carroll's part; this is congruent with the fact that Ruta and Coates (2007) and Anderson (2007) find Pantylus and Stegotretus or Pantylus and (Stegotretus + Sparodus) as sister-groups. Thus, we have, presumably unlike McGowan (2002), used Stegotretus to code Pantylidae.

Sparodus was considered a gymnarthrid by Carroll and Gaskill (1978) and Carroll (1988, 1998), but it shares similarities, including derived ones (like the single very large coronoid tooth) with Pantylidae, and indeed Anderson $(2001,2007)$ found it to be a pantylid. However, the published analyses of microsaurian intrarelationships contradict each other in many ways - for example, Anderson $(2001,2007)$ found Gymnarthridae and Pantylidae to be close relatives, while Ruta and Coates (2007) found them far apart, and at least Anderson's (2001) results are not very well supported (Anderson, 2001: fig. 7; Vallin and Laurin, 2004: fig. 7); we have therefore decided to ignore Sparodus and not to use it for the coding of any OTU. This is probably not a deviation from McGowan's coding: Sparodus was very poorly known in 1978, Carroll (1998) devotes only a single short paragraph to it (apart from an illustration of the disarticulated skeleton), and McGowan (2002) does not cite the description of that skeleton (Carroll, 1988), so McGowan probably did not use Sparodus to code Gymnarthridae.

Lastly, Ruta and Coates (2007) found Tuditanidae sensu Carroll (1998) to be paraphyletic. Because they only used two of the four species included in Tuditanidae by Carroll (1998) and Carroll and Gaskill (1978), and because they also find many other groups that are commonly considered clades to be paraphyletic (such as Diadectomorpha and even Diadectidae with respect to Amniota), we here assume the monophyly of Tuditanidae sensu Carroll (1998) in order to avoid unnecessary deviations from McGowan's (2002) coding, although this is clearly a matter that deserves more attention.

Branchiosaurids. - Many nominal species have been shuffled around several times between Branchiosaurus, Apateon, Leptorophus, and Melanerpeton (Appendix 3); Branchiosaurus and Apateon are OTUs in McGowan's (2002) matrix.

In his table 2, McGowan (2002) explains that he coded Branchiosaurus after "Branchiosaurus cf. B. petrolei" and cites Boy $(1972,1978,1987)$ as his sources (as well as personal observations of many specimens). Boy $(1972,1978)$ did treat "B. cf. B. petrolei", but Boy (1987) only kept the type species $B$. salamandroides (and the then poorly known $B$. fayoli) in Branchiosaurus. Furthermore, McGowan cites Boy $(1986,1987)$ as his sources for Apateon, but Apateon pedestris sensu Boy $(1986,1987)$, the type species of Apateon (which is, for most workers, about the same as the subgenus Branchiosaurus (Protriton) sensu Boy [1972]), contains the same specimens as "Branchiosaurus $\mathrm{cf}$. B. petrolei" sensu Boy $(1972,1978)$. It follows that, unless he confused his references, McGowan (2002) inadvertently scored the same species twice, once as Branchiosaurus and once as Apateon. We have scored Branchiosaurus only after B. salamandroides and B. fayoli.

Neither a phylogenetic analysis of the many species and subspecies (!) of Branchiosauridae nor a review of the many opinions on synonymy between its species and subspecies currently exist (see Appendix 3 for a partial compilation of these opinions); in other words, it is not clear whether or not our Apateon OTU forms a clade which excludes our Branchiosaurus and Schoenfelderpeton OTUs. But in any case, Branchiosaurus and Apateon score identically in our matrix, except for the retention of ventral scales in the former (Schoch, pers. comm. October $5^{\text {th }}, 2007$ ), the greater number of uncertainties in the former, and the greater number of polymorphisms in the latter, and so do Schoenfelderpeton and Apateon, to the extent that Branchiosaurus and Schoenfelderpeton have only three unambiguous differences; thus, the unclear monophyly of our Apateon OTU does not seem to matter for the purposes of our analysis.

Yet another problem has recently surfaced with Branchiosaurus salamandroides: Milner (2007) reports that many specimens that were previously re- 
ferred to it are actually larvae of a quite different dissorophoid, the trematopid Mordex laticeps. Furthermore, Clack and Milner (2007) find that another specimen is a larva of Platyrhinops lyelli. Most likely, thus, our Branchiosaurus OTU is chimeric and should be scored as unknown for more characters. However, as noted above, this does not seem to be a problem for the present analysis, because our Branchiosaurus and Apateon OTUs differ only in a single score and in completeness.

Amphibamids. - McGowan (2002: table 2) cited only Boy (1980), the description of Tersomius graumanni, as his source for the scoring of Tersomius, even though he scored several characters as known which are unknown in T. graumanni. However, T. graumanni is now referred to its own genus Eimerisaurus, which is closely related to Micromelerpeton (Boy, 2002) rather than being an amphibamid. Furthermore, most specimens previously referred to the type species $T$. texensis are (following Schoch and Rubidge, 2005) cautiously mentioned as "Tersomius' sp." by Huttenlocker et al. (2007), who found this probably monophyletic assemblage - the descriptions of which we have used to code the 'Tersomius' OTU - to be more closely related to Plemmyradytes and Micropholis than to 'Tersomius' mosesi. The fragmentary type specimen of $T$. texensis was not included in the analysis by Huttenlocker $e t$ al. (2007) or in ours. To make comparison with the literature easier, we use the designations Eimerisaurus, 'Tersomius', and 'Tersomius texensis', although we do not thereby endorse the validity of the latter two designations.

\section{Revision of the matrix}

McGowan (2002) did not define the limits between the states of (potentially) continuous characters. In some, like character 32 (frontals "wide" or "narrow" without further explanation), we were forced to make far-reaching interpretations that may or may not be congruent with the original intent (we have not been able to contact McGowan), but we have tried to use state delimitations which maximize congruence with the original coding, except if the distribution of phenotypes suggested that another delimitation was more appropriate. All these are discussed in Appendix 1.

Unlike McGowan, we have not run blanket analyses where all multistate characters are ordered or unordered. Instead, following e.g. Wiens (2001), multistate characters that form a clear morphocline (such as 'large/small/absent' or 'many/intermediate/ few') have been ordered, because the similarity between adjacent states is of the same kind as the similarity between values which are considered the same state. Thus, to reject ordering such characters would be logically equal to rejecting the lumping of different values into states. Multistate characters whose states can plausibly all be derived from each other with equal ease have not been ordered. We have not ordered cases of doubt. In Appendix 1 we state after the name of each multistate character whether it was ordered or unordered in our analyses, and justify this decision in the discussion of that character. Two characters (20 and 40) are ordered using Wiens' (2001) stepmatrix gap-weighting method, and one character (3) is partially ordered, following its own stepmatrix.

Appendix 1 constitutes the list of our changes to McGowan's data matrix, including the changes to character definitions and state delimitations as well as our detailed justifications for these modifications. (Our changes affect all characters except two and all OTUs.) The revised data matrix itself is Appendix 2.

\section{Results}

Analyzing the unaltered matrix with all characters unordered replicates the strict consensus tree (of two most parsimonious trees) shown by McGowan (2002) in his fig. 15, except that either Microbrachidae or Tuditanidae may be the sister-group of the Gymnarthridae-Gymnophiona clade (Fig. 2a); McGowan's idiosyncratic representation of that part of the tree may indicate the same trichotomy, but this is not explained in his article.

Analyzing the unaltered matrix with all multistate characters $(6,9,37,39,41)$ ordered according to their state numbers $(0>1>2>3)$ replicates the results mentioned by McGowan (2002: 20); the topology of the consensus tree (not illustrated by McGowan) is much less resolved (Fig. 2b) than the tree that results from the unordered analysis.

Having made all the changes discussed in Appendix 1 , and treating the multistate characters as ordered or unordered (or neither, requiring a stepmatrix) as mentioned in their names in that appendix, we performed five parsimony analyses as explained in the Methods section, as well as five bootstrap 
analyses under the same conditions. The strict consensus trees, and the corresponding bootstrap trees, differ strongly (Fig. 6) from the ones that result from McGowan's original matrix (Fig. 2).

In the most parsimonious trees of all five analyses, the lepospondyls (monophyletic microsaurs, or "paraphyletic "microsaurs + Albanerpetontidae +" Lissamphibia, or the latter three + Brachydectes) are the sister-group of Temnospondyli. The extant amphibians always form a monophyletic Lissamphibia which is the sister-group of Albanerpetontidae. The position of the clade which includes albanerpetontids and lissamphibians - within Lepospondyli or within Temnospondyli - varies between analyses. Micromelerpeton is always the sister-group of all other temnospondyls, and the tuditanids are always the sister-group of the remaining lepospondyls.

When Brachydectes and Gerobatrachus are excluded and Doleserpeton is coded as morphologically adult (as done by McGowan), PAUP* finds 3 MPTs (length $=152.606$ steps, CI without parsimony-uninformative characters $=0.5118, \mathrm{RI}=0.6949$, $\mathrm{RC}=0.3756$ ), in all of which Lissamphibia and Albanerpetontidae are nested within the 'amphibamids' as the sister-group of Doleserpeton (Fig. 6a). This clade is the sister-group of Branchiosauridae, and both together form a temnospondyl clade with $\mathrm{Mi}$ cromelerpeton.

A bootstrap analysis conducted under the same assumptions, however, reveals glaring weaknesses (Fig. 6b). The grouping of Doleserpeton with a clade which includes Albanerpetontidae and Lissamphibia has negligible support (bootstrap value of $37 \%$ ).
Temnospondyl monophyly (including Lissamphibia) only appears in $28 \%$ of the trees retained by the bootstrap analysis, and the 'microsaurs' are paraphyletic to the rest of the ingroup. Even the ingroup as a whole (minus Crassigyrinus) is not robust (bootstrap value of $61 \%$ ). Support values above $75 \%$ are only found for Batrachia, Lissamphibia + Albanerpetontidae, Branchiosauridae, Apateon + Schoenfelderpeton, and Gymnarthridae + Rhynchonkos.

When Brachydectes is included, Gerobatrachus is excluded, and Doleserpeton coded as morphologically adult (Fig. 6c), 2 MPTs are found (length = 162.392 steps, $\mathrm{CI}$ without parsimony-uninformative characters $=0.4825, \mathrm{RI}=0.6776, \mathrm{RC}=0.3442$ ), in which the Lissamphibia-Albanerpetontidae clade is the sister-group of Brachydectes and nested within the 'microsaurs'. The arrangement of the 'microsaur' OTUs is compatible with that proposed by Milner (1993: fig. 4), even though our matrix lacks ostodolepidids, Milner's tree (no matrix was published) lacks Microbrachis, Brachystelechidae, Brachydectes, Albanerpetontidae and Lissamphibia, and only four of the 12 characters mentioned by Milner are present in our matrix. (Milner counts 13 characters, but his $\mathrm{C} 3$ and $\mathrm{C} 11$ are different states of the same character, our character 38.)

The corresponding bootstrap analysis (Fig. 6d) does not support this 'microsaur' topology, however. The clade composed of Brachydectes, Albanerpetontidae and Lissamphibia has a bootstrap value of $50 \%$, but in spite of this, temnospondyl monophyly is very poorly supported (at a value of $40 \%$ ), as is lepospondyl-lissamphibian monophyly (38).

Fig. 6. Phylogenetic hypotheses resulting from our modifications of McGowan's (2002) matrix, multistate characters ordered or unordered as indicated in our Methods section. Extant taxa in bold. Numbers above internodes are percentages of MPTs (omitted if $100 \%$ ), numbers below internodes are bootstrap percentages (in bold if 50 or higher). (a) Strict and majority-rule consensus (identical) of the 3 MPTs from the analysis run without Brachydectes or Gerobatrachus and with Doleserpeton interpreted as morphologically adult (length of each MPT $=152.606$ steps, CI without parsimony-informative characters $=0.5118, \mathrm{RI}=0.6949$, $\mathrm{RC}=0.3756$ ). (b) Bootstrap tree corresponding to (a). (c) Strict consensus of the 2 MPTs from the analysis run with Brachydectes included and Doleserpeton coded as morphologically adult (length $=162.392$ steps, CI without uninformative characters $=0.4825$, $\mathrm{RI}=0.6776, \mathrm{RC}=0.3442$ ); when Gerobatrachus is added and coded as morphologically adult, the same $2 \mathrm{MPTs}$ (not shown) are found with Gerobatrachus as the sister-group of Doleserpeton (length $=166.478$ steps, CI without parsimony-uninformative characters $=0.4701, \mathrm{RI}=0.6676, \mathrm{RC}=0.3308$ ). (d) Bootstrap tree corresponding to (c); when Gerobatrachus is added and coded as morphologically adult, it is found as the sister-group of Amphibamus, and most bootstrap values decrease slightly, but otherwise the tree is identical (not shown). (e) Majority-rule consensus of the 8 MPTs from the analysis run without Brachydectes or Gerobatrachus and with Doleserpeton interpreted as immature or paedomorphic (length $=151.599$ steps, CI without parsimony-uninformative characters $=0.5154, \mathrm{RI}=0.6969, \mathrm{RC}=0.3792$ ); when Gerobatrachus is added and coded as morphologically immature, the same 8 MPTs result (length $=152.599$ steps, CI without parsimony-uninformative characters $=0.5118, \mathrm{RI}=0.6965, \mathrm{RC}=$ 0.3765), with Gerobatrachus as the sister-group of Amphibamus (not shown). (f) Bootstrap tree corresponding to (e); when Gerobatrachus is added and coded as morphologically immature, it is found as the sister-group of Amphibamus, and many bootstrap values decrease slightly, but otherwise the tree is identical (not shown). See text for more information. 


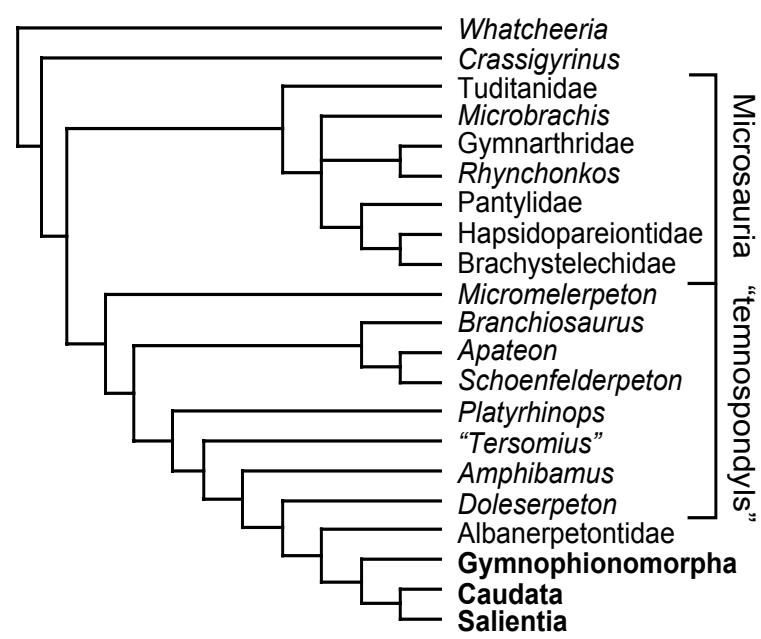

a

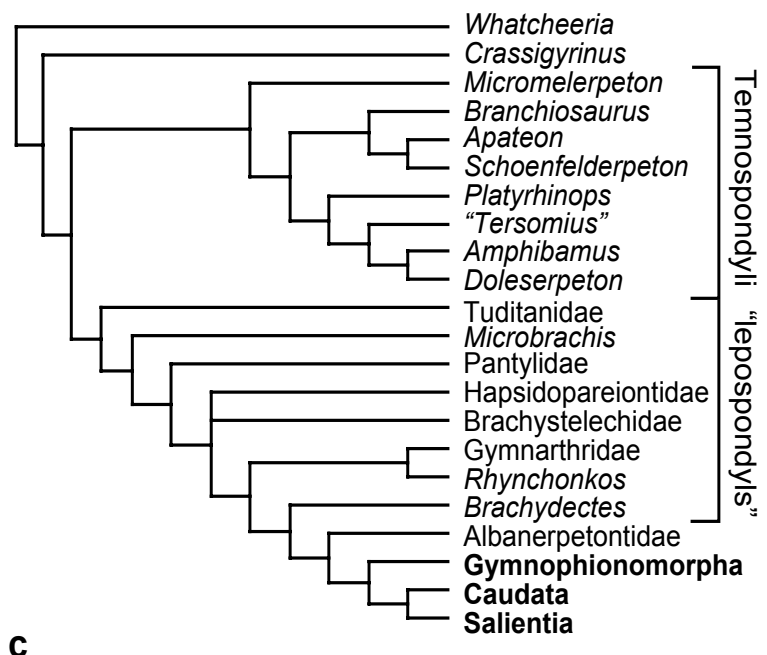

C

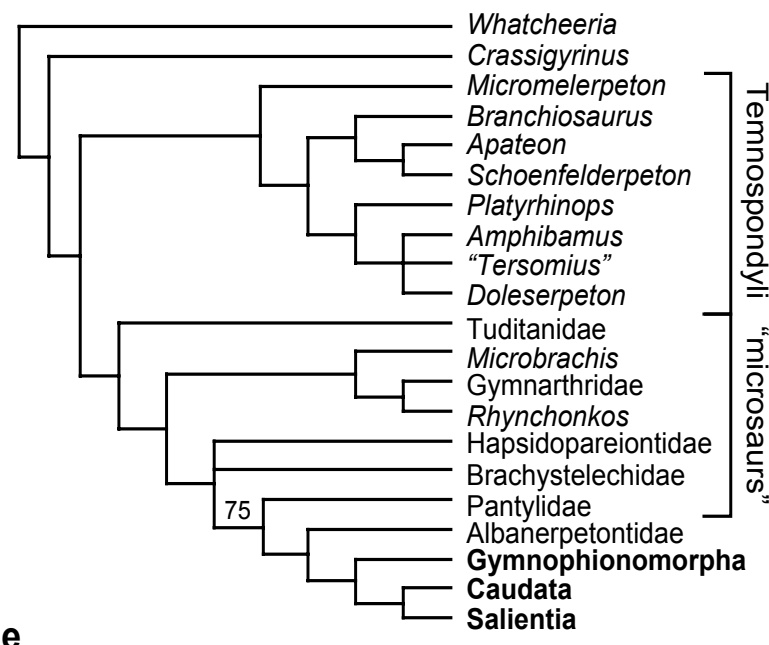

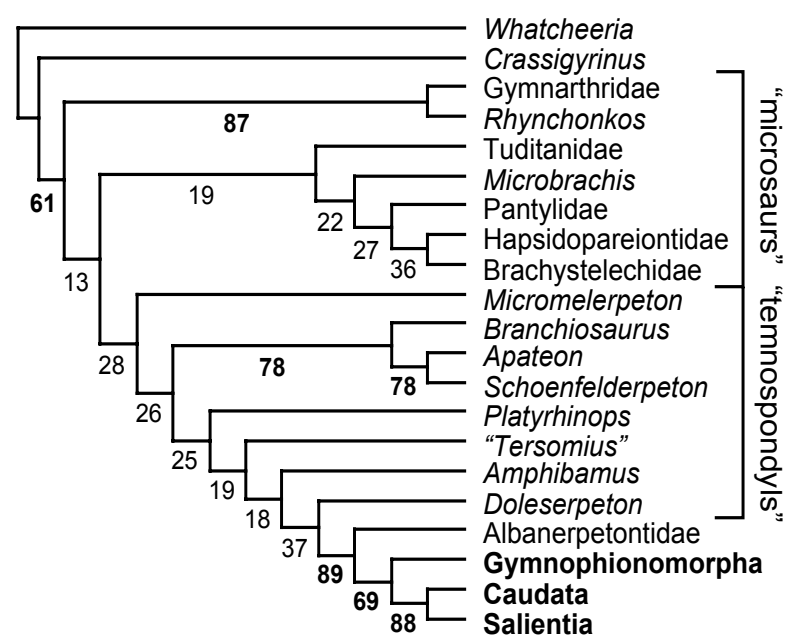

b

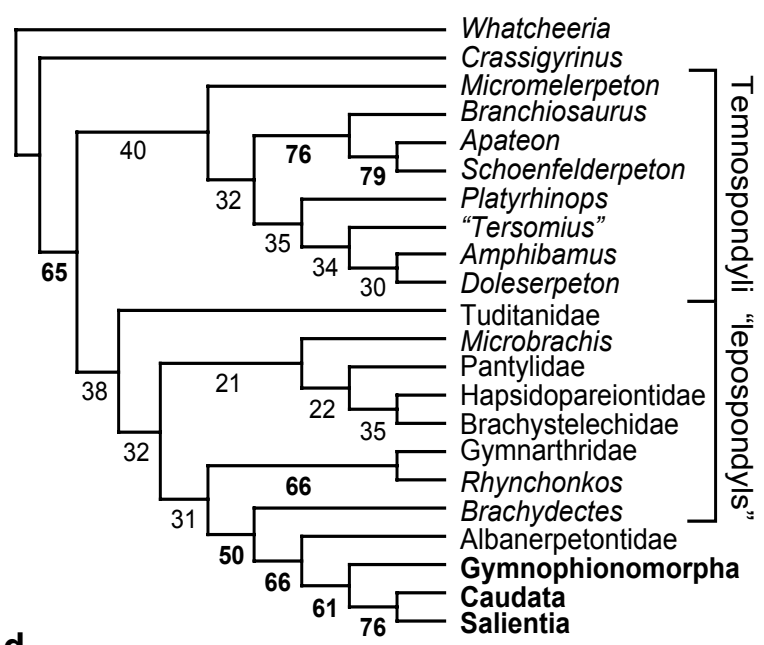

d

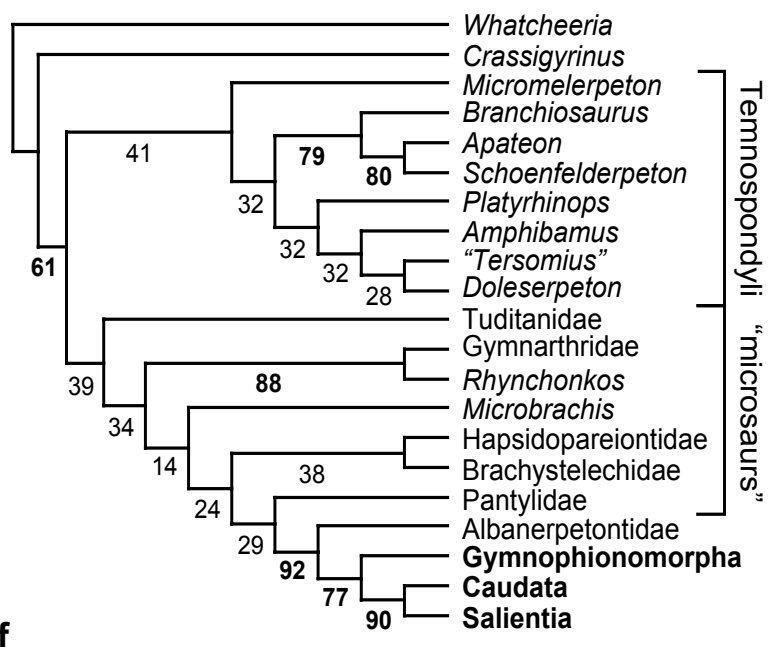


The values for Batrachia, Lissamphibia, and (Albanerpetontidae + Lissamphibia) are consistently lower than when Brachydectes is excluded; the only values in the entire tree that remain above $75 \%$ are those for Batrachia, Branchiosauridae, and Apateon + Schoenfelderpeton.

When Gerobatrachus is included and coded as morphologically adult, the otherwise same two trees (length $=166.478$ steps, CI without parsimony-uninformative characters $=0.4701, \mathrm{RI}=0.6676, \mathrm{RC}=$ 0.3308 ) as those summarized in Fig. $6 \mathrm{c}$ result (not shown); Gerobatrachus is found as the sister-group of Doleserpeton.

The corresponding bootstrap tree (not shown) likewise has the same topology as Fig. 6d, with Gerobatrachus as the sister-group of Amphibamus at a bootstrap value of $26 \%$. Most support values all over the tree decrease by 1 to $4 \%$. The most notable exception is Temnospondyli, which drops from 40 to $29 \%$; other nodes within Temnospondyli show similar behavior. Support for Lissamphibia only decreases from 61 to $57 \%$, for (Albanerpetontidae + Lissamphibia) from 66 to $62 \%$, for (Brachydectes + (Albanerpetontidae + Lissamphibia)) merely from 50 to $49 \%$, and for the lepospondyl-lissamphibian clade from 38 to $33 \%$. The only increase in support is found for the Hapsidopareiontidae-Brachystelechidae clade (from 35 to $37 \%$ ).

The analysis where Doleserpeton is coded as immature or paedomorphic (i.e. characters 7 and 35 are scored as unknown and 40 as mostly unknown) and Brachydectes and Gerobatrachus are excluded finds 8 MPTs (length $=151.599$ steps, CI without parsimony-uninformative characters $=0.5154, \mathrm{RI}$ $=0.6969, \mathrm{RC}=0.3792)$. The majority-rule consensus tree (Fig. 6e), as well as the strict consensus, shows the Albanerpetontidae-Lissamphibia clade nested within the 'microsaurs'. Doleserpeton forms a trichotomy with Amphibamus and 'Tersomius' within Temnospondyli.

The bootstrap analysis conducted under the same assumptions yields a very similar tree (Fig. 6f). At a bootstrap value of 39\% for the 'microsaur'-lissamphibian clade and $41 \%$ for the temnospondyl clade, however, the exclusion of Lissamphibia from Temnospondyli cannot be considered significantly corroborated. Values above $75 \%$ are found for Batrachia, Lissamphibia, Albanerpetontidae + Lissamphibia, Gymnarthridae + Rhynchonkos, Branchiosauridae, and Apateon + Schoenfelderpeton.

Adding Gerobatrachus and treating it as morpho- logically immature does not change the topology shown in Fig. 6e or the number of MPTs (length = 152.599 steps, CI without parsimony-uninformative characters $=0.5118, \mathrm{RI}=0.6965, \mathrm{RC}=0.3765$ ); Gerobatrachus is found as the sister-group of Amphibamus (not shown).

The corresponding bootstrap tree (not shown) is identical in topology to the one shown in Fig. 6f, except for a grouping of Gerobatrachus with Amphibamus that has a support value of $50 \%$. The bootstrap values in the rest of the tree are identical to those in Fig. 6f or lower by up to 3\%, except for the smallest clade that contains Hapsidopareiontidae and Salientia, which rises from $24 \%$ to $28 \%$, and for two nodes within Temnospondyli that drop from $32 \%$ to $25 \%$ and $27 \%$. The support for Lissamphibia is $74 \%$ instead of $77 \%$; the value for Lissamphibia + Albanerpetontidae does not change.

\section{Discussion}

\section{Implications of the size of the matrix}

Because of its small size (19, 20 or 21 ingroup and 2 outgroup taxa, 38 or 39 parsimony-informative characters - less than twice as many parsimony-informative characters as taxa), the present revised matrix still provides a limited test of the interrelationships between frogs, salamanders, caecilians, temnospondyls, and 'lepospondyls', as shown by the generally low bootstrap values, most of which lie consistently below $50 \%$. Among the most important limitations of the matrix are the following:

The number of characters in relation to the number of taxa is low, compared to recent phylogenetic analyses like those of Müller (2004), Vallin and Laurin (2004), Hill (2005), Wiens et al. (2005), Ruta and Coates (2007), Wible et al. (2007), Turner et al. (2007), or Luo et al. (2007).

By comparison with the same publications, all of which concern phylogenetic questions of comparable size to that of our analysis (or even the very same question), the number of taxa itself is very low. Only a few representatives of the dissorophoid temnospondyls are included, presumably explaining why we (and Anderson et al., 2008a) fail to replicate the topology found by Huttenlocker et al. (2007) or that found by Anderson et al. (2008b), while all other temnospondyls are missing, exaggerating the convergent similarities between dissorophoid temno- 
spondyls and 'microsaurs' and/or lissamphibians; for example, the basalmost temnospondyls retain the intertemporal bone in the skull roof, showing that separate losses of this bone occurred in temnospondyls and the ancestry of 'microsaurs', while in our tree the absence of the intertemporal (character 17 , state 1) appears as an autapomorphy of the ingroup (excluding Crassigyrinus) as a whole. Most larger 'microsaur' taxa ('families' as classified by Carroll, 1998) are present, but neither the well-known ostodolepidids nor Odonterpeton (which retains small postparietals that are fused to each other, but has lost the tabulars) nor Utaherpeton are. The latter is the oldest known 'microsaur', and it may be one of the basalmost ones (Vallin and Laurin, 2004), although Anderson (2007) suggests a very different topology. Likewise absent are all other lepospondyls, except for our addition of the only well-known lysorophian (Brachydectes). Representatives of the reptiliomorph clade (which includes Amniota, Diadectomorpha and Solenodonsaurus), which is more closely related to the lepospondyls than the temnospondyls are (Carroll, 1995, 2007; Vallin and Laurin, 2004; Pawley, 2006; Ruta and Coates, 2007; Anderson, 2007; Anderson et al., 2008a), are missing, as is the probable (Laurin and Reisz, 1999; Vallin and Laurin, 2004; Pawley, 2006; Ruta and Coates, 2007) basal lepospondyl Westlothiana.

Last but not least, the often polymorphic compound OTUs produce problems of their own; some of them may not even be monophyletic, as mentioned above.

Together, these problems may explain why the topology we find changes so drastically (Fig. 6) with the addition of a single taxon (Brachydectes) or even a change to the scores of three cells (the interpretation of Doleserpeton as immature or paedomorphic), even though the addition of Gerobatrachus hardly has any effect.

\section{Implications of the quality of the matrix}

Not only the quantity of the data contributes to the quality of a phylogenetic analysis; so does the quality of the data. Wrong scores guarantee wrong results. This may range from slightly inaccurate branch lengths or support values to outright randomized topology - and, importantly, there does not seem to be an easy way of predicting what kinds or amounts of error in the data matrix will lead to which mistakes in the tree(s). The results by Warren
(2007: fig. 10A, B) may serve as an extreme example: when the score of a single cell was changed in a matrix of 27 taxa and 195 characters, the topology changed radically. We therefore consider it justified to publish articles (like Jenner, 2001) that scrutinize the data matrices of earlier publications and would like to encourage the production of more such work, unoriginal though it arguably is. Such reanalyses are extremely important to resolve the current controversy about the origin of extant amphibians. Without such studies, we risk seeing a proliferation of different phylogenies by different authors, without these ever converging. Although it may be difficult to approach, there is only a single reality, and scrutinizing data matrices to improve their accuracy (i.e. agreement with reality) is the most direct strategy to achieve a consensus. We chose to start working towards this goal with the smallest of the current matrices on lissamphibian origins, namely, McGowan's (2002) matrix. The small size of that matrix has enabled us to carefully scrutinize all characters in all taxa in a reasonable amount of time, and to use fairly sophisticated methods to deal with continuous characters (Wiens, 2001); the same will presumably not be possible with much larger matrices such as those by Ruta and Coates (2007) and Anderson (2007).

Our work shows that, when the clearly erroneous and the debatable scores are changed, the data matrix supports lissamphibian monophyly. Thus, only three published cladistic analyses which have found lissamphibian diphyly remain (Carroll, 2007: fig. 77 'arguably'; Anderson, 2007; Anderson et al., 2008a); they will be reassessed elsewhere.

One reason for this drastic difference in the topologies found by McGowan (2002) and us seems to be that McGowan's matrix contains far less character conflict than our revision: the MPTs of which the strict consensus is shown in Fig. 2b (original matrix, all multistate characters ordered) have 97 steps, while the MPTs of which the strict consensus is shown in Fig. 6a (revised matrix, original taxon sampling) have 152.606 steps - about $63.56 \%$ more. Judging from his matrix and his character descriptions, it seems to us that McGowan has frequently attributed the same character state to all temnospondyls, all amphibamids, or all 'microsaurs' without carefully checking for exceptions. Similarly, none of the cells in McGowan's matrix contain a polymorphism, while 29 cells in ours do, contributing to the increase in tree length. 
Analyses without Gerobatrachus

Without our addition of Brachydectes and Gerobatrachus, and when Doleserpeton is interpreted as morphologically adult, this lissamphibian clade together with its sister-group, Albanerpetontidae is nested within the amphibamid temnospondyls, as the sister-group of Doleserpeton (Fig. 6a), as suggested previously (Bolt, 1969; Ruta and Coates, 2007; see also Fig. 1d). This contrasts sharply with the topology supported by McGowan's (2002) original coding, in which the 'microsaurs' were part of the smallest clade which included all extant amphibians, and in which the 'temnospondyls' were paraphyletic with respect to that clade.

When Brachydectes is included, however, a clade composed of Lissamphibia, Albanerpetontidae, and Brachydectes is nested within the 'microsaurs' rather than within the temnospondyls, which form a clade that is the sister-group of the rest of the ingroup (Fig. 6c; compare Fig. 1e).

When Doleserpeton is interpreted as immature or paedomorphic and Brachydectes is excluded, the analysis behaves as if Brachydectes were included (except for poorer resolution among the 'microsaurs'): the clade which includes Albanerpetontidae and Lissamphibia is nested within the 'microsaurs' and not within the temnospondyls (where Doleserpeton is found as usual) (Fig. 6e).

Together with the low bootstrap percentages, this lability that results from the presence or absence of a single OTU (Brachydectes) or three changes to the coding of another (Doleserpeton) highlights the importance of taxonomic sampling and the impact of heterochronic characters. Excluding one of the closest proposed proposed Paleozoic relatives of Lissamphibia (Brachydectes) can change the position of extant amphibians. Heterochronic characters may be present in Doleserpeton, in other dissorophoids, and perhaps also in Brachydectes, and these may influence phylogenetic reconstruction, as recently emphasized by Wiens et al. (2005). Lissamphibian origins remain to be assessed by a study of the causes of the incompatibilities between more comprehensive studies such as Vallin and Laurin (2004), Ruta and Coates (2007) and Anderson (2007).

It is, however, interesting that the bootstrap values of Batrachia, Lissamphibia, and Lissamphibia + Albanerpetontidae are noticeably lower when Brachydectes is present than otherwise. This suggests that Brachydectes is morphologically interme- diate between 'microsaurs' and lissamphibians + albanerpetontids, rather than just happening to be marginally more similar to the latter clade than the closest 'microsaurs' are.

Interpretation of Gerobatrachus and effects of its addition to our analyses

Gerobatrachus was described as a stem-batrachian, and the phylogenetic analysis accompanying its description (Anderson et al., 2008a) found lissamphibian diphyly. In stark contrast to this finding, adding Gerobatrachus to either our analysis where Brachydectes is included (with Gerobatrachus coded as adult) or to the analysis where Doleserpeton is coded as morphologically immature (with Gerobatrachus treated the same way as Doleserpeton) does not change the results; Gerobatrachus is found as the sister-group of either Doleserpeton or Amphibamus, the monophyletic Lissamphibia stays in the lepospondyl clade, and the bootstrap values within this clade decrease imperceptibly. Further study of the only known specimen of Gerobatrachus is clearly needed, as is its inclusion in larger data matrices.

One character, the os basale commune (fusion of distal tarsals 1 and 2), deserves special attention, even though it is not considered in McGowan's (2002) and therefore our matrix. This compound bone, which is otherwise only known in caudates, was described as present in Gerobatrachus (Anderson et al., 2008a). However, we see no reason to interpret the bone in question, which is one of only two preserved tarsal bones, as a basale commune. Comparison with the tarsi of salamanders (Shubin and Wake, 2003: figs 1B, 4, 8, 11, 12, 13B\&C) and temnospondyls (Boy, 1988: fig. 10B; Milner and Sequeira, 1994: fig. 15; Shubin and Wake, 2003: fig. 3B) or even other stem-tetrapods (embolomeres: Holmes, 1984: fig. 36; colosteids: Godfrey 1989: fig. 26) shows greater resemblance of the bone in question, in shape and relative size, to other tarsals, most often the centralia 1 (traditionally called ' $y$ ' in salamanders) and 2 (traditionally called 'centrale' in salamanders), the intermedium, and distal tarsal 4. Based on its preserved position and its size, we consider an identification as the centrale 2 most likely, but this should be considered tentative as long as no reasonably complete tarsus is known for Gerobatrachus or in fact, as far as we know, any temnospondyl other than Acheloma (of which Trematops, figured by Shubin and Wake [2003], is a junior synonym: 
Dilkes and Reisz, 1987), Sclerocephalus (Boy, 1988), and Balanerpeton (Milner and Sequeira, 1994), not counting the incompletely preserved tarsi of Ecolsonia (Berman et al., 1985: fig. 12G) and Eryops (Pawley and Warren, 2006: 562) and the incompletely ossified one of Micropholis (Schoch and Rubidge, 2005: fig. 7A).

Moreover, we doubt the interpretation by Anderson et al. (2008a) of the teeth as pedicellate, a derived condition shared by Lissamphibia, 'Tersomius', Amphibamus and Doleserpeton in the present matrix (Clack and Milner, 1993), and have scored them as unknown; see Appendix 1, character 5.

\section{'Microsaur' phylogeny}

The interrelationships of the 'microsaurs' are relatively stable (but not robust; Fig. 6b, d, f) in our analyses, though the presence or absence of Brachydectes has an effect on the topology. Consistently, the partitioning of Microsauria into Tuditanomorpha and Microbrachomorpha by Carroll and Gaskill (1978) is contradicted by our MPTs and bootstrap trees; this is not surprising, because this hypothesis has never been supported by a phylogenetic analysis - indeed, the monophyly of Microbrachomorpha (Microbrachis, Hyloplesion, Odonterpeton, Brachystelechidae, and later Utaherpeton) was already doubted by Carroll and Gaskill (1978: $11,113)$ themselves. However, the few characters on which the distinction between Tuditanomorpha and Microbrachomorpha is based (see Carroll, 1998) are not included in our matrix, and the bootstrap values never surpass $38 \%$ in this part of the tree. Thus, this result must be taken with considerable caution, for the reasons explained above.

\section{The phylogenetic position of Albanerpetontidae}

All of our analyses find Lissamphibia and Albanerpetontidae as sister-groups, a position so far only suggested by Pawley (2006: appendix 16), except that McGowan and Evans (1995: 145) mentioned that "a tree that reverses the positions of gymnophionans and albanerpetontids is only slightly longer" (than a tree where Albanerpetontidae and Batrachia are sister-groups, the arrangement also found by McGowan [2002], see Fig. 2) and that at least one of the 64 MPTs found by Ruta et al. (2003) contains the same topology. However, the bootstrap supports for Lissamphibia without Albanerpetonti- dae are always lower than those for Lissamphibia + Albanerpetontidae, even though they lie at or above $57 \%$ in all five analyses: the grouping of Albanerpetontidae with Lissamphibia is better supported than the exclusion of Albanerpetontidae from Lissamphibia (although not by much when Brachydectes is present).

By assuming the monophyly of Karauridae + Urodela (together our Caudata OTU) to the exclusion of Albanerpetontidae, our analyses are incapable of reproducing the result by Trueb and Cloutier (1991), who found Albanerpeton in two equally parsimonious positions as the sister-group of either Karaurus or Urodela (called Caudata by them). However, even though Anderson (2007) and Anderson et al. (2008a) have replicated this finding (as far as possible with their taxon sampling, which, like our matrix, had a single Caudata OTU), we consider this position unlikely because McGowan and Evans (1995) and McGowan (2002), among others, have conclusively argued against it (partly based on evidence that was unknown in 1991), and because our analyses never find the Albanerpetontidae and the Caudata OTUs as sister-groups, instead recovering a robust Batrachia clade which excludes Albanerpetontidae and is among the three best-supported clades of each tree. Thus, we think that the albanerpetontids are either basal parotoidians (the sister-group of Batrachia), or the sister-group of Gymnophionomorpha as found by Ruta and Coates (2007), or stem-amphibians (the sister-group of Lissamphibia).

This uncertainty makes it all the more frustrating that we have 'missed' the last living albanerpetontids by fewer than two million years: Delfino and Sala (2007) report a late Pliocene cooccurrence of Albanerpeton pannonicum and the extant plethodontid salamander Speleomantes. We hope that perhaps it will one day be possible to gain molecular data from the youngest albanerpetontid material.

\section{Acknowledgments}

We thank Jason Anderson for several electronic reprints and for alerting us to the fact that Clack and Milner (1993) had moved 'Amphibamus' lyelli into its own genus Platyrhinops, an anonymous referee for useful comments on an earlier draft, Rainer Schoch and Florian Witzmann for comments that likewise improved this paper, Hendrik Müller for an electronic reprint and for discussion, Darren Naish for a nomenclatural discussion (see Naish, 2008), Mark Wilkinson 
for a constructive review of an earlier draft, and two anonymous referees for exceptionally thorough and useful reviews; finally, we are grateful to one of these two referees, who pointed out that Karaurus has fewer than the 15 presacral vertebrae that the text of its original description, but not the plate, credits it with

D. M. benefited from a subsidy to university students by the Federal Republic of Austria.

\section{References}

Ahlberg PE, Milner AR. 1994. The origin and early diversification of tetrapods. Nature 368: 507-514.

Anderson JS. 2001. The phylogenetic trunk: maximal inclusion of taxa with missing data in an analysis of the Lepospondyli (Vertebrata, Tetrapoda). Systematic Biology 50: $170-193$

Anderson JS. 2002. Revision of the aïstopod genus Phlegethontia (Tetrapoda: Lepospondyli). Journal of Paleontology 76: 1029-1046.

Anderson JS. 2007. Incorporating ontogeny into the matrix: a phylogenetic evaluation of developmental evidence for the origin of modern amphibians. In: Anderson JS, Sues H-D eds. Major transitions in vertebrate evolution. Bloomington: Indiana University Press, 182-227.

Anderson JS, Reisz RR. 2003. A new microsaur (Tetrapoda: Lepospondyli) from the Lower Permian of Richards Spur (Fort Sill), Oklahoma. Canadian Journal of Earth Sciences 40: 499-505.

Anderson JS, Reisz RR, Scott D, Fröbisch NB, Sumida SS. 2008a. A stem batrachian from the Early Permian of Texas and the origin of frogs and salamanders. Nature 453: 515-518.

Anderson JS, Henrici AC, Sumida SS, Martens T, Berman DS. 2008b. Georgenthalia clavinasica, a new genus and species of dissorophoid temnospondyl from the Early Permian of Germany, and the relationships of the family Amphibamidae. Journal of Vertebrate Paleontology 28: 61-75.

Averianov AO, Martin T, Skutschas PP, Rezvyi AS, Bakirov AA. 2008. Amphibians from the Middle Jurassic Balabansai Svita in the Fergana Depression, Kyrgyzstan (Central Asia). Palaeontology 51: 471-485.

Berman DS, Reisz RR, Eberth DA. 1985. Ecolsonia cutlerensis, an Early Permian dissorophid amphibian from the Cutler Formation of north-central New Mexico. Circular 191 of the New Mexico Bureau of Mines \& Mineral Resources: 1-31.

Berman DS, Eberth DA, Brinkman DB. 1988. Stegotretus agyrus[,] a new genus and species of microsaur (amphibian) from the Permo-Pennsylvanian of New Mexico. Annals of Carnegie Museum 57: 293-323.

Bolt JR. 1969. Lissamphibian origins: possible protolissamphibian from the Lower Permian of Oklahoma. Science 166: 888-891.

Bolt JR. 1977. Dissorophoid relationships and ontogeny, and the origin of the Lissamphibia. Journal of Paleontology 51: 235-249.

Bolt JR. 1979. Amphibamus grandiceps as a juvenile dissorophid: evidence and implications. In: Nitecki $\mathrm{MH}$ ed. Mazon Creek fossils. London: Academic Press, 529-563.
Bolt JR. 1980. New tetrapods with bicuspid teeth from the Fort Sill locality (Lower Permian, Oklahoma). Neues Jahrbuch für Geologie und Paläontologie, Monatshefte 8: 449-459.

Bolt JR, Wassersug RJ. 1975. Functional morphology of the skull in Lysorophus: a snake-like Paleozoic amphibian (Lepospondyli). Paleobiology 1: 320-332.

Bolt JR, Lombard RE. 2000. Palaeobiology of Whatcheeria deltae, a primitive Missisippian tetrapod. In: Heatwole $\mathrm{H}$, Carroll RL eds. Amphibian Biology. Chipping Norton: Surrey Beatty \& Sons, 1044-1052.

Bossy KA and Miller AC. 1998. Order Nectridea MIALL 1875. In: Carroll RL, Bossy KA, Milner AC, Andrew SM, Wellstead CF. Lepospondyli. Part 1 of Wellnhofer P ed. Encyclopedia of Paleoherpetology. Stuttgart: Gustav Fischer, 73-131.

Boy JA. 1972. Die Branchiosaurier (Amphibia) des saarpfälzischen Rotliegenden (Perm, SW-Deutschland). Abhandlungen des Hessischen Landesamtes für Bodenforschung 65: $1-137$.

Boy JA. 1978. Die Tetrapodenfauna (Amphibia, Reptilia) des saarpfälzischen Rotliegenden (Unter-Perm; SW-Deutschland). 1. Branchiosaurus. Mainzer geowissenschaftliche Mitteilungen 7: 27-76.

Boy JA. 1980. Die Tetrapodenfauna (Amphibia, Reptilia) des saarpfälzischen Rotliegenden (Unter-Perm; SW-Deutschland). 2. Tersomius graumanni n. sp. Mainzer geowissenschaftliche Mitteilungen 8: 17-30.

Boy JA. 1986. Studien über die Branchiosauridae (Amphibia: Temnospondyli). 1. Neue und wenig bekannte Arten aus dem mitteleuropäischen Rotliegenden (?oberstes Karbon bis unteres Perm). Paläontologische Zeitschrift 60: 131166.

Boy JA. 1987. Studien über die Branchiosauridae (Amphibia: Temnospondyli; Ober-Karbon - Unter-Perm) 2. Systematische Übersicht. Neues Jahrbuch für Geologie und Paläontologie, Abhandlungen 174: 75-104.

Boy JA. 1988. Über einige Vertreter der Eryopoidea (Amphibia: Temnospondyli) aus dem europäischen Rotliegend (? höchstes Karbon-Perm). 1. Sclerocephalus. Paläontologische Zeitschrift 62: 107-132.

Boy JA. 1990. Über einige Vertreter der Eryopoidea (Amphibia: Temnospondyli) aus dem europäischen Rotliegend (? höchstes Karbon-Perm). 3. Onchiodon. Paläontologische Zeitschrift 64: 287-312.

Boy JA. 1995. Über die Micromelerpetontidae (Amphibia: Temnospondyli). 1. Morphologie und Paläoökologie des Micromelerpeton credneri (Unter-Perm; SW-Deutschland). Paläontologische Zeitschrift 69: 429-457.

Boy JA. 2002. Über die Micromelerpetontidae (Amphibia: Temnospondyli). 3. Eimerisaurus n. g.. Neues Jahrbuch für Geologie und Paläontologie, Abhandlungen 225: 425-452.

Boy JA, Sues H-D. 2000. Branchiosaurs: larvae, metamorphosis and heterochrony in temnospondyls and seymouriamorphs. In: Heatwole H, Carroll RL eds. Amphibian Biology. Chipping Norton: Surrey Beatty \& Sons, 11501197.

Cannatella DC, Hillis DM. 1993. Amphibian relationships: phylogenetic analysis of morphology and molecules. Herpetological Monographs 7: 1-7. 
Cannatella DC, Trueb L. 1988. Evolution of pipoid frogs: intergeneric relationships of the aquatic frog family Pipidae (Anura). Zoological Journal of the Linnean Society 94: 1-38.

Cantino PD, de Queiroz K. 2007. International Code of Phylogenetic Nomenclature. Version $4 \mathrm{~b}$. http://www.phylocode. org

Carroll RL. 1964. Early evolution of the dissorophid amphibians. Bulletin of the Museum of Comparative Zoology 131: 161-250.

Carroll RL. 1988. An articulated gymnarthrid microsaur (Amphibia [sic]) from the Upper Carboniferous of Czechoslovakia. Acta Zoologica Cracoviensia 31: 441-450.

Carroll RL. 1990. A tiny microsaur from the lower Permian of Texas: Size constraints in Paleozoic tetrapods. Palaeontology 33: 893-909.

Carroll RL. 1991. Batropetes from the Lower Permian of Europe - a microsaur, not a reptile. Journal of Vertebrate Paleontology 11: 229-242.

Carroll RL. 1995. Problems of the phylogenetic analysis of Paleozoic choanates. Bulletin du Muséum national d'Histoire naturelle de Paris $4^{\text {ème }}$ série 17: 389-445.

Carroll RL. 1998. Order Microsauria DAWSON 1863. In: Carroll RL, Bossy KA, Milner AC, Andrews SM, Wellstead CF. Lepospondyli. Part 1 of Wellnhofer P ed. Encyclopedia of Paleoherpetology. Stuttgart: Gustav Fischer, 1-72.

Carroll RL. 2000. Eocaecilia and the origin of caecilians. In: Heatwole H, Carroll RL eds. Amphibian Biology, Volume 4: Palaeontology. Chipping Norton: Surrey Beatty \& Sons, 1402-1411.

Carroll RL. 2007. The Palaeozoic ancestry of salamanders, frogs and caecilians. Zoological Journal of the Linnean Society 150: 1-140.

Carroll RL, Baird D. 1968. The Carboniferous amphibian Tuditanus [Eosauravus] and the distinction between microsaurs and reptiles. American Museum Novitates 2337: 1-50.

Carroll RL, Currie PJ. 1975. Microsaurs as possible apodan ancestors. Zoological Journal of the Linnean Society 57: 229-247.

Carroll RL, Gaskill P. 1978. The order Microsauria. Philadelphia: American Philosophical Society.

Carroll RL, Holmes R. 1980. The skull and jaw musculature as guides to the ancestry of salamanders. Zoological Journal of the Linnean Society 68: 1-40.

Carroll RL, Boisvert C, Bolt J, Green DM, Philip N, Rolian C, Schoch R, Tarenko A. 2004. Changing patterns of ontogeny from osteolepiform fish through Permian tetrapods as a guide to the early evolution of land vertebrates. In: Arratia $\mathrm{G}$, Wilson MVH, Cloutier R eds. Recent Advances in the Origin and Early Radiation of Vertebrates. Munich: Dr. Friedrich Pfeil, 321-343.

Case EC. 1911. Revision of the Amphibia and Pisces of the Permian of North America. Publications of the Carnegie Institution of Washington 146: 1-179.

Clack JA. 1996. The palate of Crassigyrinus scoticus, a primitive tetrapod from the Lower Carboniferous of Scotland. Special Papers in Palaeontology 52: 55-64.

Clack JA. 1998. The Scottish Carboniferous tetrapod Crassigyrinus scoticus (Lydekker) - cranial anatomy and relationships. Transactions of the Royal Society of Edinburgh 88: $127-142$.
Clack JA, Milner AR. 1993. Platyrhinops from the Upper Carboniferous of Linton and Nýřany and the family Amphibamidae (Amphibia: Temnospondyli). In: Heidtke U ed. New Research on Permo-Carboniferous Faunas. Pollichia-Buch 29: 185-191.

Clack J, Milner A. 2007. The amphibamid Platyrhinops, morphology and metamorphosis. Journal of Vertebrate Paleontology 27 (supplement to issue 3): 59A.

Daly E. 1994. The Amphibamidae (Amphibia: Temnospondyli), with a description of a new genus from the upper Pennsylvanian of Kansas. The University of Kansas Museum of Natural History Miscellaneous Publications 85: 1-40.

Delfino M, Sala B. 2007. Late Pliocene Albanerpetontidae (Lissamphibia) from Italy. Journal of Vertebrate Paleontology 27: 716-719.

Dilkes DW, Reisz RR. 1987. Trematops milleri Williston, 1909 identified as a junior synonym of Acheloma cumminsi Cope, 1882, with a revision of the genus. American Museum Novitates 2902: 1-12.

Duellman WE, Trueb L. 1986. Biology of Amphibians. New York: McGraw-Hill.

Dundee HA. 1989. Higher category name usage for amphibians and reptiles. Systematic Zoology 38: 398-406.

Eaton TH. 1959. The ancestry of modern Amphibia: a review of the evidence. University of Kansas Publications: Museum of Natural History 12: 155-180.

Estes R. 1969. Prosirenidae, a new family of fossil salamanders. Nature 224: 87-88.

Estes R. 1981. Gymnophiona, Caudata. Part 2 of Wellnhofer P ed. Encyclopedia of Paleoherpetology. Munich: Dr. Friedrich Pfeil.

Evans SE, Milner AR. 1996. A metamorphosed salamander from the early Cretaceous of Las Hoyas, Spain. Philosophical Transactions of the Royal Society of London, Series B 351: 627-646.

Evans SE, Sigogneau-Russell D. 2001. A stem-group caecilian (Lissamphibia: Gymnophiona) from the Lower Cretaceous of North Africa. Palaeontology 44: 259-273.

Evans SE, Lally C, Chure DC, Elder A, Maisano JA. 2005. A Late Jurassic salamander (Amphibia: Caudata) from the Morrison Formation of North America. Zoological Journal of Linnean Society 143: 599-616.

Evans SE, Milner AR, Mussett F. 1988. The earliest known salamanders (Amphibia, Caudata): a record from the Middle Jurassic of England. Geobios 21: 539-552.

Fox RC, Naylor BG. 1982. A reconsideration of the relationships of the fossil amphibian Albanerpeton. Canadian Journal of Earth Sciences 19: 118-128.

Frost DR, Grant T, Faivovich J, Bain RH, Haas A, Haddad CFB, de Sá RO, Channing A, Wilkinson M, Donnellan SC, Raxworthy CJ, Campbell JA, Blotto B, Moler P, Drewes RC, Nussbaum RA, Lynch JD, Green DM, Wheeler WC. 2006. The amphibian tree of life. Bulletin of the American Museum of Natural History 297: 1-370.

Gao K, Chen S. 2004. A new frog (Amphibia: Anura) from the Lower Cretaceous of western Liaoning, China. Cretaceous Research 25: 761-769.

Gao K, Shubin NH. 2001. Late Jurassic salamanders from northern China. Nature 410: 574-577.

Gao K, Shubin NH. 2003. Earliest known crown-group salamanders. Nature 422: 424-428. 
Gauthier J, Kluge AG, Rowe T. 1988. The early evolution of the Amniota. In: Benton MJ ed. The phylogeny and classification of the tetrapods, Volume 1: amphibians, reptiles, birds. Oxford: Clarendon Press, 103-155.

Godfrey SJ. 1989. The postcranial skeletal anatomy of the Carboniferous tetrapod Greererpeton burkemorani Romer, 1969. Philosophical Transactions of the Royal Society of London, Series B 323: 75-133.

Goodrich ES. 1930. Studies on the structure and development of vertebrates. London: Macmillan.

Heyler D. 1994. Les branchiosaures stéphaniens et permiens de Montceau-les-Mines et des autres bassins du Massif Central. In: Poplin C, Heyler D eds. Quand le Massif central était sous l'équateur - Un écosystème carbonifère à Montceau-les-Mines. Paris: CTHS, 227-247.

Hill RV. 2005. Integration of morphological data sets for phylogenetic analysis of Amniota: the importance of integumentary characters and increased taxonomic sampling. Systematic Biology 54: 530-547.

Holmes R. 1984. The Carboniferous amphibian Proterogyrinus scheelei Romer, and the early evolution of tetrapods. Philosophical Transactions of the Royal Society of London, Series B 306: 431-524.

Holmes R. 2000. Palaeozoic temnospondyls. In: Heatwole H, Carroll RL eds. Amphibian Biology. Chipping Norton: Surrey Beatty \& Sons, 1081-1120.

Holmes RB, Carroll RL, Reisz RR. 1998. The first articulated skeleton of Dendrerpeton acadianum (Temnospondyli, Dendrerpetontidae) from the Lower Pennsylvanian locality of Joggins, Nova Scotia, and a review of its relationships. Journal of Vertebrate Paleontology 18: 64-79.

Huttenlocker AK, Small BJ, Pardo JD. 2007. Plemmyradytes shintoni, gen. et sp. nov., an Early Permian amphibamid (Temnospondyli: Dissorophoidea) from the Eskridge Formation, Nebraska. Journal of Vertebrate Paleontology 27: 316-328.

International Commission on Zoological Nomenclature. 1999. International Code of Zoological Nomenclature. London: International Trust for Zoological Nomenclature. http://www.iczn.org/iczn/index.jsp

Irmis RB. 2007. Axial skeleton ontogeny in the Parasuchia (Archosauria: Pseudosuchia) and its implications for ontogenetic determination in archosaurs. Journal of Vertebrate Paleontology 27: 350-361.

Ivachnenko MF. 1979. Urodelans from the Triassic and Jurassic of Soviet Central Asia. Paleontological Journal 1978: 362-368.

Jenkins FA, Jr., Walsh DM. 1993. An Early Jurassic caecilian with limbs. Nature 365: 246-249.

Jenkins FA, Jr., Walsh DM, Carroll RL. 2007. Anatomy of Eocaecilia micropodia, a limbed caecilian of the Early Jurassic. Bulletin of the Museum of Comparative Zoology 158: $285-366$

Jenner RA. 2001. Bilaterian phylogeny and uncritical recycling of morphological data sets. Systematic Biology 50: 730-742.

Klembara J, Berman DS, Henrici AC, Čerňanský A, Werneburg R, Martens T. 2007. First description of skull of Lower Permian Seymouria sanjuanensis (Seymouriamorpha: Seymouriidae) at an early juvenile growth stage. $\mathrm{An}$ nals of Carnegie Museum 76: 53-72.
Langston W, Jr., Olson EC. 1986. Carrolla craddocki, a new genus and species of microsaur from the Lower Permian of Texas. Pearce-Sellards Series 43: 1-20.

Laurin M. 1998a. The importance of global parsimony and historical bias in understanding tetrapod evolution. Part I. Systematics, middle ear evolution, and jaw suspension. Annales des Sciences Naturelles - Zoologie et Biologie Animale 19: 1-42.

Laurin M. 1998b. The importance of global parsimony and historical bias in understanding tetrapod evolution. Part II. Vertebral centrum, costal ventilation, and paedomorphosis. Annales des Sciences Naturelles - Zoologie et Biologie Anímale 19: 99-114.

Laurin M. 2002. Tetrapod phylogeny, amphibian origins, and the definition of the name Tetrapoda. Systematic Biology 51: 364-369.

Laurin M. 2004. The evolution of body size, Cope's rule and the origin of amniotes. Systematic Biology 53: 594-622.

Laurin M, Reisz RR. 1997. A new perspective on tetrapod phylogeny. In: Sumida S, Martin K eds. Amniote Origins - Completing the Transition to Land. San Diego: Academic Press, 9-59.

Laurin M, Reisz RR. 1999. A new study of Solenodonsaurus janenschi, and a reconsideration of amniote origins and stegocephalian evolution. Canadian Journal of Earth Sciences 36: 1239-1255.

Lee MSY, Anderson JS. 2006. Molecular clocks and the origin(s) of modern amphibians. Molecular Phylogenetics and Evolution 40: 635-639.

Lillich R, Schoch R. 2007. Finally grown up - the significance of adult Micromelerpeton. Journal of Vertebrate Paleontology 27 (supplement to issue 3): 106A.

Lombard RE, Bolt JR. 1979. Evolution of the tetrapod ear: an analysis and reinterpretation. Biological Journal of the Linnean Society 11: 19-76.

Lombard RE, Bolt JR. 1995. A new primitive tetrapod, Whatcheeria deltae, from the Lower Carboniferous of Iowa. Palaeontology 38: 471-494.

Lombard RE, Sumida SS. 1992. Recent progress in understanding early tetrapods. The American Zoologist 32: 609-622.

Luo Z-X, Ji Q, Yuan C-X. 2007. Convergent dental adaptations in pseudo-tribosphenic and tribosphenic mammals. Nature 450: 93-97.

Maddison DR, Maddison WP. 2003. MacClade 4: Analysis of phylogeny and character evolution. Version 4.06. Sunderland, Massachusetts: Sinauer Associates.

Marjanović D, Laurin M. 2007. Fossils, molecules, divergence times, and the origin of lissamphibians. Systematic Biology 56: 369-388.

McGowan GJ. 2002. Albanerpetontid amphibians from the Lower Cretaceous of Spain and Italy: a description and reconsideration of their systematics. Zoological Journal of the Linnean Society 135: 1-32.

McGowan G, Evans SE. 1995. Albanerpetontid amphibians from the Cretaceous of Spain. Nature 373: 143-145.

Meckert D. 1993. Der Schultergürtel des Sclerocephalus haeuseri Goldfuss, 1847 im Vergleich mit Eryops CoPE, 1877 (Eryopoida [sic], Amphibia, Perm). Palaeontographica Abteilung A: Palaeozoologie-Stratigraphie 229: 113-140. 
Milner AR. 1982. Small temnospondyl amphibians from the Middle Pennsylvanian of Illinois. Palaeontology 25: 635664.

Milner AR. 1986. Dissorophoid amphibians from the Upper Carboniferous of Nýřany. In: Roček Z ed. Studies in Herpetology. Prague: Charles University, 671-674.

Milner AR. 1988. The relationships and origin of living amphibians. In: Benton, MJ ed. The Phylogeny and Classification of the Tetrapods, Volume 1: Amphibians, Reptiles, Birds. Oxford: Clarendon Press, 59-102.

Milner AR. 1993. The Paleozoic relatives of lissamphibians. Herpetological Monographs 7: 8-27.

Milner AR. 2000. Mesozoic and Tertiary Caudata and Albanerpetontidae. In: Heatwole H, Carroll RL eds. Amphibian Biology, Volume 4: Palaeontology. Chipping Norton: Surrey Beatty \& Sons, 1412-1444.

Milner A. 2007. Mordex laticeps and the base of the Trematopidae. Journal of Vertebrate Paleontology 27 (supplement to issue 3): $118 \mathrm{~A}$.

Milner AR, Sequeira SEK. 1994. The temnospondyl amphibians from the Viséan of East Kirkton, West Lothian, Scotland. Transactions of the Royal Society of Edinburgh 84: 331-361.

Moodie RL. 1909. Vertebrate paleontology: The Lysorophidæ. The American Naturalist XLIII: 116-119.

Müller J. 2004. The relationships among diapsid reptiles and the influence of taxon selection. In: Arratia G, Wilson $\mathrm{MVH}$, Cloutier R eds. Recent Advances in the Origin and Early Radiations of Vertebrates. Munich: Dr. Friedrich Pfeil, 379-408.

Müller H. 2006. Ontogeny of the skull, lower jaw, and hyobranchial skeleton of Hypogeophis rostratus (Amphibia: Gymnophiona: Caeciliidae) revisited. Journal of Morphology 267: 968-986.

Müller H, Oommen OV, Bartsch P. 2005. Skeletal development of the direct-developing caecilian Gegeneophis ramaswamii (Amphibia: Gymnophiona: Caeciliidae). Zoomorphology 124: 171-188.

Naish D. 2008. [Comments to his own post Surreal caecilians part I: tentacles and protrusible eyes.] Tetrapod Zoology. http://scienceblogs.com/tetrapodzoology/2008/01/surreal_ caecilians_part_i.php

Nevo E, Estes R. 1969. Ramonellus longispinus, an Early Cretaceous salamander from Israel. Copeia 1969: 540-547.

Nussbaum RA. 1977. Rhinatrematidae: a new family of caecilians (Amphibia: Gymnophiona). Occasional Papers of the Museum of Zoology - University of Michigan 682: 1-30.

Panchen AL. 1985. On the amphibian Crassigyrinus scoticus Watson from the Carboniferous of Scotland. Philosophical Transactions of the Royal Society of London, Series B 309: 505-568.

Panchen AL, Smithson TR. 1988. The relationships of the earliest tetrapods. In: Benton MJ ed. The Phylogeny and Classification of the Tetrapods, Volume 1: Amphibians, Reptiles, Birds. Oxford: Clarendon Press, 1-32.

Panchen AL, Smithson TR. 1990. The pelvic girdle and hind limb of Crassigyrinus scoticus (Lydekker) from the Scottish Carboniferous and the origin of the tetrapod pelvic skeleton. Transactions of the Royal Society of Edinburgh 81: $31-44$.
Pawley K. 2006. The Postcranial Skeleton of Temnospondyls (Tetrapoda: Temnospondyli). $\mathrm{PhD}$ thesis available at http://www.lib.latrobe.edu.au/thesis/public/adt-LTU2006 1124.124055/index.html. Melbourne: La Trobe University.

Pawley K, Warren A. 2006. The appendicular skeleton of Eryops megacephalus Cope, 1877 (Temnospondyli: Eryopoidea) from the Lower Permian of North America. Journal of Paleontology 80: 561-580.

P[ú]gener LA, Maglia AM, Trueb L. 2003. Revisiting the contribution of larval characters to an analysis of phylogenetic relationships of basal anurans. Zoological Journal of the Linnean Society 139: 129-155.

Reig OA. 1961. Noticia sobre un nuevo anuro fósil del Jurásico de Santa Cruz (Patagonia). Ameghiniana 2: 73-78.

Reiss, JO. 2002. The phylogeny of amphibian metamorphosis. Zoology 105: 85-96.

Renous S. 1990. Morphologie cranienne [sic] d'un Siphonopidé américain, Microcaecilia unicolor (Amphibien, Gymnophione) et interprétation fonctionelle. Gegenbaurs morphologisches Jahrbuch 136: 781-806.

Roček Z, Rage J-C. 2000. Proanuran stages (Triadobatrachus, Czatkobatrachus). In: Heatwole H, Carroll RL eds. Amphibian Biology, Volume 4: Palaeontology. Chipping Norton: Surrey Beatty \& Sons, 1283-1294.

Roelants K, Gower DJ, Wilkinson M, Loader SP, Biju SD, Guillaume K, Moriau L, Bossuyt F. 2007. Global patterns of diversification in the history of modern amphibians. Proceedings of the National Academy of Sciences of the United States of America 104: 887-892.

Romer AS. 1966. Vertebrate Paleontology. $3^{\text {rd }}$ edition. Chicago: University of Chicago Press.

Romer AS. 1969. The cranial anatomy of the Permian amphibian Pantylus. Breviora 314: 1-37.

Ronchi A, Tintori A. 1997. First amphibian find in Early Permian from Sardinia (Italy). Revista Italiana di paleontologia e Stratigrafia 103: 29-38.

Rose, CS. 2003. The developmental morphology of salamander skulls. In: Heatwole H, Davies M eds. Amphibian Biology, Volume 5: Osteology. Chipping Norton: Surrey Beatty \& Sons, 1684-1781.

Ruta M, Coates MI. 2007. Dates, nodes and character conflict: addressing the lissamphibian origin problem. Journal of Systematic Paleontology 5: 69-122.

Ruta M, Coates MI, Quicke DLJ. 2003. Early tetrapod relationships revisited. Biological Reviews of the Cambridge Philosophical Society 78: 251-345.

Sanch[í]z B. 1998. Salientia. Part 4 of Wellnhofer P ed. Handbuch der PaläoherpetologielEncyclopedia of Paleoherpetology. Munich: Dr. Friedrich Pfeil.

San Mauro D, Vences M, Alcobendas M, Zardoya R, Meyer A. 2005. Initial diversification of living amphibians predated the breakup of Pangaea. The American Naturalist 165: 590-599.

Schoch RR. 1992. Comparative ontogeny of Early Permian branchiosaurid amphibians from southwestern Germany. Palaeontographica Abteilung A: Palaeozoologie-Stratigraphie 222: 43-83.

Schoch RR. 1999. Comparative osteology of Mastodonsaurus giganteus (Jaeger, 1828) from the Middle Triassic (Lettenkeuper: Longobardian) of Germany (Baden-Württem- 
berg, Bayern, Thüringen). Stuttgarter Beiträge zur Naturkunde, Serie B (Geologie und Paläontologie) 278: 1-178.

Schoch RR. 2001. Can metamorphosis be recognised in Paleozoic amphibians? Neues Jahrbuch für Geologie und Paläontologie, Abhandlungen 220: 335-367.

Schoch RR. 2002. The early formation of the skull in extant and Paleozoic amphibians. Paleobiology 28: 278-296.

Schoch RR. 2004. Skeleton formation in the Branchiosauridae: a case study in comparing ontogenetic trajectories. Journal of Vertebrate Paleontology 24: 309-319.

Schoch RR. 2006. Skull ontogeny: developmental patterns of fishes conserved across major tetrapod clades. Evolution \& Development 8: 524-536.

Schoch RR, Carroll RL. 2003. Ontogenetic evidence for the Paleozoic ancestry of salamanders. Evolution \& Development 5: 314-324.

Schoch RR, Fröbisch NB. 2006. Metamorphosis and neoteny: alternative pathways in an extinct amphibian clade. Evolution 60: 1467-1475.

Schoch RR, Milner AR. 2004. Structure and implications of theories on the origin of lissamphibians. In: Arratia G, Wilson MVH, Cloutier R eds. Recent Advances in the Origin and Early Radiation of Vertebrates. Munich: Dr. Friedrich Pfeil: 345-377.

Schoch RR, Rubidge BS. 2005. The amphibamid Micropholis from the Lystrosaurus Assemblage Zone of South Africa. Journal of Vertebrate Paleontology 25: 502-522.

Schultze H-P, Foreman B. 1981. A new gymnarthrid microsaur from the Lower Permian of Kansas with a review of the tuditanomorph microsaurs (Amphibia). Occasional Papers of the Museum of Natural History of the University of Kansas 91: 1-25.

Shubin NH, Wake DB. 2003. Morphological variation, development, and evolution of the limb skeleton of salamanders. In: Heatwole H, Davies M eds. Amphibian Biology, Volume 5: Osteology. Chipping Norton: Surrey Beatty \& Sons, 1782-1808.

Sollas WJ. 1920. On the structure of Lysorophus, as exposed by serial sections. Philosophical Transactions of the Royal Society of London, Series B 209: 481-527.

Swofford DL. 2003. PAUP*: Phylogenetic Analysis Using Parsimony (*and other methods). Version 4.0b10. Sunderland, Massachusetts: Sinauer Associates.

Swofford DL, Begle DP. 1993. PAUP - Phylogenetic Analysis Using Parsimony. Version 3.1 March 1993. User's Manual. Laboratory of Molecular Systematics, Smithsonian Institution.

Thorn R. 1968. Les salamandres d'Europe, d'Asie et d'Afrique $d u$ Nord. Paris: Paul Lechevalier.

Trueb L, Cloutier R. 1991. A phylogenetic investigation of the inter- and intrarelationships of the Lissamphibia (Amphibia: Temnospondyli). In: Schultze H-P, Trueb L eds. Origins of the Higher Groups of Tetrapods - Controversy and Consensus. Ithaca: Cornell University Press, 223-313.

Turner AH, Pol D, Clarke JA, Erickson GM, Norell M. 2007. A basal dromaeosaurid and size evolution preceding avian flight. Science 317: 1378-1381.

Vallin G, Laurin M. 2004. Cranial morphology and affinities of Microbrachis, and a reappraisal of the phylogeny and lifestyle of the first amphibians. Journal of Vertebrate Paleontology 24: 56-72.
Venczel M, Gardner JD. 2005. The geologically youngest albanerpetontid amphibian, from the Lower Pliocene of Hungary. Palaeontology 48: 1273-1300.

Vickaryous MK, Hall BK. 2006. Homology of the reptilian coracoid and a reappraisal of the evolution and development of the amniote pectoral apparatus. Journal of Anatomy 208: 263-285.

Wake MH. 1989. Metamorphosis of the hyobranchial apparatus in Epicriniops (Amphibia: Gymnophiona: Rhinatrematidae): replacement of bone by cartilage. Annales des Sciences Naturelles, Zoologie, $13^{e}$ Série 10: 171-182.

Wake MH. 2003. The osteology of caecilians. In: Heatwole H, Davies M eds. Amphibian Biology, Volume 5: Osteology. Chipping Norton: Surrey Beatty \& Sons, 18091876.

Wang Y. 2004. A new Mesozoic caudate (Liaoxitriton daohugouensis sp. nov.) from Inner Mongolia, China. Chinese Science Bulletin (English edition) 49: 858-860.

Wang Y, Evans SE. 2006. A new short-bodied salamander from the Upper Jurassic/Lower Cretaceous of China. Acta Palaeontologica Polonica 51: 127-130.

Wang Y, Rose CS. 2005. Jeholotriton paradoxus (Amphibia: Caudata) from the Lower Cretaceous of southeastern Inner Mongolia, China. Journal of Vertebrate Paleontology 25: 523-532.

Wang X, Zhou Z, He H, Jin F, Wang Y, Zhang J, Wang Y, $\mathrm{Xu}$ X, Zhang F. 2005. Stratigraphy and age of the Daohugou Bed in Ningcheng, Inner Mongolia. Chinese Science Bulletin (English edition) 50: 2369-2376.

Warren A. 2007. New data on Ossinodus pueri, a stem tetrapod from the Early Carboniferous of Australia. Journal of Vertebrate Paleontology 27: 850-862.

Wellstead CF. 1982. A Lower Carboniferous aïstopod amphibian from Scotland. Palaeontology 25: 193-208.

Wellstead CF. 1991. Taxonomic revision of the Lysorophia, Permo-Carboniferous lepospondyl amphibians. Bulletin of the American Museum of Natural History 209: 1-90.

Wellstead CF. 1998. Order Lysorophia ROMER 1930. In: Carroll RL, Bossy KA, Milner AC, Andrews SM, Wellstead CF. Lepospondyli. Part 1 of Wellnhofer P ed. Encyclopedia of Paleoherpetology. Stuttgart: Gustav Fischer, 133-148.

Werneburg R. 1986. Die Stegocephalen (Amphibia) der Goldlauterer Schichten (Unterrotliegendes, Perm), Teil I: Apateon flagrifer (WHITTARD). Freiberger Forschungshefte C 410 - Paläontologie: 88-98.

Werneburg R. 1987. Dissorophoiden (Amphibia, Rhachitomi) aus dem Westfal D (Oberkarbon) der CSSR. Zeitschrift für geologische Wissenschaften 15: 681-690.

Werneburg R. 1988a. Die Stegocephalen der Goldlauterer Schichten (Unterrotliegendes, Unterperm), Teil II: $A p a-$ teon kontheri n. sp., Melanerpeton eisfeldi n. sp. des Thüringer Waldes und andere. Freiberger Forschungshefte C 427 - Paläontologie: 7-29.

Werneburg R. 1988b. Die Stegocephalen (Amphibia) der Goldlauterer Schichten (Unterrotliegendes, Perm) des Thüringer Waldes. Teil III. Apateon dracyiensis (Boy), Branchierpeton reinholdi $\mathrm{n}$. sp. und andere. Veröffentlichungen des Naturkundemuseums Erfurt 1988: 80-96.

Werneburg R. 1988c. Die Amphibienfauna der Oberhöfer Schichten (Unterrotliegendes, Unterperm) des Thüringer 
Waldes. Veröffentlichungen des Naturhistorischen Museums Schleusingen 3: 2-27.

Werneburg R. 1991. Die Branchiosaurier aus dem Unterrotliegend des Döhlener Beckens bei Dresden. Veröffentlichungen des Naturhistorischen Museums Schleusingen 6: 75-99.

Werneburg R. 1996. Temnospondyle Amphibien aus dem Karbon Mitteldeutschlands. Veröffentlichungen des $\mathrm{Na}$ turhistorischen Museums Schleusingen 11: 23-64.

Werneburg R. 2001. Apateon dracyiensis - eine frühe Pionierform der Branchiosaurier aus dem Europäischen Rotliegend, Teil 1: Morphologie. Veröffentlichungen des Naturhistorischen Museums Schleusingen 16: 17-36.

Werneburg R. 2002. Apateon dracyiensis - eine frühe Pionierform der Branchiosaurier aus dem Europäischen Rotliegend, Teil 2: Paläoökologie. Veröffentlichungen des Naturhistorischen Museums Schleusingen 17: 17-32.

Werneburg R, Ronchi A, Schneider JW. 2007. The Early Permian branchiosaurids (Amphibia) of Sardinia (Italy): systematic palaeontology, palaeoecology, biostratigraphy and palaeobiogeographic problems. Palaeogeography, Palaeoclimatology, Palaeoecology 252: 383-404.

Wible JR, Rougier GW, Novacek MJ, Asher RJ. 2007. Cretaceous eutherians and Laurasian origin for placental mammals near the K/T boundary. Nature 447: 10031006.

Wiens JJ. 2001. Character analysis in morphological phylogenetics: problems and solutions. Systematic Biology 50: 689-699.

Wiens JJ, Bonett RM, Chippindale PT. 2005. Ontogeny discombobulates phylogeny: paedomorphosis and higherlevel salamander relationships. Systematic Biology 54: 91-110.
Wilkinson M, Nussbaum RA. 2006. Caecilian phylogeny and classification. In: Exbrayat J-M ed. Reproductive Biology and Phylogeny. Science Publishers: Enfield, 39-78.

Witzmann F. 2006. Developmental patterns and ossificiation sequence in the Permo-Carboniferous temnospondyl Archegosaurus decheni (Saar-Nahe Basin, Germany). Journal of Vertebrate Paleontology 26: 7-17.

Witzmann F. 2007. The evolution of the scalation pattern in temnospondyl amphibians. Zoological Journal of the Linnean Society 150: 815-834.

Witzmann F, Pfretzschner H-U. 2003. Larval ontogeny of Micromelerpeton credneri (Temnospondyli, Dissorophoidea). Journal of Vertebrate Paleontology 23: 750-768.

Witzmann F, Schoch RM. 2006. The postcranium of Archegosaurus decheni, and a phylogenetic analysis of temnospondyl postcrania. Palaeontology 49: 1211-1235.

Zhang P, Zhou H, Chen Y-Q, Liu Y-F, Qu L-H. 2005. Mitogenomic perspectives on the origin and phylogeny of living amphibians. Systematic Biology 54: 391-400.

Zylberberg L, Wake MH. 1990. Structure of the scales of Dermophis and Microcaecilia (Amphibia: Gymnophiona), and a comparison to dermal ossifications of other vertebrates. Journal of Morphology 206: 25-43.

Received: 28 May 2008

Accepted: 14 August 2008

Published online: 24 November 2008

Online supplementary information is accessible through: http://www.ctoz.nl and http://www.repository.naturalis.nl 
Appendix-Table 1. The sources for our data matrix (Appendix 2). The listed specimens of Apateon, Microbrachis and Micromelerpeton were examined, but did not contradict the literature or reveal additional information.

\begin{tabular}{|c|c|}
\hline$\overline{\text { OTU }}$ & $\begin{array}{l}\text { Species used to code OTU (type species } \\
\text { first, the others in alphabetical order) }\end{array}$ \\
\hline Whatcheeria & W. deltae \\
\hline Crassigyrinus & C. scoticus \\
\hline Branchiosaurus & B. salamandroides, B. fayoli \\
\hline Apateon & $\begin{array}{l}\text { A. pedestris (including 'Branchiosaurus cf. B. petrolei'), A. caducus, A. dracyi } \\
\text { (including A. 'dracyiformis'), A. flagrifer, A. gracilis, A. intermedius, A. kontheri, } \\
\text { Branchiosaurus petrolei sensu Heyler (1994); see Appendix } 3 \text { for a synonymy list }\end{array}$ \\
\hline Schoenfelderpeton & S. prescheri \\
\hline Albanerpetontidae & $\begin{array}{l}\text { Albanerpeton inexpectatum, A. arthridion, } \text { A. galaktion, A. nexuosum, } \\
\text { A. pannonicum, Celtedens megacephalus, } C \text {. ibericus }\end{array}$ \\
\hline Tuditanidae & Tuditanus punctulatus, Asaphestera intermedia, Boii crassidens, Crinodon limnophyes \\
\hline Hapsidopareiontidae & Hapsidopareion lepton, Llistrofus pricei, Saxonerpeton geinitzi \\
\hline Pantylidae & Pantylus cordatus, Stegotretus agyrus \\
\hline Gymnarthridae & $\begin{array}{l}\text { Cardiocephalus sternbergi (of which Gymnarthrus is a junior synonym), C. peabodyi, } \\
\text { Bolterpeton carrolli, Euryodus primus, E. dalyae, E. sp., Hylerpeton dawsoni, } \\
\text { Leiocephalikon problematicum }\end{array}$ \\
\hline
\end{tabular}

Brachystelechidae

Rhynchonkos

Gymnophionomorpha
Batropetes fritschi (replacement name for Brachystelechus fritschi),

Carrolla craddocki, Quasicaecilia texana

R. stovalli (replacement name for Goniorhynchus stovalli)

Eocaecilia micropodia, Rubricacaecilia monbaroni, various gymnophionans
Caudata

Salientia
Karauridae: Karaurus sharovi, Kokartus honorarius, Marmorerpeton sp.; various extant and Mesozoic members of Urodela (the crown-group of Caudata); possible urodeles: all members of Batrachosauroididae, Hylaeobatrachus croyi, Jeholotriton paradoxus,

Laccotriton subsolanus, Liaoxitriton zhongjiani, L. daohugouensis, Pangerpeton sinense, Prosiren elinorae, Ramonellus longispinus, all 'scapherpetontids', Sinerpeton fengshanense

Triadobatrachus massinoti, Prosalirus bitis, Vieraella herbstii, Notobatrachus degiustoi, Yizhoubatrachus macilentus, various extant and extinct members of Anura (the crown-group of Salientia)

\begin{tabular}{ll}
\hline Platyrhinops & P. lyelli (formerly often called Amphibamus lyelli) \\
\hline Amphibamus & A. grandiceps \\
\hline 'Tersomius' & 'T. texensis' (but see Huttenlocker et al., 2007) \\
\hline Doleserpeton & D. annectens \\
\hline Micromelerpeton & M. credneri \\
\hline Brachydectes & B. newberryi, B. elongatus \\
\hline Gerobatrachus & G. hottoni \\
\hline
\end{tabular}




\section{Appendix 1}

coded after

Lombard and Bolt (1995), Bolt and Lombard (2000) Panchen (1985), Panchen and Smithson (1990), Clack (1996, 1998)

Milner (1986), Boy (1987), Werneburg (1987), Heyler (1994) Boy $(1978,1986,1987)$, Werneburg $(1986,1988$ a, b, c, 1991, 1996, 2001, 2002), Schoch (1992, 2002), Heyler (1994), Ronchi and Tintori (1997), Boy and Sues (2000), Holmes (2000), Schoch and Fröbisch (2006); MB.Am.1080, MB. Am.1165, MB.Am.1169 (all three A. pedestris) Boy $(1986,1987)$

Fox and Naylor (1982), McGowan and Evans (1995), McGowan (2002), Venczel and Gardner (2005)

Carroll and Baird (1968), Carroll and Gaskill (1978) Carroll and Gaskill (1978) Romer (1969), Carroll and Gaskill (1978), Berman et al. (1988) Carroll and Gaskill (1978), Anderson and Reisz (2003)

Carroll and Gaskill (1978), Vallin and Laurin (2004); MB.Am.808, MB.Am.815.1, MB.Am.815.2 (counterplate of MB.Am.815.1), MB.Am.815.3 (plaster mold of MB. Am.815.1), MB.Am.815.5 (plaster mold of MB.Am.815.2), MB.Am.822.2 (plaster cast), MB.Am.825.1 (plaster cast), MB.Am.830.1 (plaster cast), MB.Am.831, MB.Am.836, MB.Am.837, MB.Am.838.2 (guttapercha cast), MB.Am.839 Carroll and Gaskill (1978), Langston and Olson (1986), Carroll (1990, 1991, 1998) Carroll and Gaskill (1978), Carroll (1998, 2000)

Duellman and Trueb (1986), Jenkins and Walsh (1993), Carroll (2000, 2007), Evans and Sigogneau-Russell (2001), Wake (2003), Müller et al. (2005), Müller (2006), Jenkins et al. (2007)

Thorn (1968), Nevo and Estes (1969), Estes (1969, 1981), Ivachnenko (1979), Carroll and Holmes (1980), Duellman and Trueb (1986), Evans et al. (1988, 2005), Evans and Mil ner (1996), Milner (2000), Gao and Shubin (2001), Rose (2003), Wang (2004), Wang and Rose (2005), Wang and Evans (2006), Carroll (2007), Averianov et al. (2008) Reig (1961), Carroll and Holmes (1980), Duellman and Trueb (1986), Sanchíz (1998), Roček and Rage (2000), Púgener et al. (2003), Gao and Chen (2004), Carroll (2007); MNHN MAE 126a, b (part and counterpart of the holotype and only known specimen [a negative - a natural mold of the dissolved bones] of Triadobatrachus massinoti, along with a silicon rubber mold [a positive] and a cast [a negative])

Carroll (1964), Bolt (1979), Milner (1982, 1993), Clack and Milner (1993), Daly (1994), Schoch (2002)

Carroll (1964), Bolt (1979), Milner (1982, 1986, 1993, 2000), Clack and Milner (1993), Daly (1994), Schoch (2001) Carroll (1964, 2000), Bolt (1977), Clack and Milner (1993) Bolt $(1969,1977)$

Boy (1972, 1995), Boy and Sues (2000), Holmes (2000), Lillich and Schoch (2007); MB.Am.1180

Wellstead (1991)

Anderson et al. (2008a)

\section{Institutional abbreviations}

MB: $\quad$ Museum für Naturkunde der Humboldt-Universität zu Berlin.

MNHN: Muséum National d'Histoire Naturelle (Paris).

YPM: Yale Peabody Museum (New Haven).

Modified scores, character definitions and state delimitations

Character 1: ribs longer (0) or shorter (1) than three successive articulated vertebrae in adults.

McGowan did not quantify this character; he called the states "short straight ribs" and "long straight ribs", explaining only that "[l]ong straight ribs around the body are found in early temnospondyls and Palaeozoic amphibians; short straight ribs first appear in Balanerpeton" (McGowan, 2002: 26). We also note that not all ribs are straight; in the present data matrix, straight ribs with expanded ends seem to be limited to the dissorophoids and Salientia, while the ribs of all other OTUs are curved and pointed.

Setting the boundary between the states at the length of three successive articulated vertebrae keeps the condition of the most mature known branchiosaurids and (marginally) the most mature Micromelerpeton specimens published so far as 1, as scored by McGowan (who assigned state 1 to all temnospondyls and lissamphibians in his matrix, and state 0 to all microsaurs and the all-zero ancestor), and thus congruent with the state in lissamphibians. Rib length increases in the ontogeny of Apateon dracyi: a larva with ribs only as long as one vertebra is pictured by Werneburg $(2001,2002)$, but in the ontogenetically older holotype, the longest ribs reach 3 times vertebral length (Werneburg, 2002). However, the ribs stopped growing at this stage in Apateon gracilis (Schoch, pers. comm. November $\left.20^{\text {th }}, 2007\right)$, the only species of which metamorphosed individuals are known. We have therefore scored Apateon as showing state 1 and Branchiosaurus and Schoenfelderpeton as unknown.

Our definition also necessitates scoring Rhynchonkos and even Cardiocephalus (and thus, because rib length is unknown in other gymnarthrids, Gymnarthridae as a whole) as 1 (Carroll and Gaskill, 1978). McGowan had scored all microsaurs as retaining long ribs.

It is possible that this character is, in temnospondyls, size-related rather than directly ontogeny-related, with small individuals (whether larval or adult) having short straight ribs and large adults having long curved ribs. Indeed, adult dissorophids have the long curved ribs that are normal for temnospondyls, while the small Dendrerpeton (Holmes et al., 1998) and Balanerpeton (Milner and Sequeira, 1994) have short straight ribs despite being phylogenetically far distant from Dissorophoidea. The transformation between these two states is well documented in growth series of Archegosaurus and Sclerocephalus (Witzmann and Schoch, 2006). However, such a relation between rib length, rib curvature and body size does not exist in microsaurs (see illustrations in Carroll and Gaskill, 1978, and Carroll et al., 2004: fig. 5) or lissamphibians (see illustrations in Estes, 1981, and Jenkins and Walsh, 1993). Furthermore, the temnospondyl Acheloma 
including Trematops, which is larger than all temnospondyls in the present matrix, has ribs shorter than those of published specimens of Micromelerpeton (Case, 1911: fig. 46; Boy and Sues, 2000; Holmes, 2000).

In the recently announced (Lillich and Schoch, 2007) metamorphosed specimens of Micromelerpeton, the ribs are unmistakably longer than three successive articulated vertebrae (Schoch, pers. comm. November $20^{\text {th }}, 2007$ ), so we have scored Micromelerpeton as showing state 0 .

The only known specimen of Gerobatrachus exhibits state 1. For the analysis where we consider it juvenile, however, we have scored it as unknown because the ribs become relatively longer in dissorophoid ontogeny (see above).

By coding variation in rib length compared to vertebra length, we imply that the length of vertebrae depends only on absolute body size. This might be expected to be an issue in elongate animals with reduced or absent limbs, namely Gymnarthridae, Brachydectes, and Gymnophionomorpha; however, comparison of figs 9 (showing the plesiomorphic microsaur Asaphestera, considered a tuditanid) and 35 (showing the gymnarthrid Cardiocephalus peabodyi) of Carroll and Gaskill (1978) to each other and to fig. 1 of Wellstead (1991) (showing both species of Brachydectes) argues against such an interpretation for the taxa in the present matrix: they all show similar proportions except for the number of vertebrae and the length of the ribs. Additionally, neither taxa with drastically long nor taxa with drastically short vertebrae compared to the height of the vertebrae occur in this matrix; compare sauropod dinosaur necks or the difference between the aïstopods Phlegethontia longissima and P. linearis (Anderson, 2002: fig. 10)

Character 2: Caudodorsal triangular (alary) process of the premaxilla with a broad base flanked on both sides by a straight, transverse premaxilla-nasal suture (0); narrow median caudodorsal process of the premaxilla (1); broad dorsal process with straight, transverse premaxilla-nasal contact (2) (unordered). McGowan only distinguished 'broad' (0) and 'narrow' (1) premaxilla-nasal contacts and did not explain how he defined these states; his explanation of the 'narrow' condition (which he calls 'alary process') did not enable us to understand it. In McGowan's matrix, a narrow contact (his state 1) was a potential synapomorphy of temnospondyls and lissamphibians.

No sequence is obvious for the three states, theoretically or empirically, so we have kept this character unordered.

The distribution of the three redefined states is more complex than the initial coding. Generally, state 0 , the 'alary process' proper, is characteristic of temnospondyls, state 1 is standard in amniotes, and state 2 is common in lepospondyls, but there are exceptions.

Pantylus and Stegotretus show a condition intermediate between states 1 and 2; accordingly, Pantylidae has been scored as having one or the other.

We have scored Caudata as possessing state 0 , because this state is observed in Karaurus, Kokartus, Cryptobranchus, Batrachuperus, Salamandrella, Valdotriton, Necturus, Salamandra, and Pleurodeles, despite the fact that Amphiuma, Opisthotriton, and arguably Ambystoma have state 1 (Milner, 2000); clearly, state 0 is plesiomorphic for Caudata.

Salientia shows state 1 (unknown in Triadobatrachus).

We have scored Gymnophionomorpha as polymorphic (states 0 and 1) because Gymnophiona possesses state 1, the condition in Rubricacaecilia is unknown, and Eocaecilia shows state 0 (Jenkins et al., 2007).

The condition seen in Gerobatrachus (Anderson et al. 2008a: fig. 2a) does not fit any of the three states here, but this is not surprising given the tiny size of the specimen: the skull is less than $2 \mathrm{~cm}$ long, so that the relatively enormous external nares do not leave much space for an alary process (state 0 ). Furthermore, the skull is only visible in ventral view and the premaxilla appears to be damaged on both sides. Lastly, in the analysis where we consider the specimen to be juvenile, we have to take into account that the shape of the premaxilla-nasal contact can change in dissorophoid ontogeny. In sum, we have scored Gerobatrachus as unknown for the purposes of both analyses that include it.

Character 3: Teeth with one cusp throughout ontogeny (0), a labiolingual ridge at any point in ontogeny (1), two cusps arranged labiolingually at any point in ontogeny (2), or two or three cusps arranged mesiodistally at any point in ontogeny (3) (stepmatrix).

State 1 is among the most conspicuous characters shared by most lissamphibians (with the albanerpetontids as the most notable exception - assuming that they are lissamphibians; see Discussion) and all of the amphibamids in the present matrix. The sequence $0>1>2$ is obvious (Bolt, 1977; Anderson and Reisz, 2003), suggesting ordering, but state 3 does not necessarily fit into this straight sequence: a lineage evolving from state 2 to state 3 or the reverse might pass through states 1 and 0 , through a state (not present in this matrix) where at least three cusps are arranged in a triangle or another two-dimensional shape (compare the molariform teeth of mammalomorphs), or possibly even rotate the teeth. We have therefore applied the stepmatrix shown in Appendix-Table 2 to this character. For more information on stepmatrices see Swofford and Begle (1993: 15-18).

Appendix-Table 2. The stepmatrix for character 3.

\begin{tabular}{|c|c|c|c|c|}
\hline From & To & & & \\
\hline & State 0 & State 1 & State 2 & State 3 \\
\hline State 0 & 0 & 1 & 2 & 1 \\
\hline State 1 & 1 & 0 & 1 & 2 \\
\hline State 2 & 2 & 1 & 0 & 2 \\
\hline State 3 & 1 & 2 & 2 & 0 \\
\hline
\end{tabular}

McGowan (2002) only distinguished monocuspid (0) and bicuspid (1) teeth (and did not expressedly state which ontogenetic stage was coded); to account for the tricuspid teeth of albanerpetontids and Batropetes (McGowan explicitly mentioned this condition and coded it as monocuspid), we have added state 3 . The three cusps of these teeth are arranged mesiodistally, rather than linguolabially as in the bicuspid teeth of most lissamphibians and amphibamids. The two cusps of the teeth of Carrolla are also arranged in a mesiodistal line, and the teeth of Quasicaecilia are unknown, so we have scored Brachystelechidae as only possessing state 3 .

Anderson and Reisz (2003) and Anderson (2007) argue for recognizing the teeth of Bolterpeton and Cardiocephalus 
sp., which possess a short edge instead of a sharp point, as "weakly bicuspid", citing Bolt $(1977,1980)$. This is our state 1 , which therefore occurs only as part of the polymorphism of Gymnarthridae. (The dissorophoid temnospondyl cf. Broiliellus, which shares this state according to Bolt [1977], is not part of the present matrix.) McGowan's state 1 thus becomes our state 2 .

Juvenile 'Tersomius texensis' have bicuspid teeth, at least sometimes (Bolt, 1977); this is how McGowan scored Tersomius, but as his source for Tersomius he only cited Boy (1980) who states the opposite for the "postmetamorphic" (but juvenile: Boy, 2002: 428) specimen of Eimerisaurus (his Tersomius graumanni). Because Eimerisaurus is closely related to Micromelerpeton rather than a species of Tersomius, we have, like McGowan has apparently done, coded 'Tersomius' after 'T. texensis' as showing state 2 .

Character 4: Ventral scales (gastralia) well ossified (0), poorly ossified (1), or absent (2) (ordered).

McGowan did not distinguish ventral and dorsal scales; however, even outside of amniotes and diadectomorphs, the presence of one does not necessarily imply the presence of the other (Witzmann, 2007), so we treat these two characters separately; the dorsal scales are treated in our character 42 . Furthermore, McGowan coded only two states, presence (0) and absence (1) of scales; we have separated states 1 (poorly ossified) and 2 (absent) for the ventral scales to account for the difference between Platyrhinops and Gymnophionomorpha on the one hand and Caudata, Salientia, and Whatcheeria on the other.

A sequence is apparent: a lineage evolving from state 0 to state 2 or the reverse would more likely than not pass through state 1 . We have therefore ordered the character.

McGowan coded all microsaurs as retaining scales. However, there is no evidence for ventral scales in Tuditanus, and, given the preservation of some specimens (e.g., Carroll and Baird, 1968), we take this as evidence of absence. Still, ventral scales are present in Asaphestera and Crinodon (Carroll and Gaskill, 1978: 183). Thus, we have scored Tuditanidae as polymorphic (states 0 and 2).

Scales are furthermore completely absent in all articulated gymnarthrid specimens, and the associations of disarticulated gymnarthrids with scales are all questionable (Carroll and Gaskill, 1978: 183), so we score Gymnarthridae as lacking ventral scales (as well as dorsal ones, see character 42).

Likewise, "[s]cales are not known among the several articulated specimens of" Rhynchonkos (Carroll and Gaskill, 1978: 185), and McGowan did not cite evidence to the contrary, so we have corrected McGowan's scoring of state 0 to state 2 .

Scales are plesiomorphic for Gymnophiona. They are unknown in Eocaecilia and Rubricacaecilia, but the poorly ossified state of gymnophionan scales makes it unlikely that such scales would have been preserved in Eocaecilia; preservation of any scales in the fragmentary Rubricacaecilia would be unexpected. We have therefore scored Gymnophionomorpha as possessing state 1 . The homology of gymnophionan scales with those that are plesiomorphically present in bony vertebrates is uncertain (Zylberberg and Wake, 1990), but to avoid unnecessary deviations from the original coding, we assume their homology, as McGowan did.
In Platyrhinops, coded as having lost the scales by McGowan, "[g]astralia are only present in the largest [American] specimen and then poorly ossified in relation to size compared to A[mphibamus] grandiceps and most Palaeozoic temnospondyls"; "poorly developed gastralia" are also present in one Czech specimen (Clack and Milner, 1993: 186-187). This is recoded as our state 1 (poorly ossified).

The condition in 'Tersomius' and Doleserpeton is unknown, contra McGowan (Clack and Milner, 1993).

Character 5: Teeth never pedicellate (0) or pedicellate at some point in ontogeny (1).

State 1 is among the most conspicuous characters shared by most lissamphibians (but not the albanerpetontids) and certain amphibamids.

Juvenile 'Tersomius texensis' have pedicellate teeth, at least sometimes (Bolt, 1977); this is how McGowan (who did not expressedly consider ontogenetic variation) scored Tersomius, but as his source for Tersomius he only cited Boy (1980) who states the opposite for the "postmetamorphic" (but juvenile: Boy, 2002: 428) specimen of Eimerisaurus (his Tersomius graumanni). Because Eimerisaurus is closely related to Micromelerpeton rather than a species of Tersomius, we have scored 'Tersomius' after 'T. texensis' as showing state 1 .

Gerobatrachus was described as having pedicellate teeth. However, even though such teeth are not unexpected in an amphibamid (especially a possibly juvenile one), we doubt their occurrence in Gerobatrachus. The only available illustration is fig. 3a of Anderson et al. (2008a), a photo whose relatively low resolution leaves considerable room for interpretation. Of the three teeth shown in that figure, all of which were interpreted as being pedicellate, the left and the right one only show a constriction so far as we can see; the middle one may have an obliquely oriented break that may be continuous with what appears to be a break in the matrix between the middle tooth and the right one. Furthermore, even articulated fossils with pedicellate teeth most often preserve the pedicels, but not the crowns, which have fallen off, as indicated by Jenkins et al. (2007: 327) for Eocaecilia: "Although tooth crowns are rarely preserved in situ on the pedicels, disarticulated tooth crowns were recovered [...]". Judging from fig. 2 (two drawings with fairly high resolution), the specimen preserves a large number of empty alveoli and a few complete teeth, but no lone pedicels. Because we have not seen the specimen and because the ontogeny of Gerobatrachus is unknown, we have scored the pedicely of Gerobatrachus as unknown for both analyses that include it.

Character 6: Number of presacral vertebrae: over 24 (0), 18 to 24 (1), 17 or less (2) (ordered).

Except for certain derived salamanders, lissamphibians other than gymnophionans share short presacral vertebral columns (state 1 or 2) with the branchiosaurids, Amphibamus, Gerobatrachus, the pantylids, and the brachystelechids. Neomorphic presacral vertebrae do not, as far as we know, ever appear en masse, nor do presacral vertebrae disappear en masse, and large saltational changes in the location of the pelvis and the caudal extent of the internal organs are likewise improbable, so we think that changes in this character are normally gradual, justifying our decision to order this character, a decision 
that is already implied in not coding each number of vertebrae as a separate state (Wiens, 2001).

McGowan distinguished two states within our state 2. One, however (his state 2: "16 or fewer" presacral vertebrae), was limited to Caudata, and the other (McGowan's state 3: "5-8 presacral vertebrae" - which should be 5 to 9 or 10 , including the atlas [Vieraella (9 or 10) and Ascaphus (9): Púgener et al., 2003; Leiopelma (9) and Notobatrachus (9): Carroll, 2007: fig. 62]) is restricted to Salientia other than Triadobatrachus. Triadobatrachus - mentioned as possessing less than 16 presacrals, but apparently not considered in the coding of 'Salientia', by McGowan - shows an intermediate state in McGowan's coding, namely 14 presacral vertebrae (Roček and Rage, 2000). Furthermore, some basal caudates have less than 16 presacral vertebrae: Karaurus has 12 or 13 (Ivachnenko, 1979: plate IX; pers. obs. on photos taken by M. L. in 2006; contra the text of Ivachnenko, 1979), Pangerpeton has 14 (Wang and Evans, 2006), Liaoxitriton zhongjiani has 15 (Wang and Rose, 2005), and Liaoxitriton daohugouensis has 15 or 16 (Wang, 2004), as do Jeholotriton and an unnamed Early Cretaceous caudate from Spain (Wang and Rose, 2005). Rather than retaining these two states, one of which occurs only as an autapomorphy of part of one OTU, we have merged them.

Extant salamanders have 10 to 60 presacral vertebrae (Duellman and Trueb, 1986), but this wide range (most of which is confined to Plethodontidae) is clearly a recent phenomenon: in addition to the examples mentioned above, Valdotriton has 17 presacrals (Milner, 2000), Iridotriton is estimated at the same number (Evans et al., 2005), Hylaeobatrachus and Laccotriton have 16 (Wang and Rose, 2005), and Chunerpeton, described as the oldest (most likely Early Cretaceous; Wang et al., 2005) cryptobranchid, has 15 (Gao and Shubin, 2003). Hence, the most parsimonious hypothesis is that Caudata primitively had no more than 17 presacrals (state 2). For early urodele phylogeny see Evans et al. (2005).

Character 7: Palatine fangs present (0) or absent (1) in adults. In McGowan's matrix, state 1 united most of the ingroup branchiosaurids, microsaurs, and Doleserpeton; he did not mention ontogeny.

To ensure that this character is independent of character 35 (which refers to vomerine fangs), we have reworded the definition of this character from the original which referred to "palatal" fangs. Pantylus, which has palatine but not vomerine fangs (see below and character 35), shows that these two characters are indeed independent. The embolomeres, which are not included in this analysis, have fangs on the palatine and the ectopterygoid, but not on the vomer; this further demonstrates that these two characters are reasonably independent.

The difference between "teeth" and "fangs", not explained by McGowan (2002: 26) except by means of a few examples, is somewhat difficult to judge in branchiosaurids. We have coded all as possessing 'fangs' because, except for clearly larval specimens, they all have two sizes of teeth on both the vomer and the palatine, and the bigger teeth occur singly or in the familiar pairs, while the smaller ones qualify as denticles (Boy, 1972, 1978, 1986, 1987). Possibly 'tusk' would be a better term than 'fang'.

The replacement pit which often accompanies the fang in a pair has, to our knowledge, not been described or illus- trated in any microsaur. However, this could be related to the small size of the specimens, which makes observation of such pits difficult, or to the speed of tooth replacement, so we do not consider it as a criterion for distinguishing 'teeth' and 'fangs'; instead, we rely on size, fangs being larger than marginal teeth.

McGowan (2002: 26) stated that the tuditanid Asaphestera lacks fangs, presumably because the large teeth on its palatine (larger than the marginal teeth, as mentioned by McGowan) are arranged in a row parallel to the marginal dentition (Carroll and Gaskill, 1978), rather than alone or in pairs. Based on their size, however, we consider them fangs. The relevant region of the palate is unknown in Tuditanus and Boii (Carroll and Gaskill, 1978), but Crinodon, not mentioned by McGowan, has several fangs in an irregular (and asymmetric) distribution (Carroll and Gaskill, 1978), so we have scored Tuditanidae as possessing palatine fangs based on Asaphestera and Crinodon.

Pantylus has one large fang on each palatine (Carroll and Gaskill, 1978). McGowan did not consider these "large crushing teeth on the palatal bones" (McGowan, 2002: 26) 'fangs', perhaps because they are rather blunt, but we see no reason to doubt their primary homology to palatine fangs. On the other hand, Stegotretus (Berman et al., 1988) lacks this tooth and instead has a hole in the palatine that accommodated the coronoid 'tusk' (which is also present in Panty$l u s)$. We have therefore scored Pantylidae as polymorphic.

Brachystelechidae is scored as lacking palatine fangs because Carrolla, the only brachystelechid which can be scored, has "[p]robably no palatal dentition" (Carroll, 1998: 63).

As far as known, Doleserpeton lacks palatine fangs; however, this condition is also found in juveniles of Amphibamus but not in the single adult specimen (Daly, 1994), so we have scored this character as unknown in Doleserpeton in the analysis where we treat the described material of Doleserpeton as morphologically immature.

Character 8: Ectopterygoid at least about half as long as palatine (0), about a third as long as the palatine or shorter (1), or absent (2) (ordered).

McGowan distinguished only two states which he called "large" and "small or absent". In his matrix, the resulting state 1 is shared by most of the ingroup - all dissorophoids other than Platyrhinops, all lissamphibians, and almost half of the microsaurs.

As usual with quantitative characters, McGowan did not explain how he defined the states. However, a morphological gap between 'large' and 'small' is readily apparent in the distribution. Still, this is a potentially continuous character and should therefore be ordered (Wiens, 2001).

McGowan coded 'Tersomius', Micromelerpeton, Branchiosaurus, and Apateon as possessing state 1, but their ectopterygoid is at least as long compared to the palatine as that of Platyrhinops ('Tersomius': Bolt, 1977; Micromelerpeton: Boy, 1995; Branchiosaurus: Boy, 1987; Apateon: Boy, 1978, 1986, 1987; Platyrhinops: Clack and Milner, 1993), which he scored ' 0 ', and are very different from the other taxa McGowan scored as showing state 1. In 'Tersomius' as reconstructed by Bolt (1977: fig. 2), the ectopterygoid is even longer than the palatine. Accordingly, we have scored all these OTUs as possessing state 0 . 
Unlike the other branchiosaurids, Schoenfelderpeton, scored by McGowan as having a small or absent ectopterygoid, indeed has an extremely small, toothless ectopterygoid (Boy, 1986). It is apparently never that small in the ontogeny of Apateon (Schoch, 1992, and pers. comm. November $20^{\text {th }}$, 2007). Thus, we have scored Schoenfelderpeton as having state 1 .

The presence or absence of ectopterygoids is unknown in Eocaecilia (although state 0 can be ruled out: Jenkins et al., 2007) and Rubricacaecilia. In gymnophionans, the ectopterygoid is usually absent, but state 1 has been reported in Grandisonia (Carroll and Currie, 1975), Geotrypetes, Schistometopum, Herpele, Siphonops, Gymnopis (Duellman and Trueb, 1986: 309, but not the fig. 13-10 cited there; for Gymnopis, see also Jenkins et al., 2007: fig. 6C), Microcaecilia (Renous, 1990), Praslinia (Wake, 2003), and Hypogeophis (Müller, 2006). Less unambiguously, Wake (2003: fig. 7H) illustrates a skull of Boulengerula taitana (a close relative of Herpele; Wilkinson and Nussbaum, 2006) in ventral view, where a peculiar flange of bone of comparable size and position to the ectopterygoids of the aforementioned gymnophionans is continuous with the palatine but not the maxillary portion of the maxillopalatine, separated from the maxillary portion by a suture on the right side and a notch on the left side of the skull. However, all of these gymnophionans are teresomatans (Wilkinson and Nussbaum 2006), so that Gymnophiona, and Gymnophionomorpha as a whole, is still most parsimoniously scored as ancestrally lacking ectopterygoids (state 2), as shown in Fig. 4. (See also Swofford and Begle, 1993: 24.) The ectopterygoid seen in the abovementioned teresomatans must be considered a reversal (or a neomorph not homologous with the ectopterygoid), at least at the present state of knowledge of the fossil record.

(In the rhinatrematid Epicriniops, the vomerine/palatine toothrow, and the ridge to which it is attached, continues onto the pterygoid in adults [Nussbaum, 1977: fig. 1], suggesting the possibility that the ectopterygoid is present and fused to the pterygoid. However, as far as we know, this possibility is currently untested, so we take the adult condition - absence of a separate ectopterygoid - at face value.)

This leaves state 1 to Schoenfelderpeton and the hapsidopareiontid and brachystelechid microsaurs, and state 2 to the albanerpetontids, salamanders, frogs, pantylids, and Doleserpeton, as well as Brachydectes and Gymnophionomorpha.

Character 9: Intercentra at least as large as pleurocentra (0), markedly smaller (1), or absent (2) (ordered).

In McGowan's matrix, state 2 occurred in Caudata, Salientia, Albanerpetontidae, and most microsaurs, while state 1 was ascribed to Gymnophionomorpha, the remaining microsaurs, Doleserpeton, and Micromelerpeton; the rest of the ingroup was given state 0 .

McGowan omitted the "at least" part from state 0 , but most of the taxa he scored as such have more or less classical rhachitomous vertebrae, where the intercentra are larger than the pleurocentra.

Crassigyrinus has large crescentic intercentra and lacks ossified pleurocentra altogether; this almost certainly corresponds to small and cartilaginous pleurocentra and therefore to state 0 .

Pleurocentra are likewise unknown from branchiosaurids; intercentra are preserved in a single specimen, the most mature one known of Apateon gracilis (Schoch and Fröbisch, 2006). In the absence of illustrations or descriptions, we interpret the presence of intercentra and absence of pleurocentra in that specimen, together with the fact that the intercentra ossify before the pleurocentra (Schoch and Fröbisch, 2006; Witzmann, 2006) in temnospondyls that are known to be rhachitomous (state 0), as indications that Apateon gracilis was rhachitomous, too. Thus, we have coded Apateon as 0 and Branchiosaurus and Schoenfelderpeton as unknown.

In some extant frogs, the intervertebral discs mineralize and then sometimes fuse to adjacent (pleuro)centra (Duellman and Trueb, 1986: 332). Carroll (2007: 43) therefore compares these discs to intercentra. However, such ossifications have not been reported from Ascaphus, Leiopelma (Carroll, 2007: 43), or any Mesozoic anuran as far as we know (except for atlas and probably axis intercentra, which are present in Triadobatrachus: Roček and Rage, 2000), so we consider these cases to be reversals and have kept McGowan's scoring of Salientia as (plesiomorphically) lacking intercentra (state 2).

While small intercentra (state 1) are present in Eocaecilia (Jenkins et al., 2007), they are absent in Gymnophiona (Duellman and Trueb, 1986), if not Gymnophioniformes as a whole (judging from the basapophyses of Rubricacaecilia: Evans and Sigogneau-Russell, 2001; see also character 11). Given the mineralized intervertebral discs of some frogs mentioned above, as well as the rather chaotic distribution of intercentra in microsaurs, we cannot simply assume that state 1 is plesiomorphic for Gymnophionomorpha and have therefore scored this OTU as polymorphic (states 1 and 2).

As shown by Boy $(1972,1995)$, Micromelerpeton is rhachitomous, having much larger intercentra than pleurocentra (0), rather than gastrocentrous (1) as scored by McGowan.

Character 10: Dermatocranium and neurocranium can disarticulate from each other post mortem (0) or not (1) in adults. McGowan (2002: 27) called this character absence (0)/presence (1) of "fusion of the neurocranium and dermatocranium" and did not mention ontogenetic considerations. In his original coding, state 1 ("fusion") was a potential synapomorphy of microsaurs and lissamphibians. However, obliteration of the sutures (actual fusion; Irmis, 2007) is limited to a single OTU, Gymnophionomorpha (where the large parasphenoid and the entire caudal half of the neurocranium fuse to form the so-called os basale), necessitating our present reinterpretation to avoid making the character parsimony-uninformative.

Branchiosaurids are almost always found as complete articulated skeletons, so the skull had little opportunity to disarticulate, but, like McGowan, we have scored them as 0 because their exoccipitals ossify very late (and most of the rest of the braincase may not ossify at all, even after metamorphosis; Schoch, 2002).

All codable microsaurs (Carroll and Gaskill, 1978; Carroll, 1990) except the pantylids (Romer, 1969; Carroll and Gaskill, 1978; Berman et al., 1988) and possibly Carrolla (Langston and Olson, 1986) show state 0. To avoid problems with the interpretation of ontogeny (Quasicaecilia, which, taken at face value, has state 0 , is only known from a very juvenile specimen), we have scored Brachystelechidae as unknown. 
Also contra McGowan, however, we have scored Doleserpeton as 1 because of its high degree of neurocranium ossification, unusual for a temnospondyl, but common in lissamphibians: "Prootic and opisthotic bones are well ossified, although rarely fused. [...] There is no supraoccipital bone, and indeed no room for one, as the opisthotics cover the tops of the exoccipitals and, in maturer specimens, fuse above the foramen magnum." (Bolt, 1969: 889)

We have scored 'Tersomius' as unknown because Carroll (1964) does not make the condition clear; he does, however, explain that the braincase is less well ossified than in Doleserpeton.

In Gerobatrachus, the braincase is slightly disarticulated and highly incomplete, but the latter may reflect lack of ossification of some elements, if the specimen represents a juvenile. We have interpreted this condition as disarticulation (state 0 ) in the analysis where we treat Gerobatrachus as adult, but scored this character as unknown in the analysis where we treat it as immature or paedomorphic.

Character 11: Basapophyses absent (0) or present (1).

The so-called basapophyses of salamanders and albanerpetontids are thickenings on the cranioventral edges of the centra that usually bear articular processes. McGowan scored the condition in Gymnophionomorpha as unknown because "[i]t is not known whether the parapophyses of gymnophionans are homologous [to the basapophyses of salamanders]" (McGowan, 2002: 27). Indeed the misnamed 'parapophyses' of gymnophionans are closely associated with the parapophyses, unlike the basapophyses of salamanders (Duellman and Trueb, 1986: figs 13-23, 13-25; Evans and Sigogneau-Russell, 2001: fig. 6), but, judging from the condition in Rubricacaecilia where, unlike in at least some extant caecilians, the basapophyses are associated with the ventral edge of the centrum (Evans and Sigogneau-Russell, 2001: fig. 6), this seems to have more to do with the position of the parapophysis on the centrum (in the middle in salamanders, near the cranial edge in caecilians) than with the homology of the basapophyses of each group, so, in the absence of contradictory developmentary or fossil evidence, they should be considered primary homologues.

Basapophyses are thus present in Gymnophioniformes (Duellman and Trueb, 1986; Evans and Sigogneau-Russell, 2001), although the basapophyses of Rubricacaecilia lack processes (Evans and Sigogneau-Russell, 2001). In Eocaecilia, however, basapophyses are entirely absent (Carroll, 2000; Evans and Sigogneau-Russell, 2001; Jenkins et al., 2007), so we have coded Gymnophionomorpha as polymorphic.

In Caudata, basapophyses are likewise widespread but not universal. Most importantly, they are lacking in the two karaurids that can be scored for this character (Marmorerpeton: Evans et al., 1988: fig. 8f, h; Kokartus: Averianov et al., 2008). They are furthermore absent in 1) all 'scapherpetontids' (Estes, 1981), an enigmatic, possibly polyphyletic (Evans et al., 1988) caudate assemblage of unknown (and almost uninvestigated), therefore possibly basal, phylogenetic position(s) within Caudata; 2) in Jeholotriton (Wang and Rose, 2005) and 3) Pangerpeton (Wang and Evans, 2006) which are known to share a single synapomorphy (single-headed ribs on all vertebrae) with Cryptobranchoidea, 'salamander B' from the Middle Jurassic of England, and the Late Jurassic neocaudate Iridotriton (Evans et al., 2005) and may therefore be assumed to lie somewhere around the origin of Urodela, and apparently 4) in the mysterious caudate Ramonellus (judging from the figures in Nevo and Estes, 1969). (Note that the assignment of Jeholotriton and Pangerpeton, together with all other Mesozoic East Asian caudates, to Cryptobranchoidea by Marjanović and Laurin [2007] was based only on the single-headed ribs, a number of plesiomorphies, and geography.) With basapophyses being present in most of Urodela but absent in the only two scorable certain non-urodeles (Marmorerpeton and Kokartus) as well as in most possible non-urodeles (Batrachosauroididae and Prosiren possess basapophyses: Estes 1969, 1981), we have scored Caudata as polymorphic because both states are observed within the group and both states can equally parsimoniously be reconstructed for the first caudate.

Like McGowan, we consider taxa in which the pleurocentra do not reach the ventral margin of the vertebral column to lack basapophyses, because they invariably lack comparable thickenings or processes on the pleuro- as well as intercentra. Carroll (2000), on the other hand, implies that basapophyses and intercentra are mutually exclusive and functionally analogous (or even homologous, though this appears doubtful to us). Therefore we cannot exclude the possibility that coding the basapophyses as unknown (= inapplicable) rather than absent in taxa that retain intercentra might have been more appropriate.

In either case, however, basapophyses are present in Albanerpetontidae but absent or unknown in all other OTUs except for the polymorphisms of Gymnophionomorpha and Caudata. This distribution makes this character parsimonyuninformative - a consequence of the usage of supraspecific OTUs.

Character 12: Radial condyle of humerus not much larger (0) or substantially larger (1) than ulnar condyle.

A gap in the distribution of this potentially continuous character is evident. According to McGowan's coding, state 1 is present in lissamphibians and in most microsaurs.

This condyle often does not ossify in salamanders, so our (and McGowan's) coding of all temnospondyls as 0 rather than unknown is tentative. McGowan added hemispherical shape to size, but that shape is not present in gymnarthrids and Pantylus (Carroll and Gaskill, 1978: figs 33G, 41B, $122 \mathrm{~A}, \mathrm{~B})$ and is more strongly dependent on ossification than size is.

Tuditanidae has state 0 (Carroll and Gaskill, 1978: figs $5 \mathrm{D}$ and 8E), contra McGowan (2002). In Tuditanus the radial condyle is even smaller than the ulnar one.

Saxonerpeton, the only scorable hapsidopareiontid, has a radial condyle that is only marginally larger than the ulnar condyle and lacks a ball in distal view (Carroll and Gaskill, 1978: figs 24, 123C). Therefore, we have changed the score of Hapsidopareiontidae from uncertain to 0 .

Rhynchonkos likewise shows state 0 (Carroll and Gaskill, 1978: fig. 69B).

McGowan cited Jenkins and Walsh (1993) for his statement that Eocaecilia shows state 1. Neither that publication nor those by Carroll $(2000,2007)$ contain any description or illustration of the distal end of the humerus, but Jenkins et al. (2007: 344) confirm the presence of "a bulbous, hemisphe- 
roidal capitulum for the proximal radius" on the distal end of the humerus, so we have retained McGowan's score for Gymnophionomorpha (state 1).

Character 13: Tabular present (0) or absent (1).

McGowan followed Carroll's interpretation (Carroll and Gaskill, 1978; Carroll, 1998) that the large bone in the caudolateral corner of the microsaur skull roof should be considered the tabular. Carroll (1998) acknowledges that, based on its position and its large size, it could be a fusion of tabular and supratemporal; but in other lepospondyls, whenever a separate supratemporal is present, it is a long, narrow strip of bone that lies between the large tabular and the squamosal (see illustrations in Wellstead, 1982, and Bossy and Milner, 1998), so it may have genuinely vanished in the microsaurs or alternatively makes up a small part of the 'tabular' or the squamosal, while the tabular itself is present. Therefore we have retained McGowan's coding of all microsaur OTUs as possessing a tabular and lacking a supratemporal (see character 37).

Eocaecilia likewise possesses a bone that could be a supratemporal or a tabular (Jenkins et al., 2007). It is absent in Gymnophiona (and the skull is unknown in Rubricacaecilia), but because we do not see a reason to assume that it could be a neomorph (for example, Eocaecilia lacks osteoderms that could have participated in the formation of the skull roof and be identified as supernumerary skull bones like in some ankylosaurian dinosaurs), we regard it as primary homologous to the supratemporal or the tabular. Unfortunately, without making an a priori assumption about whether gymnophionomorphs are temno- or lepospondyls, we cannot decide between these two options. We therefore choose to score this bone as a tabular to avoid the possibility of a counterintuitive reversal: temnospondyls have both a supratemporal and a tabular, so the condition of Eocaecilia can be derived from the temnospondyl condition by the loss of a bone in either case; microsaurs have only the tabular, so that, if Eocaecilia is coded as possessing a supratemporal instead, the reappearance of a long-lost bone would be required if Gymnophionomorpha were nested among the microsaurs. With the tabular thus being present in Eocaecilia, unknown in Rubricacaecilia and absent in Gymnophiona, we have coded Gymnophionomorpha as polymorphic.

The tabular is thus absent only in Albanerpetontidae, Caudata, Salientia, and part of Gymnophionomorpha (see the Methods section for our coding of Brachydectes as retaining the tabular).

Character 14: Interglenoid tubercle of atlas absent (0), present (1).

State 1 was a synapomorphy of lissamphibians and microsaurs (reversed in Salientia) in McGowan's matrix.

The atlantal centrum is unknown in all branchiosaurids, in which only the neural arches ossify (except for the most mature specimen of Apateon gracilis, which has ossified intercentra, but still no pleurocentra; Schoch and Fröbisch, 2006). Therefore, we have changed their scores from 0 to unknown.

Given the fact that McGowan neither mentioned Rubricacaecilia nor cited its description (Evans and Sigogneau-Russell, 2001), we do not know why he scored Gymnophionomorpha as ancestrally possessing the interglenoid tubercle; however, this score is the most parsimonious one, because both Eocaecilia and Rubricacaecilia (Evans and SigogneauRussell, 2001; Jenkins et al., 2007) show this feature in spite of its absence throughout Gymnophiona (Duellman and Trueb, 1986).

McGowan likewise coded the interglenoid tubercle as absent in all amphibamids. It is, however, unknown in all of them except Gerobatrachus, which possesses state 1 (Anderson et al., 2008a). In Doleserpeton, the presence or absence of the tubercle has never been described or illustrated, even though the atlas was already mentioned as known by Bolt (1969); Carroll (2007: fig. 65C) does illustrate the atlas, but the drawing in cranial view is not sufficiently three-dimensional for us to judge if a tubercle like that seen in Gerobatrachus (or smaller) was present (although, in that case, it would have to have been much flatter dorsoventrally than in the lissamphibians that possess it - whether this was also the case in Gerobatrachus, which is currently only accessible in ventral view, is unknown), and the text does not mention the condition of Doleserpeton. We have accordingly scored Doleserpeton, Amphibamus, 'Tersomius' and Platyrhinops as unknown.

In sum, the condition of all temnospondyls in the matrix except Gerobatrachus (and that of Whatcheeria) is unknown, and state 0 is restricted to Salientia and Crassigyrinus; all other OTUs have state 1.

Character 15: Interclavicle large in relation to the clavicles (0), small (1), or absent (2) (ordered).

McGowan combined size and shape in this character, but the shape varies very widely in ontogeny wherever ontogenetic series are known (Branchiosaurus: Werneburg, 1987; Apateon: Werneburg, 1986, 1988a; Boy, 1987; Schoch, 1992; Micromelerpeton: Boy, 1995). He also did not distinguish between 'small' and 'absent'; the latter condition is likely an autapomorphy of Lissamphibia or a slightly larger clade and therefore of interest to the present study. Small interclavicles (state 1) are known from the three branchiosaurids, Gymnarthridae, Platyrhinops, Amphibamus, Micromelerpeton, and Brachydectes.

Morphological gaps in this potentially continuous character are readily apparent. Since it is potentially continuous, however, it should be ordered (Wiens, 2001).

Contra McGowan, the interclavicle of Rhynchonkos is unknown (Carroll, 1998: 22).

Despite its comparable anatomical position, the omosternum of some frogs does not seem to be homologous to the interclavicle because it is always at least partially cartilaginous and apparently an autapomorphy of a clade within the crown-group Anura (Duellman and Trueb, 1986). The monotreme interclavicle does have an endochondral part (which forms part of the sternum in therians), but this element has so far not been found in any other vertebrates (Vickaryous and Hall, 2006). Therefore we retain McGowan's scoring of Salientia as lacking an interclavicle.

Character 16: Number of coronoids in adults: 0 or $1(0), 2$ (1), 3 (2) (ordered).

McGowan's character 16 stated the presence (0) or absence (1) of the supratemporal. This character duplicated character 37 (supratemporal small [0]/large [1]/absent [2]) with less precision, so we have removed it (including the erroneous 'unknown' scoring of character 16 for Branchiosaurus). 
The rostralmost coronoid is always lost first. We have therefore ordered this character.

To preserve the original numbering of the other characters, we have given the number 16 to one of the derivatives of the original character 39; McGowan's character 39 concerned the number and the dentition of the coronoids at once (in only three states), yet these two characters do not always correlate. For example, 'Tersomius' has three toothless coronoids (Carroll, 1964), combining the most plesiomorphic state of the number with the most derived state of the dentition. We have also added the ontogenetic specification in the name of the present character to account for losses and fusions that are not visible in the fossils of adults.

Contra McGowan (2002), the lower jaws of Platyrhinops and Amphibamus have not been described or illustrated anywhere in the literature he cites, nor in the additional literature we have been able to find. Accordingly, both had to be scored as unknown.

Generally, lissamphibians lack coronoids as adults. Most salamanders possess at least one coronoid as larvae, but only neotenic species retain at most one into adulthood (Rose, 2003), so we have coded Caudata as lacking coronoids as adults (state 0), ignoring the neotenic species following Wiens et al. (2005). No coronoid has, to the best of our knowledge, ever been reported in Salientia or Albanerpetontidae (although lingual views of clearly articulated lower jaws of albanerpetontids are rarely available). In the few known gymnophionan ontogenies, a single coronoid fuses to the dentary and an ossification of Meckel's cartilage to form the 'pseudodentary' and bears the second, lingual toothrow (Müller et al., 2005; Müller, 2006) which is also found on the 'pseudodentary' of Eocaecilia. Thus, adult anurans lack discernible coronoids because no such centers of ossification ever appear in ontogeny; metamorphosed urodeles lack discernible coronoids because they are resorbed in ontogeny; and adult caecilians lack discernible coronoids because they are fused to the dentaries. These three conditions may not be homologous. However, coding them as different states would lead to problems: except for ontogenetic data, the only evidence for the existence of a coronoid in adult gymnophionomorphs is the lingual toothrow. In taxa without a coronoid toothrow and without a well-studied ontogeny (such as Albanerpetontidae and Brachydectes), it is thus impossible to determine the presence of toothless coronoids that might have fused to the dentary. Therefore we have decided to score the adult condition at face value. However, because - ignoring gymnophionan ontogeny as mentioned - none of the OTUs in our matrix happen to show a single coronoid, we have coded the presence of a single coronoid as the same state as the complete lack of coronoids. The loss of two of the three coronoids in the adult appears homologous between Gymnophiona, Urodela, Anura, Albanerpetontidae and Brach$y$ dectes, even if the loss of the third coronoid may not be.

Thus, we have coded Albanerpetontidae, Gymnophionomorpha, Caudata, Salientia and Brachydectes as having 0 or 1 coronoids (state 0 ).

Where the lingual side of the lower jaw is known, at least one coronoid is present in all other OTUs, although, because the number of coronoids cannot be determined with any more precision, Apateon, Schoenfelderpeton, Tuditanidae and Pantylidae had to be coded as unknown. Two coronoids (state
1) are counted in Rhynchonkos, two or three (state 1 or 2) in Micromelerpeton, and three (state 2) in Whatcheeria, Crassigyrinus, Gymnarthridae, Microbrachis and 'Tersomius'.

\section{Character 17: Intertemporal present (0) or absent (1).}

Contra McGowan, there is no sign of an intertemporal in Platyrhinops (Clack and Milner, 1993), Amphibamus (Milner, 1982), 'Tersomius' (Carroll, 2000), or for that matter Eimerisaurus (Boy, 1980, 2002). It is of course imaginable that the intertemporal is actually present and fused to the supratemporal, perhaps explaining the size of the 'supratemporal' (and possibly also some of the pathologic states reported by Boy [1972] in a few Micromelerpeton specimens), but the same holds for all other temnospondyls in the matrix (and would make the microsaurs very difficult to score, requiring detailed and hardly testable assumptions about the fate of the intertemporal in their ancestors). We suspect a typographic error on McGowan's part.

Thus, the presence of an intertemporal (unknown in Gerobatrachus) is limited to the outgroups (Whatcheeria and Crassigyrinus) in our matrix, so that its absence serves as an autapomorphy of the ingroup. This is an obvious artefact of the taxon sampling (Vallin and Laurin, 2004; Pawley, 2006; Ruta and Coates, 2007; Anderson, 2007).

Character 18: Lacrimal at least about as large (in area) as the prefrontal (0), much smaller than the prefrontal (1), or absent (2) (ordered).

We have coded 'small' and 'absent' as separate states to increase the amount of signal that can be extracted from the character. McGowan only distinguished "large" $(0)$ and "absent or very small" (1), with state 1 being limited to Gymnophiona, Caudata, and Salientia.

Morphological gaps in this potentially continuous character are readily apparent between morphologically adult specimens. Still, being potentially continuous, it should be ordered (Wiens, 2001).

McGowan (2002: 27) described the branchiosaurids as having a small lacrimal, but scored them as having a large one. The latter is correct at least for Apateon: the lacrimal reaches normal temnospondyl proportions (lacrimal about twice as large as prefrontal) in adults of Apateon gracilis (Schoch and Fröbisch, 2006). The known (immature or neotenic) specimens of Branchiosaurus and Schoenfelderpeton show a condition intermediate between our states 0 and 1 , as do immature Apateon specimens (Boy, 1987; Heyler, 1994); rather than scoring this condition (where the lacrimal is almost as large as the prefrontal) as state 0 and potentially biasing our results against McGowan's, we have scored Branchiosaurus and Schoenfelderpeton as having state 0 or 1 (Wiens et al., 2005).

Eocaecilia has a corner in the orbit where a small lacrimal could have been, although none has been found in any specimen (Jenkins et al., 2007). In Gymnophiona, a small lacrimal that later fuses to the maxillopalatine has been reported in the ontogeny of Gegeneophis (Müller et al., 2005) and Hypogeophis (Müller, 2006), but this bone does not lie in the position where a lacrimal would be expected; after research on caecilians that have separate septomaxillae and prefrontals as adults, Müller now considers it the prefrontal $(\mathrm{H}$. Müller, pers. comm. March $\left.30^{\text {th }}, 2008\right)$. With the condition in Rubri- 
cacaecilia unknown, we have scored Gymnophionomorpha as lacking a lacrimal (state 2).

Plesiomorphically, salamanders possess a small lacrimal (Thorn, 1968; Ivachnenko, 1979; Duellman and Trueb, 1986; Gao and Shubin, 2001). This corresponds to our state 1.

Frogs lack any trace of a lacrimal where determinable (Duellman and Trueb, 1986; Sanchíz, 1998), so we have coded Salientia as 2, even though the condition in Triadobatrachus is unknown (Roček and Rage, 2000; pers. obs. May 30 ${ }^{\text {th }}$, 2008).

In sum, apart from uncertainties, we assign state 1 only to Caudata and Brachydectes (though in the latter the small relative size of the lacrimal could be a result of the short snout and the very large prefrontal) and state 2 to Gymnophionomorpha and Salientia.

Character 19: Scapulocoracoid a single bone (0) or two bones (1) in adults.

McGowan assigned state 1 to Albanerpetontidae, Salientia, and the temnospondyl OTUs (except for Micromelerpeton, which he coded as unknown).

However, we have not been able to find a mention of separate scapulae and coracoids in any temnospondyl in the literature, with the notable exception of Mastodonsaurus (Schoch, 1999). Instead (e.g., Onchiodon: Boy, 1990; Archegosaurus: Witzmann and Schoch, 2006; Sclerocephalus: Meckert, 1993), there is a single ossification center in the dorsal part of the scapular portion, as is apparently the case in microsaurs (Carroll and Gaskill, 1978; Carroll, 1991).

On the other hand, it is not obvious where the phylogenetic signal in this character lies and thus how it should be coded. Separate scapular and coracoid ossifications occur not only in amniotes, diadectomorphs, and Mastodonsaurus, but also in frogs, in the paedomorphic salamanders Amphiuma and Siren (Goodrich, 1930), a "presumably [...] younger individual" of the likely paedomorphic stem-salamander Kokartus (Averianov et al., 2008: 480, fig. 7B), and in the distantly related (Laurin and Reisz, 1999; Vallin and Laurin, 2004; Ruta and Coates, 2007; Anderson, 2007) seymouriamorphs. Even a specimen of Whatcheeria shows state 1; two others have, despite the absence of a suture, a notch in the place where the scapula and the coracoid would be expected to have fused (Lombard and Bolt, 1995). It is thus possible that at least two bones or cartilages are primitively present in limbed vertebrates and may (or may not) fuse during ontogeny, as they observably do in many amniotes (e.g., Vickaryous and Hall, 2006), Mastodonsaurus (Schoch, 1999), and apparently Kokartus (Averianov et al., 2008: fig. 7A). If so, the phylogenetic signal of this character probably lies in the point in ontogeny at which (if ever) the bones or perhaps cartilages fuse. By only scoring the adult condition, we have hopefully extracted part of this phylogenetic signal without having to make assumptions about the ontogeny of the OTUs. (Due to the absence of independent ontogenetic data, we have coded Whatcheeria as polymorphic.)

As mentioned, McGowan coded all three branchiosaurid OTUs as possessing state 1 . However, the endochondral shoulder girdle is to the best of our knowledge entirely unknown in Branchiosaurus and Schoenfelderpeton.

In larval, metamorphosing, and neotenic Apateon, the endochondral shoulder girdle consists only of a part of the dorsal part of the scapular portion (Boy and Sues, 2000); however, the coracoid portion is ossified in the most adult known specimen of Apateon gracilis (Werneburg, 1991; Schoch and Fröbisch, 2006) and is continuous with the scapular portion (illustrated by Werneburg, 1991; confirmed by Schoch, pers. comm. October $\left.5^{\text {th }}, 2007\right)$; thus, we have assigned state 0 to Apateon.

"Only in the largest specimens of Microbrachis is there any ossification of the primary shoulder girdle. At most there is only a small triangular bone, apparently restricted to the area of the scapular blade adjacent to the glenoid." (Carroll and Gaskill, 1978: 174; see also fig. 119) We regard this condition as related to the paedomorphosis of this perennibranchiate microsaur and therefore (Wiens et al., 2005) score it as unknown.

"The suture between the scapula and [the] coracoid is preserved as a faint lineation that passes from the incisure across the glenoid" in Eocaecilia (Jenkins et al., 2007: 343). Shoulder girdles are not known elsewhere in Gymnophionomorpha. Therefore we have changed the score of Gymnophionomorpha to state 1 .

We have not been able to find any mention of the endochondral shoulder girdle of any of the amphibamid OTUs in the literature, except for a short statement in Carroll (1964), which implies that there was a single bone in Platyrhinops, and Bolt's (1969: 890) mention of the existence of a "scapulocoracoid" in Doleserpeton, which we take to mean that a single bone is present. Accordingly, we have scored Platyrhinops and Doleserpeton as 0 and Amphibamus and 'Tersomius' as unknown. It is not evident to us why McGowan assigned state 1 to all of them; we suspect a typographic error.

We interpret Boy's (1995: 444; translated by D.M.) remark that '[t]he scapulocoracoid is almost completely ossified' in the most metamorphic specimens of Micromelerpeton as state 0 ; McGowan had scored it as unknown.

This leaves state 1 to Albanerpetontidae, Gymnophionomorpha, Salientia, and part of the polymorphic Whatcheeria.

Character 20: Ratio of width of cultriform process of parasphenoid to length of skull base (see state definitions in Appendix-Table 3) (ordered).

McGowan did not quantify this character or explain how he divided this continuous character into states, only distinguishing "slender cultriform process" $(0)$ and "wide anteriorly projecting parasphenoid" (1) and noting that state 0 occurred in "temnospondyls" (McGowan, 2002: 27); state 1 united Gymnophiona, Caudata and Salientia in his matrix. We have measured (Appendix-Table 3, Appendix-Fig. 1) the length of the skull base as the rostrocaudal distance between the rostral margin of the basipterygoid processes and the caudal margin of the skull in the sagittal plane in ventral view, and the width of the cultriform process rostral to the bulk of the constriction (or anywhere along the length, if a constriction is absent). To divide this continuous character into discrete states, we have used stepmatrix gap-weighting (Wiens, 2001): each observed value is a separate state, the weight of each transition is directly proportional to the difference between the values that the states represent, and the character is ordered. As the factor that converts the mentioned differences into the weights of the transitions, we 


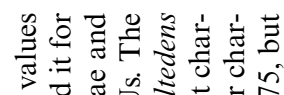

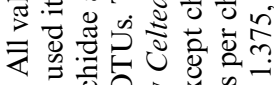

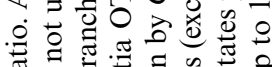

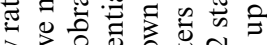

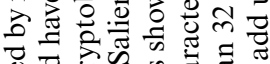

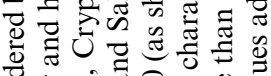

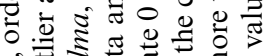

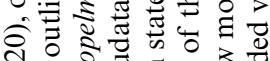

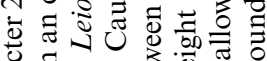

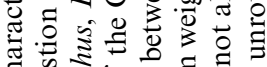
ट्ट

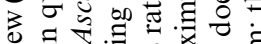

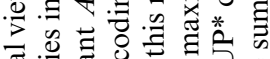

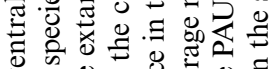

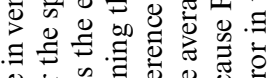

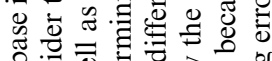

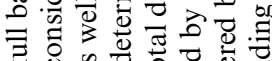
至

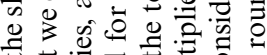

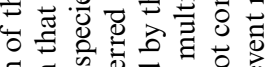

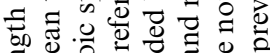
छ

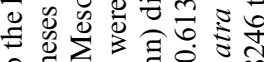
을 등

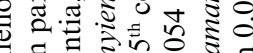

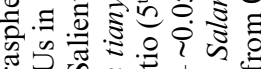

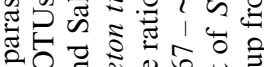

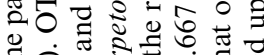

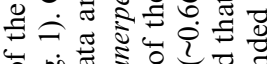
क.

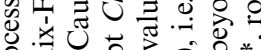

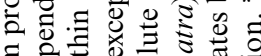

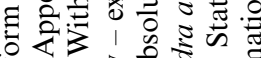

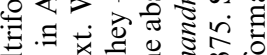

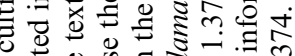
을

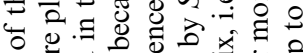

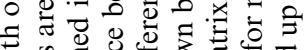

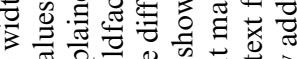

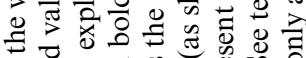

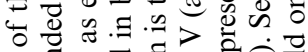

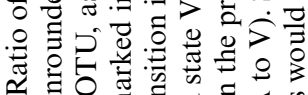

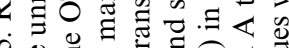

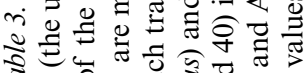
₹ 0 .

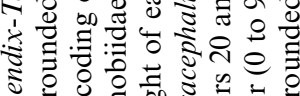

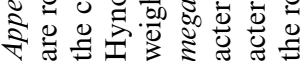

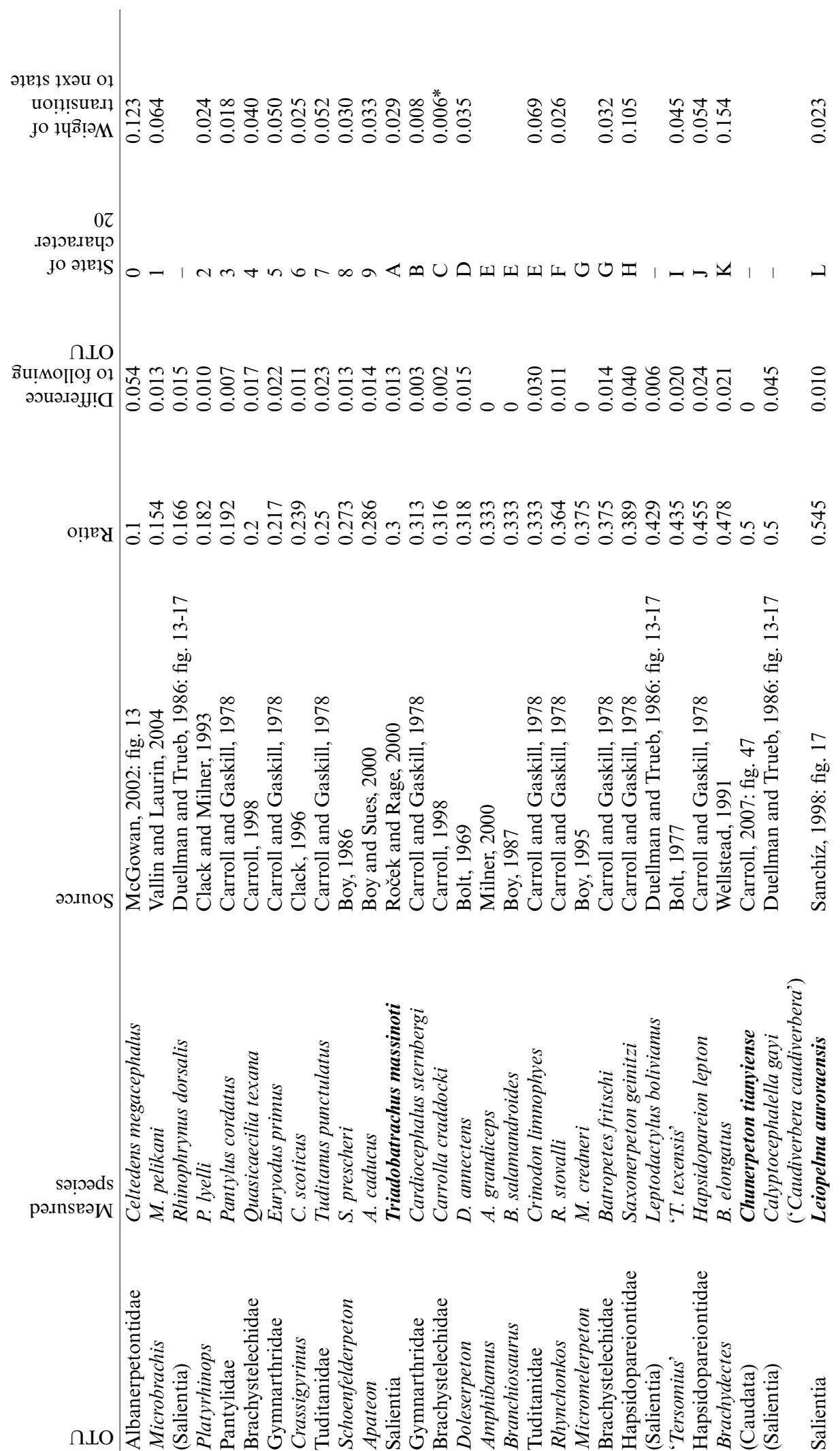




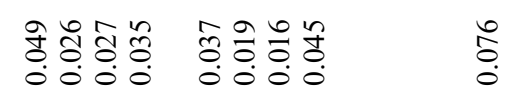

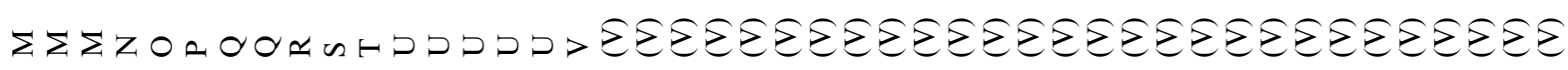

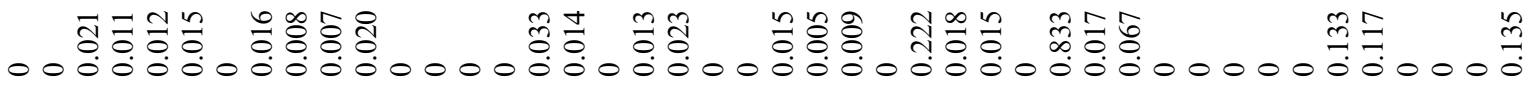

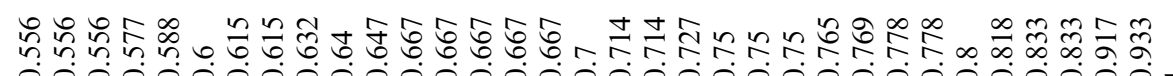

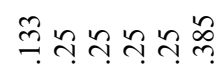

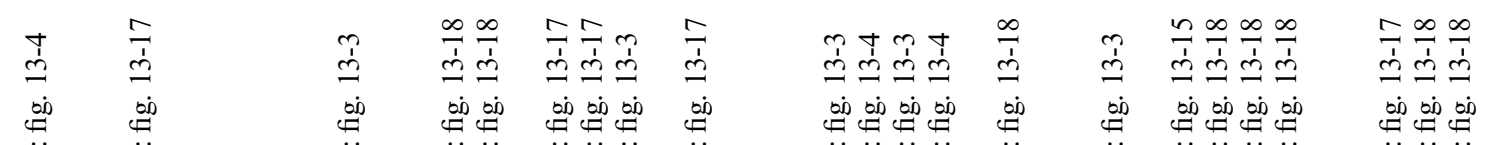

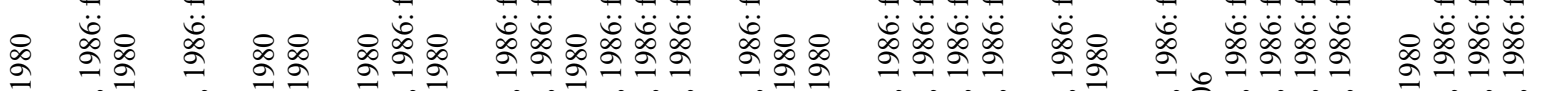

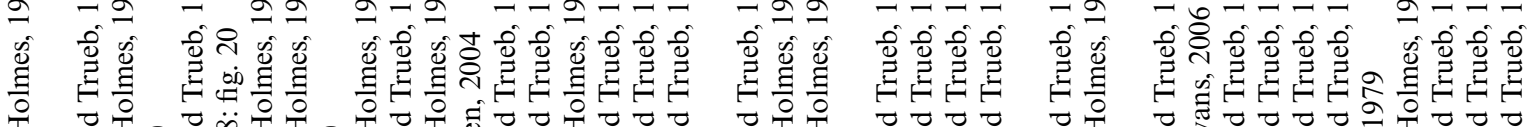

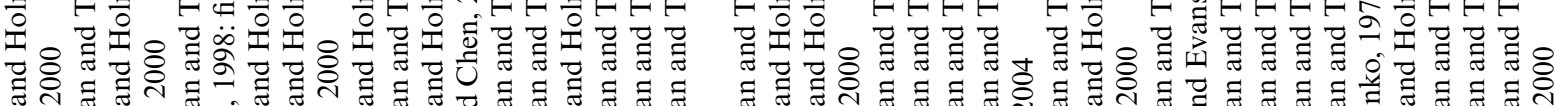

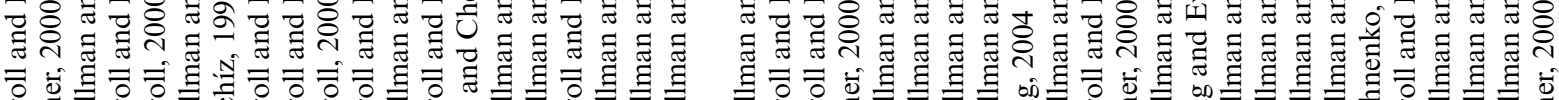

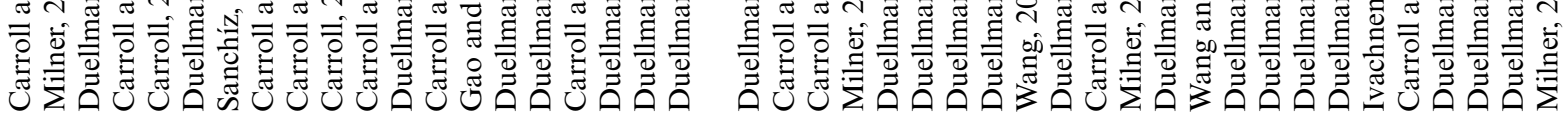
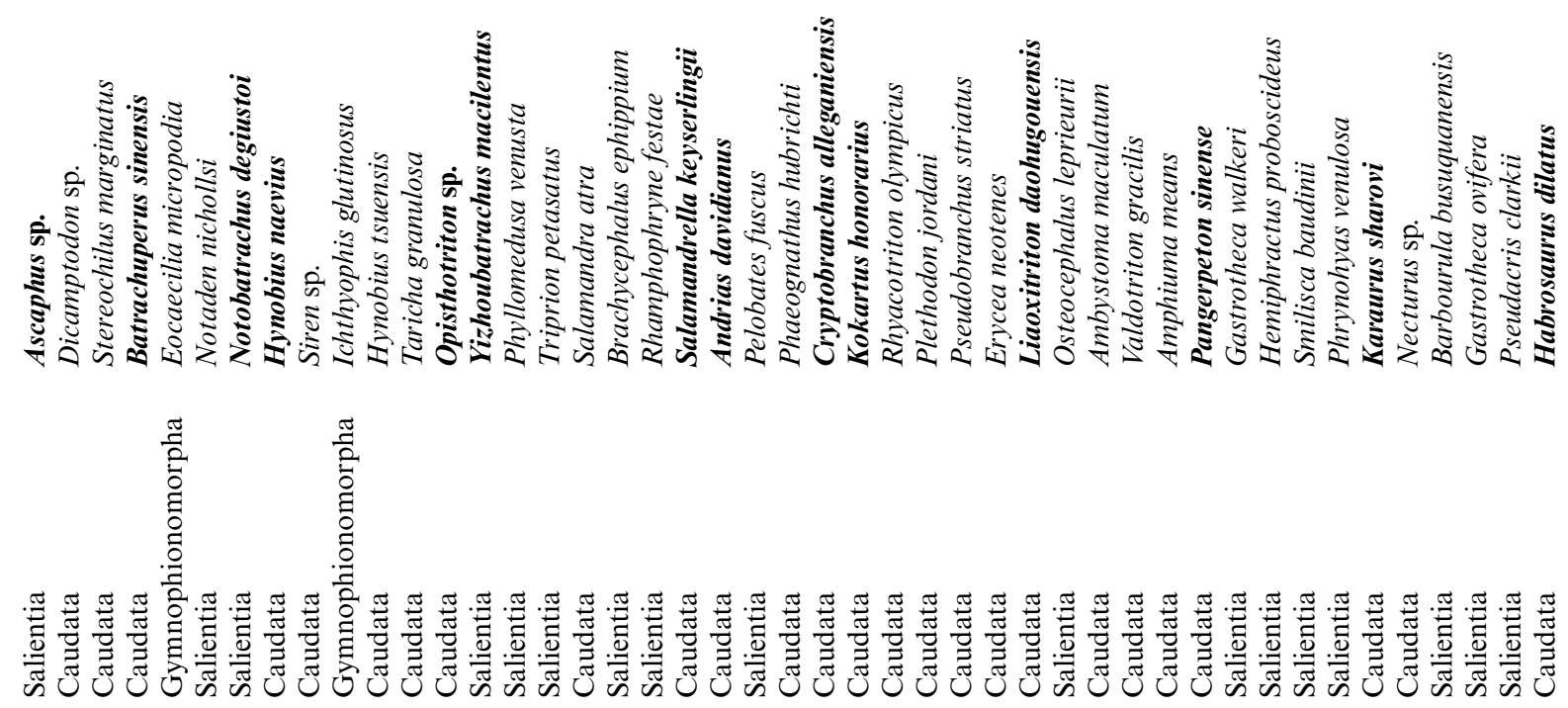
have not chosen 1 as suggested by Wiens (2001), but 1.375, which is the average maximum possible weight of each character in the present matrix (i.e. their number of states minus one) if we disregard characters 20 and 40 . These weights are used to construct a symmetric stepmatrix (see supplementary information) that produces an ordered character the states of which are not equidistant.

PAUP* can only deal with multistate characters up to 32 states. Because of polymorphism, we found more than 32 states in the terminal taxa. We have recognized 32 states, starting from the lowest values. The states which could not be recognized by PAUP* all represent variation within OTUs (Salientia and Caudata) whose plausible ancestral morphotype is encompassed in our 32 states, so this should not be a problem.

By using "cultriform process" vs. "parasphenoid" in the names of his character states, McGowan implied using the distinctness of the cultriform process as a criterion for character delimitation. However, whether the cultriform process is distinct from the basal plate of the parasphenoid depends less on the breadth of the cultriform process than on the presence of lateral processes on the parasphenoid that cover the basipterygoid processes of the basisphenoid, as shown by the very similar values for Siren and Hynobius (0.61-0.65, measured in the illustrations by Carroll and Holmes, 1980) where the cultriform process is unambiguously distinct from the basal plate in Hynobius but continuous with it in Siren, as well as by the value of 1 found in Pangerpeton (Wang and Evans, 2006) in which the cultriform process is very distinct, so we have not used this additional criterion.

The following codings are not immediately obvious from Table 3 and deserve comment:

Tuditanidae is polymorphic, with Tuditanus possessing state 7 and Crinodon showing state E.

Hapsidopareiontidae is polymorphic, with Saxonerpeton showing state $\mathrm{H}$ and Hapsidopareion possessing state $\mathrm{J}$.

Brachystelechidae is likewise polymorphic, with Quasicaecilia having state 4, Carrolla state C and Batropetes state G.

So is Gymnarthridae, with state 5 in Euryodus primus and state B in Cardiocephalus sternbergi.

Eocaecilia shows state $\mathrm{O}$, and the gymnophionan Ichthyophis shows state $\mathrm{S}$, making Gymnophionomorpha polymorphic.

The only measured caudate with a state lower than $\mathrm{M}$ is Chunerpeton (between states $\mathrm{K}$ and $\mathrm{L}$ ). Because it is thought to be nested several nodes within the crown-group (as a cryptobranchid), and because the measured karaurids (Karaurus and Kokartus) as well as the extant cryptobranchids (Andrias

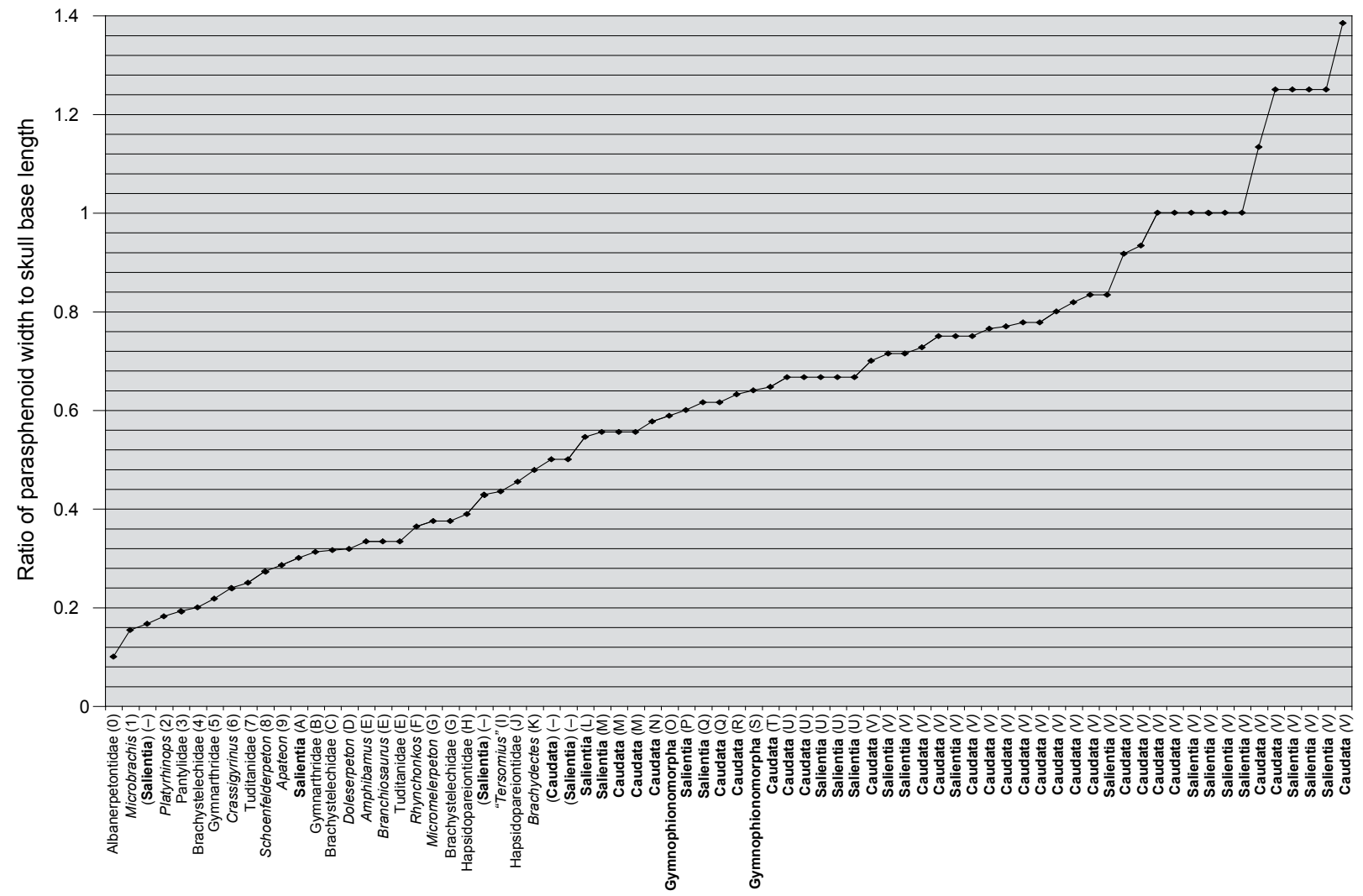

Appendix-Fig. 1. Ratio of cultriform process width to skull base length in dorsal view (character 20). The line drawn between the data points is meant to visualize the sizes of the morphological gaps by its varying steepness. The state of each OTU is indicated after its name. Extant taxa in bold. Data shown in Appendix-Table 3. 
and Cryptobranchus) have very high ratios, we regard the condition in Chunerpeton as autapomorphic and have scored Caudata as possessing states $\mathrm{M}, \mathrm{N}, \mathrm{Q}, \mathrm{R}, \mathrm{T}, \mathrm{U}$, and V.

Triadobatrachus has a very narrow cultriform process (state A) (Roček and Rage, 2000: fig. 3). Otherwise, Salientia shows states $\mathrm{L}$ and higher, with the lone and clearly derived exceptions of Rhinophrynus (between 1 and 2), Leptodactylus (between $\mathrm{H}$ and I), and Calyptocephalella ('Caudiverbera') (between K and L) (Appendix-Table 3; Appendix-Fig. 1). We have therefore scored Salientia as possessing states A, L, M, P, Q, U and V.

\section{Character 21: Pubis ossified (0) or not (1).}

The pubis does not ossify in Crassigyrinus, branchiosaurids, caudates, and salientians (with the exception of Pipidae: Goodrich, 1930; Cannatella and Trueb, 1988); the situation is unknown in Eocaecilia (Jenkins et al., 2007) and inapplicable in Gymnophioniformes (except possibly Rubricacaecilia, in which the presence of limbs and limb girdles is unknown).

Because we have not been able to find descriptions or illustrations of the pubes of Amphibamus and Platyrhinops, nor statements on whether they are known at all, we have scored both OTUs as unknown.

McGowan scored 'Tersomius' as having an ossified pubis, but the referral of any pelvis to Tersomius is too uncertain (Huttenlocker et al., 2007), so we have coded 'Tersomius' as unknown.

On the other hand, McGowan scored Micromelerpeton as unknown, but the recently discovered largest and most mature specimens have an ossified pubis (Lillich and Schoch, 2007), so we have assigned it state 0 .

Contradictory statements exist in the literature about Brachydectes. Wellstead (1991) states on p. 25 that "[t]he ilium, ischium, and pubis form a simple, triangular plate with a modest iliac blade at the apex, but do not co-ossify", yet explains that, of all lysorophians, remains of the pelvic girdle are only known from one specimen each of $B$. newberryi (both ilia and ischia: p. 33, fig. 8C) and B. elongatus (the left ilium: p. 45, fig. 20C). Schoch and Milner (2004: 360) cite Wellstead (1998) for stating that Brachydectes lacks an ossified pubis, but we have not been able to find such a claim in Wellstead (1998) who simply repeats (on p. 142) the sentence cited above verbatim. Because of the disarticulated condition of the B. newberryi specimen that preserves the ilia and ischia, we have scored the pubis of Brachydectes as unknown.

In the only known specimen of Gerobatrachus, the pubes are missing; given the good preservation of the articulated ischia and the caudalmost presacral vertebrae, this suggests a lack of ossification. We have accordingly scored Gerobatrachus as possessing state 1 for the analysis where we treat it as adult, but as unknown for the analysis where we treat it as immature or paedomorphic.

\section{Character 22: Opercular absent (0) or present (1).}

This refers to the ear ossicle found in most extant salamanders and frogs (os operculare auris), not to the largest bone in the gill lid of more plesiomorphic bony vertebrates (os operculare), which is not homologous to any ear ossicle. In McGowan's matrix, presence of the opercular (state 1) is a synapomorphy of Caudata and Salientia, with the situation unknown in Albanerpetontidae.

Usually the opercular is thought to be restricted to salamanders and frogs (and now Eocaecilia; Jenkins et al., 2007). However, in the explanation of the present character, McGowan (2002: 27) notes: "It is not known whether the accessory ossicle (AO) seen in some microsaurs e.g., gymnarthrids, ostodolep[id]ids and Rhynchonkos) is homologous or analogous with the opercular (Carroll [...], 1998). Therefore, it is treated as unknown in those microsaurs that are known to possess an AO." However, Carroll and Gaskill (1978: all quotes 163-164) show that the matter is more complicated:

"Except in Pantylus, the otic capsule is open ventrally [in microsaurs], posterior or medial to the footplate of the stapes. In Pantylus, this area is filled in with a small but distinct ossification not known in other early tetrapods. An ossification in this position brings to mind the opercular bone in salamanders [...]. It appears much too fully integrated with the skull, in this genus at least, to function as a movable ear ossicle."

"In Goniorhynchus [= Rhynchonkos], gymnarthrids, and ostodolep[id]ids, a further ear ossicle [= other than the stapes] has been consistently observed. It is referred to simply as an accessory ossicle. Typically, it is a small, vertically oriented plate of bone, suspended above the stem of the stapes. It must have been fairly strongly set in connective tissue to have survived the decomposition of the skulls without significant displacement. It may be significant that it occurs in all the tuditanomorph microsaurs in which the occiput is behind the level of the quadrate, and in no other forms."

"Without implying any significant relationship, the closest analogy with the ear structure of microsaurs may be provided by the modern salamanders. [...] Although there is no supporting evidence from physiological experimentation, it is assumed that two methods of sound conduction are practiced by urodeles: from the jaws via the stapes in aquatic forms; and through the forelimbs and shoulder girdle via the 'opercularis' muscles and the operculum in terrestrial forms [...]. There is, of course, no possibility of verifying the presence of any opercularis muscle in microsaurs, but the possibility of there being more than a single sound-conducting system is suggested by the configuration of the stapes and its relation to surrounding structures."

"Ostodolep[id]ids, gymnarthrids, and goniorhynchids [= rhynchonkids $=$ Rhynchonkos $]$ all have an unossified area adjacent to the footplate of the stapes that might be attributed to the presence of a salamanderlike operculum. In Pantylus there is, however, a separate but quite immovable ossification in this area. There is also the possibility that the accessory ossicle acted in some way like an operculum, to detect airborne vibrations, while the massive stapes transmitted groundborne, low[-] frequency oscillations." (This would, however, be unlike terrestrial frogs, where - whenever both are present - the operculum detects low-frequency vibrations, whether air- or groundborne, and the stapes high-frequency airborne ones; unlike terrestrial salamanders, where the operculum is the only bone that functions in hearing and again detects low-frequency vibrations; and unlike aquatic frogs and salamanders, in which the operculum is absent and the stapes transmits water-borne oscillations; see below and Lombard and Bolt, 1979.)

However, Jenkins et al. (2007: 359) add: "The accessory ear 
ossicle described by Carroll and Gaskill (1978: 163, fig. 113) in Rhynchonkos and other microsaurs is consistently suspended above the stem of the stapes; in shape and position this ossicle appears to differ from the operculum of Eocaecilia, which [like in batrachians] is oval and, in one specimen at least, is preserved in close association with the fenestra ovalis."

In sum, the opercular of frogs and salamanders, the "accessory ossicle' of gymnarthrids and Rhynchonkos, and possibly the unique bone of Pantylus might be analogous in function, but while primary homology to the opercular cannot be ruled out for the extra ossicle of Pantylus, it is ruled out between lissamphibians on one hand, and gymnarthrids and Rhynchonkos on the other, by Jenkins et al. (2007). Because no additional research seems to have been done on this question, we have changed the scores of Gymnarthridae and Rhynchonkos to state 0, but that of Pantylidae to unknown.

Furthermore (Lombard and Bolt, 1979: 46), "[t]he otic opercular bone fails to develop in those frogs and salamanders which are totally aquatic in adult life", and in amphibious and terrestrial salamanders it develops only at metamorphosis. The reason seems to be that the opercular system can pick up groundborne and low-frequency airborne vibrations, but not waterborne ones. Therefore we have scored all OTUs that are only known from unambiguously obligatorily aquatic individuals - Whatcheeria, Crassigyrinus, Micromelerpeton, Branchiosaurus, Schoenfelderpeton, Microbrachis, and Brachydectes - as inapplicable (i.e. unknown). We have also scored Apateon as unknown (rather than absent) because most of its braincase apparently does not ossify even after metamorphosis.

The condition in Gymnophiona should be interpreted as inapplicable rather than absent, because the opercular system not only includes the bone, but also the opercular muscle, which connects the bone to the shoulder girdle; no trace of a shoulder girdle is present in extant caecilians, which means that the opercular system cannot be present (Milner, 1988; Jenkins et al., 2007). Because both the braincase and the presence or absence of the shoulder girdle are unknown in Rubricacaecilia, we have had to rely entirely on Eocaecilia to code Gymnophionomorpha; in Eocaecilia, as mentioned above, the opercular is present (Jenkins et al., 2007). We have accordingly changed the score of Gymnophionomorpha to state 1.

In sum, state 0 unites the amphibamids, Brachystelechidae, Hapsidopareiontidae, Tuditanidae, Gymnarthridae and Rhynchonkos in our matrix, while state 1 is found in Gymnophionomorpha, Caudata and Salientia. All other OTUs are scored as unknown (or inapplicable).

Character 23: Postorbital present (0) or absent (1).

State 1 occurs in Albanerpetontidae, Caudata, and Salientia.

Jenkins et al. (2007) reconstruct a postfrontal, but no postorbital, for Eocaecilia. Within Gymnophiona, a 'circumorbital bone' that may be homologous with the postfrontal or possibly the postorbital is present in Ichthyophis and Uraeotyphlus (Duellman and Trueb, 1986; Carroll, 2000; Wake, 2003); rhinatrematid ontogeny is poorly known (in adult rhinatrematids the orbit is entirely surrounded by the maxillopalatine, which may or may not include the fused pre- and postfrontal). Following Jenkins et al. (2007), we have scored the postorbital as absent in Gymnophionomorpha (contra McGowan) and retained McGowan's scoring of the postfrontal (character 24) as present.
See above for our scoring of Brachydectes as possessing a postorbital (and not possessing a postfrontal).

Character 25: Jugal present (0) or absent (1).

Salientia and Caudata lack jugals, as does Brachydectes.

A jugal is present in Eocaecilia (Jenkins and Walsh, 1993; Jenkins et al., 2007), which is probably why McGowan scored Gymnophionomorpha as possessing a jugal. A jugal is, however, apparently absent throughout gymnophionan ontogeny (Wake, 2003; Müller et al., 2005; Müller, 2006), so we have scored Gymnophionomorpha as polymorphic.

It has not escaped our attention that the 'squamosal' of Gymnophiona occupies the same area as the squamosal and the jugal of Eocaecilia throughout gymnophionan ontogeny (compare Wake, 2003; Müller, 2006; Jenkins et al., 2007). As far as we can tell, interpretation of this bone as either the squamosal or the jugal is more or less equally parsimonious, with both interpretations leading to similar numbers of problems, so possibly Gymnophionomorpha should rather be scored as always possessing a jugal. However, given this ambiguity and the fact that in Gegeneophis this bone appears in a decidedly dorsal position (Müller et al., 2005: fig. 2a), we have opted to stay conservative. Fossil evidence could be very helpful, but has not been discovered so far - the skull of $R u$ bricacaecilia is unknown (with the probable exception of the palatine).

Character 26: Hyobranchial skeleton not ossified (0) or ossified (1) in adults.

Absence of hyobranchial bones is difficult to distinguish from post-mortem disarticulation in all but the best-preserved articulated specimens, and ontogenetic variation is also widespread at least in temnospondyls and salamanders; surprisingly, this variation can go in both directions, with ossified hyobranchial elements being present in larvae and disappearing during metamorphosis in some taxa, changing shape but staying present in the adults of others, and absent in larvae and ossifying during metamorphosis in yet others (Wake, 1989; Schoch, 2001; Witzmann and Schoch, 2006). McGowan assigned state 0 to the amphibamids, Salientia, Caudata, Gymnophiona, and the all-zero ancestor, while the branchiosaurids, Micromelerpeton, Pantylidae, and Hapsidopareiontidae shared state 1 in his matrix.

Due to the lack of known adults for Branchiosaurus and Schoenfelderpeton, we have scored both as unknown.

Hyobranchial elements are not preserved in the metamorphic specimens of Apateon gracilis (Schoch and Fröbisch, 2006: 1470), but post-mortem disarticulation cannot be ruled out, so we have scored Apateon as unknown.

McGowan states that hyobranchial bones are present in the albanerpetontid Celtedens megacephalus and illustrates them (McGowan, 2002: fig. 13), but scores them as unknown in albanerpetontids; we go with the text and figure rather than the matrix.

None of the many articulated specimens of Microbrachis preserves a hyobranchus (Carroll and Gaskill, 1978; Vallin and Laurin, 2004). However, the paedomorphic condition of all known specimens makes this unreliable. Therefore (Wiens et al., 2005) we have kept McGowan's scoring of Microbrachis as unknown.

McGowan scored Caudata as possessing state 0 . Howev- 
er, the hyobranchial skeleton is partly ossified in cryptobranchoids, sirenids, and Karaurus (Ivachnenko, 1979), making it plausible that this is the plesiomorphic state for Caudata unless paedomorphosis (in cryptobranchoids and sirenids) and the presumed juvenile age of the only known Karaurus specimen (Ivachnenko, 1979) explain this ossification. Accordingly, we have scored Caudata as unknown.

The hyobranchial skeleton disappears in Amphibamus during metamorphosis (Schoch, 2001), so we have kept McGowan's score (state 0 ).

Character 27: Acrodont or subthecodont (0) or pleurodont (1) tooth implantation.

McGowan coded all lissamphibians and branchiosaurids as pleurodont (and did not mention subthecodont implantation, lumping it with acrodonty, which probably does not occur in this data matrix at all).

The distinction between the states of this character is often a matter of degree; for example, some microsaurs like Microbrachis apparently have somewhat pleurodont lower jaws (Carroll and Gaskill, 1978), as occurs in some temnospondyls outside the present data matrix, where the labial wall of the dentary is slightly higher than the lingual wall, and the teeth are attached to it as well as to the alveolar floor (D. M., pers. obs. of a not yet catalogued specimen likely belonging to Metoposaurus diagnosticus krasiejowensis, July 2007). We have kept McGowan's coding of 0 for such intermediate cases.

However, Carrolla is "possibly pleurodont" (Langston and Olson, 1986: 11; see also fig. 4). Because teeth and tooth-bearing bones are entirely unknown in Quasicaecilia, and because the tooth attachment of Batropetes has never been commented upon and cannot be determined from the available figures, we have scored Brachystelechidae as unknown.

Character 28: Ectopterygoid contacting maxilla (0) or separated from maxilla by rostral expansion of subtemporal fenestra (1).

McGowan scored this character as unknown only in Albanerpetontidae and Brachystelechidae, even though it is inapplicable in the absence of an ectopterygoid (character 8). State 1 appears in his matrix for the branchiosaurids and Pantylidae.

However, like the albanerpetontids, salamanders and frogs, Pantylus and Stegotretus lack a separate ectopterygoid (e.g., Carroll and Gaskill, 1978; Berman et al., 1988), so we have scored Pantylidae as unknown (inapplicable).

Carrolla has state 0; we have generalized this to Brachystelechidae because the condition in Batropetes and Quasicaecilia is unknown.

Whenever a distinct ectopterygoid is present in gymnophionans (see character 8 ), it contacts the maxillary portion of the maxillopalatine, so we have retained McGowan's score of Gymnophiona as showing state 0 .

Salamanders and frogs (like Brachydectes) lack an ectopterygoid, so we have scored them as unknown (inapplicable) rather than as sharing the branchiosaurid condition.

Character 29: Prefrontal-postfrontal suture (0); frontal participates in margin of orbit (1).

Unlike McGowan, we have scored this character as inapplicable (i.e. unknown) when the postfrontal is absent (in Al- banerpetontidae, Caudata, Salientia, and Brachydectes - see above). McGowan had assigned state 1 to these taxa as well as to 'Tersomius', Doleserpeton, Micromelerpeton, Brachystelechidae, Hapsidopareiontidae, and the branchiosaurids.

However, Branchiosaurus shows state 0 (Milner, 1986; Werneburg, 1987; Heyler, 1994).

Apateon is polymorphic: independently of ontogenetic stage, A. caducus, A. pedestris, A. flagrifer (Werneburg, 1986, 1988b), A. kontheri (Werneburg, 1988a), and A. gracilis (Schoch and Fröbisch, 2006) show state 1, while A. intermedius and A. dracyi possess state 0 (Werneburg, 1988c, 1996, 2001).

The only gymnophionomorph where this character is unambiguously applicable is Eocaecilia, which has state 0 . In those gymnophionans in which a 'circumorbital' is present, its contact with the prefrontal is variable - sometimes the squamosal and the maxillopalatine share a suture instead, because the orbit is so small (Carroll, 2000: fig. 2E, right side) - but the frontal (and even the prefrontal) never participates in the orbit margin; instead, the entire dorsal margin of the orbit is formed by the 'circumorbital' which we here interpret as the postfrontal (see above). This condition could either be scored as state 0 or as inapplicable, neither of which contradicts McGowan's scoring of Gymnophionomorpha as having only state 0 . We have therefore retained this score.

Character 30: Intervomerine fenestra absent (0) or present (1). This feature is often called the 'intervomerine pit' despite lacking a bony 'floor'. McGowan scored it as present in Caudata, Salientia, 'Tersomius', and Micromelerpeton, and as unknown in Hapsidopareiontidae, Microbrachis, Brachystelechidae, and Rhynchonkos.

Microbrachis, however, possesses state 0 (Vallin and Laurin, 2004)

\section{Character 31: More (0) or less (1) than 60 teeth per upper jaw} ramus.

Among the taxa in the present matrix, only Platyrhinops is known to possess state 0 , so the character is parsimony-uninformative. It was not uninformative in the original, where McGowan had also given state 0 to the all-zero ancestor because "e.g. early temnospondyls" share it (McGowan, 2002: 28).

McGowan scored the branchiosaurids as unknown, and indeed most illustrations of branchiosaurid skulls ignore the usually badly crushed marginal toothrows, but Branchiosaurus salamandroides (Werneburg, 1987), Apateon spp. (Boy, 1972, 1978; Werneburg, 1986, 1988a, b, c, 2001), and Schoenfelderpeton (Boy, 1986) are all known to have state 1.

Character 32: Frontals no more than 50\% longer than broad (0) or at least $50 \%$ longer than broad (1).

McGowan did not quantify this character ("wide paired frontals" (0), "narrow paired frontals" (1); McGowan, 2002: 28). He assigned state 1 to Doleserpeton and Micromelerpeton and state 0 to all other OTUs.

There is a large morphological gap between the states in most OTUs; the frontal of taxa displaying state 0 is about as long as broad, whereas it is usually at least twice as long as broad in state 1 . In the present matrix only adult specimens of Platyrhinops and some brachystelechids, some 
gymnophionans, and some caudates are known to have state 0 , as detailed below; therefore the character is parsimony-uninformative. We also do not understand why McGowan made explicit that in both states the frontals are "paired" - the frontals are fused in albanerpetontids and some salientians, yet McGowan neither distinguished this condition as a separate state nor scored the mentioned taxa as inapplicable/unknown.

Branchiosaurus has state 1 (Werneburg, 1987; Boy, 1987).

In Apateon gracilis the frontals are very long and narrow and grow in length throughout its ontogeny (Werneburg, 1988c, 1991; Schoch and Fröbisch, 2006). The same holds for A. flagrifer (the youngest specimens approach state 0: Werneburg, 1986, 1988b; Boy, 1987). This is also seen in $A$. intermedius (Werneburg, 1996), A. dracyi (where the youngest specimens approach state 0; Boy, 1986, 1987; Werneburg, 1988c, 2001), A. pedestris (Boy, 1978, 1986, 1987; the youngest specimens approach state 0: Heyler, 1994), $A$. kontheri (Werneburg, 1988a), A. caducus (Boy, 1978, 1987; Schoch, 2002; Schoch and Fröbisch, 2006), and A. pusillus (Boy, 1987). Interestingly, the ontogeny of Platyrhinops runs in the other direction (Schoch, 2002).

Schoenfelderpeton has state 1 (Boy, 1986, 1987).

Albanerpetontidae has state 1 (Albanerpeton: Fox and Naylor, 1982; Celtedens: McGowan, 2002).

We have scored Tuditanidae as state 1, though this is only unambiguous in Crinodon and Boii (Carroll and Gaskill, 1978: Figs 10, 11, 12)

Hapsidopareiontidae is scored 1, primarily after Llistrofus (Carroll and Gaskill, 1978: figs 15, 16).

Pantylidae shares state 1 (Carroll and Gaskill, 1978: fig. 25; Berman et al., 1988: figs 9A, 10B).

Rhynchonkos, too, has state 1 , though only marginally so in the apparently less crushed specimen (Carroll and Gaskill 1978: fig. 63).

Microbrachis has state 1 (not quite clear in the reconstruction by Vallin and Laurin [2004], but unambiguous in the specimen drawings by Carroll and Gaskill [1978: figs 74, 75, 77A, 78A]).

Batropetes, too, possesses state 1 (Carroll and Gaskill, 1978), but Carrolla and Quasicaecilia are closer to 0 (Carroll, 1998). Although the conditions of Carrolla and Quasicaecilia could be related to their short snouts and the possibly juvenile condition of the specimens (especially in Quasicaecilia), we score Brachystelechidae as polymorphic.

Eocaecilia seems to possess state 1 (although this is not straightforward to measure due to the unique shape of the frontal; Jenkins et al., 2007), but all or almost all gymnophionans figured by Duellman and Trueb (1986) have 0, as do some of those figured by Carroll (2000). We have thus scored Gymnophionomorpha as polymorphic.

According to the literature, the frontals are fused to the parietals in all salientians. In the skull roof of Triadobatrachus, where the strong sculpture and the fact that the only known specimen is a natural mold make it extremely difficult, if not impossible, to distinguish sutures from cracks or even from meaningless patterns in the sculpture - in our opinion, even the presence, let alone the position, of the pineal foramen proposed by Roček and Rage (2000) cannot be ascertained (pers. obs. May $\left.30^{\text {th }}, 2008\right)$ - one of the pos- sible frontal-parietal sutures would put Triadobatrachus at the boundary between state 0 and state 1 . In short, we have scored Salientia as unknown.

With the exception of Jeholotriton (Wang and Rose, 2005), urodeles and possible urodeles show state 1 (extant: Duellman and Trueb, 1986; Sinerpeton: Gao and Shubin, 2001; Valdotriton: Evans and Milner, 1996; apparently also Iridotriton: Evans et al., 2005), but its sister-group, the Karauridae, possesses state 0 (Karaurus and Kokartus: Milner, 2000). Accordingly we have scored Caudata as polymorphic.

'Tersomius texensis' (Carroll, 2000) shows state 1, as incidentally does Eimerisaurus (Boy, 1980, 2002), so we have scored 'Tersomius' accordingly.

Character 33: Contact between maxilla and jugal and/or quadratojugal present (0) or absent (1).

In McGowan's matrix, state 1 unites Apateon, Schoenfelderpeton, and Caudata.

Because Apateon gracilis has state 0 from metamorphosis onwards (Schoch and Fröbisch, 2006), and even without metamorphosis such a contact is established in late larval stages of $A$. pedestris and A. caducus (see character 8; Schoch, 1992), we score Apateon as 0 and Schoenfelderpeton as unknown (Wiens et al., 2005).

This restricts state 1 to Caudata and Brachydectes, so that, when Brachydectes is excluded from the analysis, the character becomes parsimony-uninformative.

Character 34: Pterygoid-vomer suture excluding palatine from interpterygoid vacuity (0); palatine participates in margin of interpterygoid vacuity (1); palatine absent (2) (unordered).

McGowan assigned state 0 to all microsaurs (except Brachystelechidae, scored as unknown) and the all-zero ancestor, and state 1 to all other OTUs (except Albanerpetontidae, scored as unknown).

Carrolla and Batropetes have state 0 (Carroll, 1998), however, so we have scored Brachystelechidae as 0.

Brachydectes lacks interpterygoid vacuities (the parasphenoid and the pterygoids are in contact throughout), but because the pterygoids are sutured to the vomers, so that the palatines do not contact the parasphenoid, we have assigned state 0 to Brachydectes.

Of all caudates only sirenids have a (separate) palatine as adults. The lack of a palatine is a third state (state 2). The sirenids are not the sister-group of the rest of Caudata, therefore their condition is most parsimoniously interpreted as a reversal (perhaps related to their paedomorphosis); we have accordingly assigned state 2 to the Caudata OTU.

Character 35: Vomerine fangs present (0) or absent (1) in adults.

See character 7 for more information. McGowan deemed vomerine fangs present only in the amphibamids, Micromelerpeton, and the all-zero ancestor, scoring Albanerpetontidae as unknown; he also did not mention ontogeny.

Following Carroll and Gaskill (1978), we judge Crinodon to possess vomerine fangs. Because the vomer is unknown in Asaphestera, Tuditanus, and Boii (Carroll and Gaskill, 1978), we score Tuditanidae as showing state 0. 
Brachystelechidae is scored as lacking vomerine fangs because Carrolla, the only scoreable brachystelechid, has "[p]robably no palatal dentition" (Carroll, 1998: 63).

Doleserpeton is famous for lacking vomerine fangs and possessing a tooth row instead (Bolt, 1969, 1977). We suspect that McGowan's scoring of Doleserpeton as possessing vomerine fangs is a typographic error and have assigned it state 1. However, the condition seen in Doleserpeton is also found in juveniles of Amphibamus but not in the single adult specimen (Daly, 1994), so we have scored this character as unknown in Doleserpeton in the analysis where we treat the described material of Doleserpeton as immature.

Character 36: Teeth on cultriform process of parasphenoid present (0) or absent (1) in adults.

McGowan scored the branchiosaurids, Albanerpetontidae, Caudata, Salientia, 'Tersomius', and Doleserpeton as possessing state 1, and Pantylidae as unknown; he also did not mention ontogeny.

The pantylid Stegotretus has teeth on the cultriform process (Berman et al., 1988), so we have assigned state 0 to Pantylidae.

Cardiocephalus lacks parasphenoid teeth (Carroll and Gaskill, 1978: 56), while Euryodus has teeth on the cultriform process and elsewhere on the parasphenoid (Carroll and Gaskill, 1978: fig. 38B, p. 64, figs 42 and 43, and p. 69). In the other gymnarthrids the parasphenoid is unknown. Accordingly, we have scored Gymnarthridae as polymorphic.

Carrolla, as mentioned above, lacks a palatal dentition altogether, while Batropetes has "a few small denticles at the base of the cultriform process of the parasphenoid" (Carroll, 1991). Carroll (1990) never mentions the presence or absence of any palatal dentition in Quasicaecilia. Thus, we have scored Brachystelechidae as polymorphic.

We have also scored Gymnophionomorpha as polymorphic because Eocaecilia is unique among known caecilians in retaining denticles on the cultriform process (Carroll, 2000; Jenkins et al., 2007).

Platyrhinops (Schoch, 2002) and Amphibamus (Daly, 1994, Schoch, 2001) lack denticles on the cultriform process (state 1) after metamorphosis, so we have scored both accordingly (Wiens et al., 2005); McGowan had scored both as retaining them (state 0), which is the case in Platyrhinops before metamorphosis is completed (Schoch, 2002).

Character 37: Supratemporal at least about twice as long as broad (0), about as long as broad (1), or absent (2) (ordered). The ordering sequence, changed from the original (which had "supratemporal [as] long as broad" as state 0 and "supratemporal longer than broad" as state 1), follows from the fact that supratemporals in state 0 are about twice as large as supratemporals in state 1 (relative to total skull size) because the supratemporal in state 1 is shorter but not broader than in state 0 . Since we have replaced the all-zero ancestor by real taxa, the fact that state 1 , rather than 0 , is most likely plesiomorphic does not matter anymore because the tree is rooted by the outgroup, not by the character states that we happen to call ' 0 '; what matters is that in order to change from state 0 to state 2 (as now coded) or vice versa a lineage would most likely have to pass through state
1, supporting the present ordering sequence instead of McGowan's.

Thus, McGowan gave our state 1 to the all-zero ancestor, Branchiosaurus, Apateon, and the amphibamids, and our state 0 to Schoenfelderpeton and Micromelerpeton.

Apateon flagrifer (Werneburg, 1986, 1988b), A. pedestris (Boy, 1978; Heyler, 1994), and A. kontheri (Werneburg, 1988a) have state 0, but $A$. intermedius shows state 1 (Werneburg, 1996), as does the adult and metamorphosed $A$. gracilis (Schoch and Fröbisch, 2006). A. dracyi (Werneburg, 2001) and $A$. caducus (Schoch and Fröbisch, 2006), however, change from 1 to 0 in ontogeny. (Incidentally, the same change happens in Seymouria sanjuanensis and in Discosauriscus: Klembara et al., 2007.) To cope with this diversity, we have scored Apateon as possessing both state 0 and state 1 .

We did not change McGowan's scoring of all microsaurs as lacking a supratemporal (state 2), but see character 13 .

As explained above, we have scored Brachydectes as sharing state 2 .

For Gymnophionomorpha, see character 13.

Character 38: Caudal edge of skull roof straight or concave (0) or convex (1) in dorsal view.

McGowan's matrix shows state 1 for all microsaurs and Gymnophiona.

McGowan (2002: 29) defined this character as "0, posterior skull shape straight; 1 , posterior skull shape convex", but even if a smooth (straight or hyperbolic) line is drawn between the caudolateral edges of the tabulars and the caudal tips of the exoccipitals, most microsaurs still have straight or even concave caudal skull margins, despite being scored as having convex ones. Because the braincase never makes a large difference and is often not preserved in temnospondyls, we omit it from the character definition.

Tuditanids have straight or concave caudal skull edges (Carroll and Gaskill, 1978), corresponding to state 0.

Hapsidopareiontids have straight edges (Carroll and Gaskill, 1978).

Pantylus has a very slightly convex edge (Romer, 1969; Carroll and Gaskill, 1978) that we consider to be within the definition of 'straight' because of uncertainty in the reconstruction resulting from distortion of the specimen and probable individual variation. Furthermore, it is very far from the condition seen in caecilians or Cardiocephalus. The condition in Stegotretus is likewise almost straight, though marginally concave (Berman et al., 1988). We have accordingly scored Pantylidae as having state 0 .

Microbrachis has either a straight (Carroll and Gaskill, 1978) or a slightly concave edge (Vallin and Laurin, 2004), but not a convex one as coded by McGowan.

Gymnarthridae is scored as polymorphic because Cardiocephalus has a convex and Euryodus (especially E. dalyae) a straight caudal skull roof edge; the condition in the other gymnarthrids is unknown (Carroll and Gaskill, 1978, despite the reconstructions in fig. 104).

McGowan also scored Brachystelechidae as having a convex caudal skull edge, but Batropetes and Carrolla have straight ones (Carroll and Gaskill, 1978; Carroll, 1998), while the one of Quasicaecilia is (perhaps ironically) strongly concave (Carroll, 1998).

This leaves state 1 for Gymnophionomorpha, Rhynchon- 
kos, and Brachydectes, and 0 for all other OTUs, except for the polymorphisms mentioned above.

Character 39: Coronoid region with fangs and shagreen (0), shagreen only (1), a single toothrow parallel to that of the dentary (2), toothless (3) (unordered).

See character 16 for the number of coronoids, treated as the same character by McGowan. We have not ordered this character because a gradual reduction of the coronoid dentition might be a reduction in size $(0>2>1>3$ or $2>0>1>3)$, number of rows $(1>0>2>3)$, or both $(0>1>2>3)$; each of these possibilities implies a different ordering sequence, and we lack data to decide between these possibilities or even to test the underlying assumption that any reduction of the coronoid dentition has to be gradual at all.

The situation in Branchiosaurus is unknown (contra McGowan).

Schoenfelderpeton (states 0,1 or 2) and Apateon (entirely unknown) are scored after Boy (1986).

Tuditanidae is scored after Crinodon, which has "a number of large coronoid fangs" that are slightly bigger than the marginal teeth (Carroll and Gaskill, 1978: 25, fig. 10).

Pantylidae is scored as possessing state 0 because the teeth are irregulary arranged and have irregular sizes, even though a classical 'shagreen' is not present.

The polymorphism for Gymnarthridae (states 1 and 2) follows from the conditions of Hylerpeton (which has a second toothrow consisting of two teeth on coronoid III; still state 2) on the one hand and Leiocephalikon (which has three toothrows on coronoid III; state 1) (Carroll and Gaskill, 1978), Bolterpeton (which has a shagreen at least on coronoids I and II; state 1) and Cardiocephalus sp. (two parallel rows of small teeth spanning all three coronoids; most similar to state 1) (Anderson and Reisz, 2003) on the other hand. For Cardiocephalus sternbergi, Carroll and Gaskill (1978) reconstruct what looks like a shagreen (state 1 or 0 ), but "[t]he coronoids cannot be exposed, and only the anterior portion of the dentary can be seen" (Carroll and Gaskill, 1978: 57), so we did not take that species into account.

McGowan scored Hapsidopareiontidae as having "three coronoids with irregular teeth" (his state 0 ), but the situation is unknown in all hapsidopareiontids (Carroll and Gaskill, 1978).

Gymnophionomorpha shows state 2 (the portion of the 'pseudodentary' that bears the lingual toothrow in gymnophionans is indeed homologous to a coronoid; Müller et al., 2005; Müller, 2006).

As stated above, 'Tersomius' has three toothless coronoids (state 3) (Carroll, 1964)

The lower jaws of Platyrhinops and Amphibamus have not been described or illustrated anywhere in the literature McGowan (2002) cites, nor in the additional literature we have been able to find. Accordingly, both had to be scored as unknown.

The score of Micromelerpeton (state 1) follows Boy (1995).

Character 40: Ratio of orbit length to skull-roof length (see state definitions in Appendix-Table 4) (ordered).

McGowan did not quantify this character or explain how he measured orbit size to divide this continuous character into two states; he assigned state 1 ("reduced orbits") to Gymnarthridae, Microbrachis, Rhynchonkos and Gymnophiona, and state 0 ("large orbits") to all other OTUs.

We have measured the ratio of rostrocaudal orbit length (independent of orbit orientation) to skull-roof length along the midline in dorsal view (Appendix-Table 4, Appendix-Fig. 2). Using this metric, it turns out McGowan placed the boundary between the two states into one of the smallest available gaps in the distribution (between Microbrachis, state 1, and Micromelerpeton, state 0). We see no reason for this decision. Instead, we have used stepmatrix gap-weighting (Wiens, 2001) as explained above for character 20 .

We have scored Branchiosaurus and Schoenfelderpeton as possessing their measured character state or any higher-numbered one (see Appendix-Table 4), because none of the known specimens are adult and because, unsurprisingly, relative orbit size decreases in the ontogeny of Apateon gracilis (Schoch and Fröbisch, 2006).

We have not measured any salientians, but, with very few and clearly derived exceptions, such as Calyptocephalella ('Caudiverbera': Duellman and Trueb, 1986: figs 13-17F), the orbit makes up at least half of skull length (Reig, 1961; Duellman and Trueb, 1986; Sanchíz, 1998; Gao and Chen, 2004; Carroll, 2007). Although most of its snout is not preserved, so that the skull roof length is unknown, the same seems to hold for Triadobatrachus judging from the curvature of its jaws (Roček and Rage, 2000; pers. obs. May $30^{\text {th }}, 2008$ ). Thus, we have treated Salientia as having a ratio of 0.5 and thus possessing state 0 .

The skull roof of Gerobatrachus is slightly disarticulated, so precise measurements cannot be made. However, the orbits were clearly about half as long as the skull roof (Anderson et al., 2008a: fig. 2). We have therefore scored this taxon as possessing state 0 in the analysis where we treat it as adult, and as unknown (i.e., state 0 or higher) in the analysis where we treat it as immature or paedomorphic.

The other scores are explained in Appendix-Table 4. To further avoid the effect of ontogeny, we have only used the smallest ratio we could find for each OTU, except for Gymnophionomorpha, where we have only used Eocaecilia which was, in what is most parsimoniously interpreted as a plesiomorphic condition, less strongly adapted to burrowing (Jenkins et al., 2007) and thus has relatively larger orbits than the extant caecilians (including the aquatic ones, which retain small eyes).

We have not tried to correct for the well-known ontogeny-independent correlation between relative eye size and absolute body size. Firstly, we are not aware of any other ontogeny-independently size-dependent characters in our matrix - size itself has a strong phylogenetic signal (Laurin, 2004) and can therefore do no harm if only one character correlated to it is present in a data matrix. Secondly, most of the animals studied here have similar sizes. Thirdly, the orbits of (at least) salientians, caudates, and presumably albanerpetontids and Brachydectes accommodate not only the eyes, but also jaw muscles, the relative size of which does not have a simple relationship with body size; in fact, all else being equal, the expected relation between orbit size and body size could even be negative, because muscle force scales with muscle cross-sectional area and thus the $2^{\text {nd }}$ 


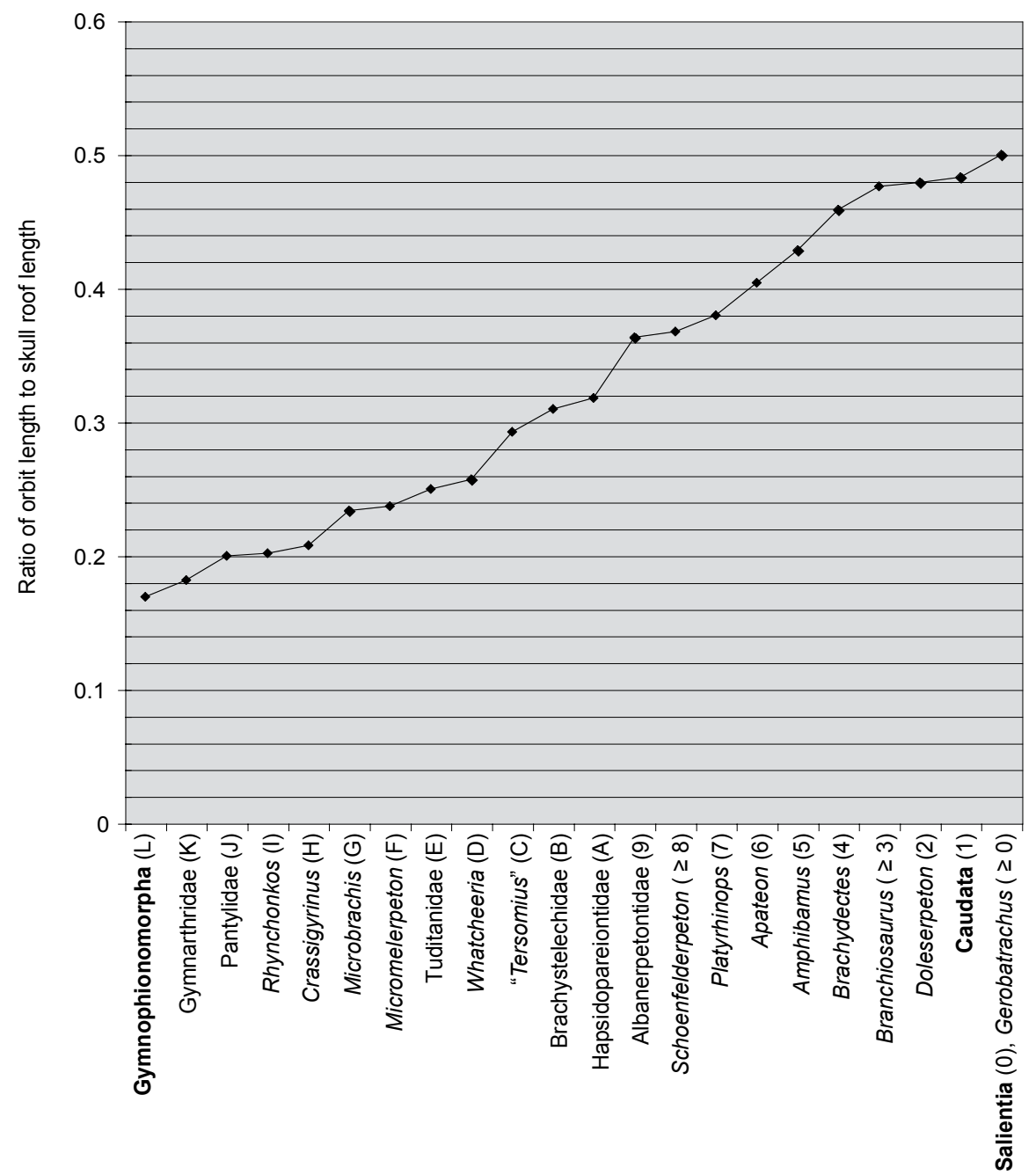

Appendix-Fig. 2. Ratio of rostrocaudal orbit length to skull roof length in dorsal view (character 40). The line drawn between the data points is meant to visualize the sizes of the morphological gaps by its varying steepness. The state of each OTU is indicated after its name. Extant taxa in bold. Data shown in Appendix-Table 4.

power of body length, while body mass scales with the $3^{\text {rd }}$ power, so that, if bite forces are to be proportional to body mass, a larger body requires disproportionately large jaw muscles and thus disproportionately large orbits (or 'orbitotemporal fenestrae' as they are sometimes called in salientians and caudates). Last but not least, not much of a size trend is apparent in the data-most conspicuously, the largest animal in the data matrix, Crassigyrinus, has a relative orbit size similar to those of small microsaurs; the next largest animal, Whatcheeria, has a much larger relative orbit size than Crassigyrinus; and Whatcheeria has considerably larger orbits than Micromelerpeton, the temnospondyl with the most plesiomorphic skull shape in the matrix, which in turn has only marginally larger orbits than the paedomorphic microsaur Microbrachis. Furthermore, while eye size is correlated to lifestyle in extant amphibians (larvae and aquatic adults having markedly smaller eyes than terrestrial adults; Witzmann and Pfretzschner, 2003), this does apparently not hold for other taxa in the present matrix, at least not for Micromelerpeton, which has "strikingly large [orbits] for a water-dwelling amphibian" (compared to extant amphibians) (Witzmann and Pfretzschner, 2003: 761), yet considerably smaller ones than the equally aquatic and much larger Whatcheeria, as mentioned above. Also, like Micromelerpeton, Whatcheeria does not have a disproportionately small skull.

Character 41: jaw joints well caudal of the exoccipitals (0), at the same level (within 5\% of skull length in the sagittal plane) (1), or well rostral to it (2) (ordered).

McGowan had exchanged states 1 and 2 to fit his scenario of evolution, even though it has to be assumed that the evolutionary change between these two states of this continuous character must have happened gradually, passing through the third, which is why we have ordered this character (Wiens, 2001). Thus, McGowan assigned our state 1 to Pantylidae and Salientia, and state 0 to the amphibamids, Micromelerpeton, and the all-zero ancestor.

We have added the quantification of the states of this potentially continuous character (although few if any borderline cases exist where presumably adult specimens cannot be assigned to one of two adjacent states by eye), and the speci- 


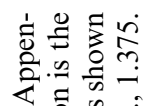

.

氖氙

a

ปั

की

苟步

ช

引웜웅

引.

矛过穴

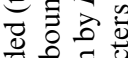

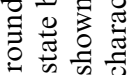

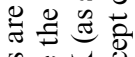

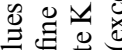

急要

过

字芴

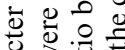

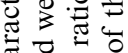

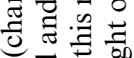

훙히

․․ㄹ

赵

을

$\Xi$

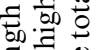

可

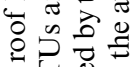

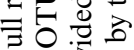

至

일

艁

6on

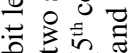

요류

氙焉?

요에

约 일

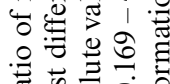

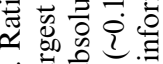

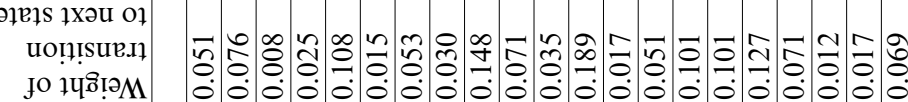

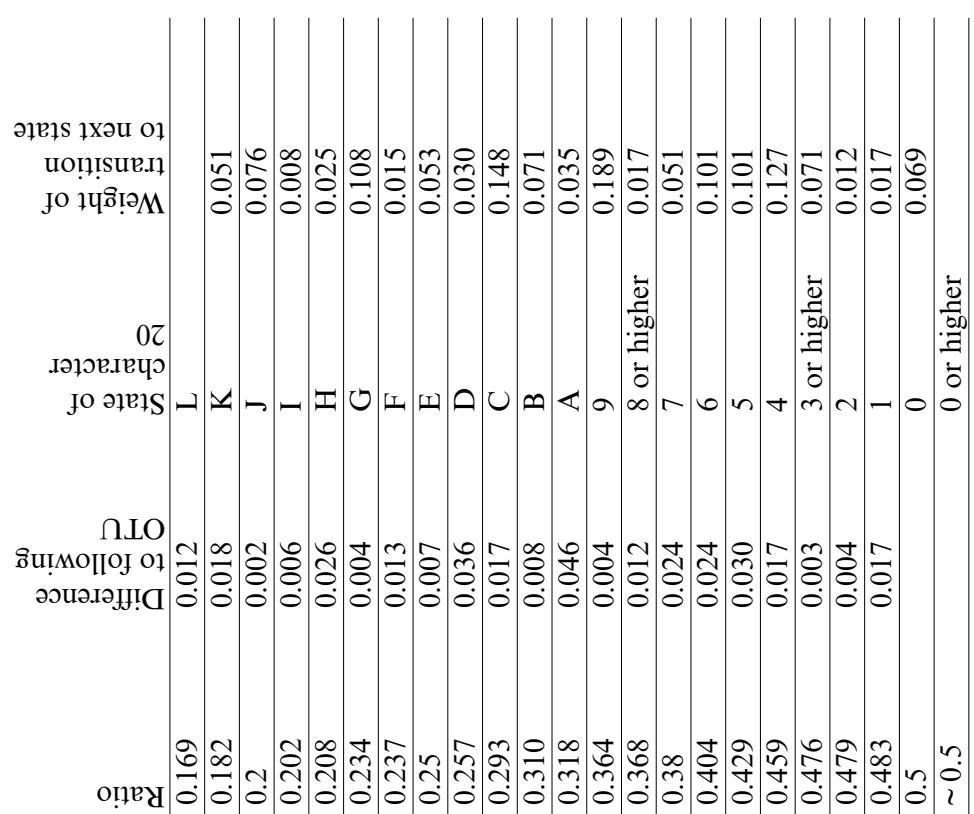

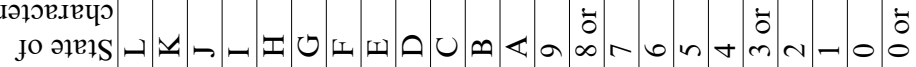

กLO

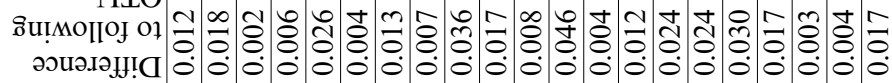

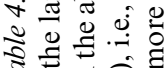

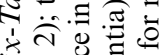

bo

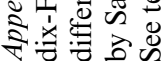

оाру

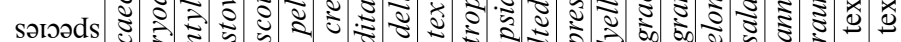

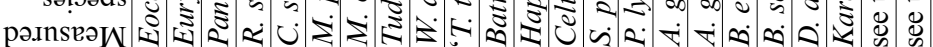

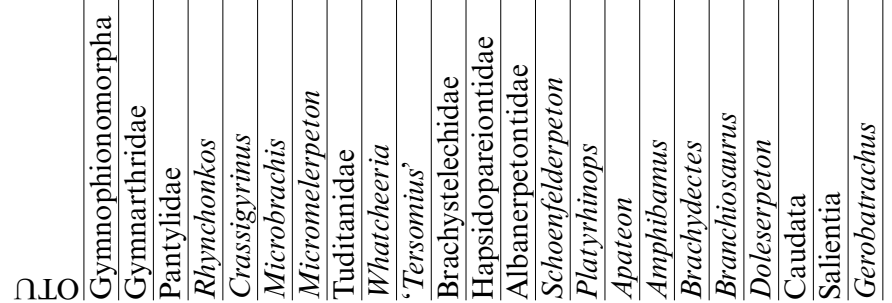


fication of what 'occiput' should mean - if the caudal margin of the skull roof were chosen, too much correlation with character 38 would likely result.

McGowan scored all branchiosaurids as showing our state 2, but this character changes from 2 to 1 and then to 0 in ontogeny, reaching 1 in neotenic adults of Apateon caducus and late larvae of $A$. gracilis, and continuing to 0 in adults of A. gracilis (Schoch and Fröbisch, 2006). (In Leptorophus tener, too, state 0 is known to occur: Boy, 1986.) Accordingly, we have scored Apateon as 0 and the other two branchiosaurids as unknown (Wiens et al., 2005) because metamorphic adults are only known from $A$. gracilis. In the case of Branchiosaurus, however, we have been able to restrict the uncertainty to 'state 0 or 1', because B. salamandroides is known to have reached at least state 1 (Boy, 1987).

The tuditanids Asaphestera, Crinodon, and most likely Boii have state 1, but Tuditanus itself exhibits state 0 (Carroll and Gaskill, 1978), so we have scored Tuditanidae as possessing both states.

The hapsidopareiontids Hapsidopareion, Llistrofus, and Saxonerpeton (Carroll and Gaskill, 1978) and Microbrachis (Carroll and Gaskill, 1978; Vallin and Laurin, 2004) show state 1 .

The karaurid Kokartus (Milner, 2000) seems to be the only caudate with state 1; all others have state 2 (Duellman and Trueb, 1986; Milner, 2000), so we have kept McGowan's scoring of Caudata as possessing state 2 .

Triadobatrachus has state 0 (Roček and Rage, 2000), while all other salientians (Sanchíz, 1998) seem to have state 1 as scored by McGowan (with a few clearly derived exceptions), so we have scored Salientia as showing both states.

Gerobatrachus exhibits state 1, which we have taken at face value for the analysis in which we treat Gerobatrachus as adult. Further growth could, however, have resulted in state 0 because the suspensorium normally moves caudally in temnospondyl and lissamphibian ontogeny (Schoch and Fröbisch, 2006, and references therein), so we have scored it as possessing state 1 or 0 for the analysis where we treat it as immature or paedomorphic.

Character 42: Dorsal scales well ossified (0), poorly ossified (1), or absent (2) (ordered).

McGowan treated dorsal and ventral scales as the same character, but they are independent (Witzmann, 2007), so we have have split McGowan's character 4; see our character 4 for more information. Furthermore, McGowan coded only two states, presence (0) and absence (1) of scales; we have separated states 1 (poorly ossified) and 2 (absent) for the dorsal scales to account for the difference between Tuditanus and
Gymnophionomorpha on the one hand and most other OTUs on the other, and ordered it for the same reason as character 4.

Dorsal scales are absent (state 2) in Whatcheeria, Crassigyrinus, Rhynchonkos (see also character 4), Caudata, Salientia, and Brachydectes. Elsewhere, dorsal scales are generally present (states 0 and 1). Their absence in both outgroups happens to make their presence an autapomorphy of the ingroup, illustrating once again the dangers of low outgroup sampling in particular and low taxon sampling in general.

Although they are reduced in Tuditanus (Carroll and Baird, 1968; Carroll and Gaskill, 1978: 17, 183), dorsal scales are well ossified in the other tuditanids, so we have assigned states 0 and 1 to Tuditanidae.

Most specimens of Pantylus lack scales, and the single exception only shows "fragments" (Carroll and Gaskill, 1978: 183); however, this is likely due to disarticulation and/or preparation. "[E]xtensive scalation" (Carroll and Gaskill, 1978: 183) is present in Trachystegos, which may or may not be a pantylid or gymnarthrid, among other possibilities (Carroll and Gaskill, 1978; Schultze and Foreman, 1981; Berman et al., 1988; Carroll, 1998). No specimen of Stegotretus is well enough preserved that the absence of scales could be taken at face value. Based on the 'fragments' in the mentioned Pantylus specimen, we have scored dorsal scales as well ossified in Pantylidae.

Scales are absent in all articulated gymnarthrid specimens, and the associations of disarticulated gymnarthrids with scales are all questionable (Carroll and Gaskill, 1978: 183), so we have scored Gymnarthridae as lacking dorsal scales (as well as ventral ones, see character 4) under the assumption that Trachystegos is not a gymnarthrid.

Among brachystelechids, only Batropetes is known from more than an isolated skull, and Batropetes has not been prepared in dorsal view (Carroll, 1991). We have therefore scored Brachystelechidae as unknown.

Scales are not known in Eocaecilia, but given the poor preservation potential of the scales of extant caecilians and the state of preservation of all specimens of Eocaecilia shown or described by Jenkins et al. (2007), we have relied on Gymnophiona alone (Rubricacaecilia being much too fragmentary for us to expect preserved scales) in assigning state 1 to Gymnophionomorpha.

Among amphibamids, dorsal scales are known only from Eoscopus (Daly 1994), which is not in the present matrix. However, as in character 4, we have only taken this at face value (state 2) for Platyrhinops and Amphibamus, for which specimens are known that are well enough preserved to distinguish nonpreservation from absence. 


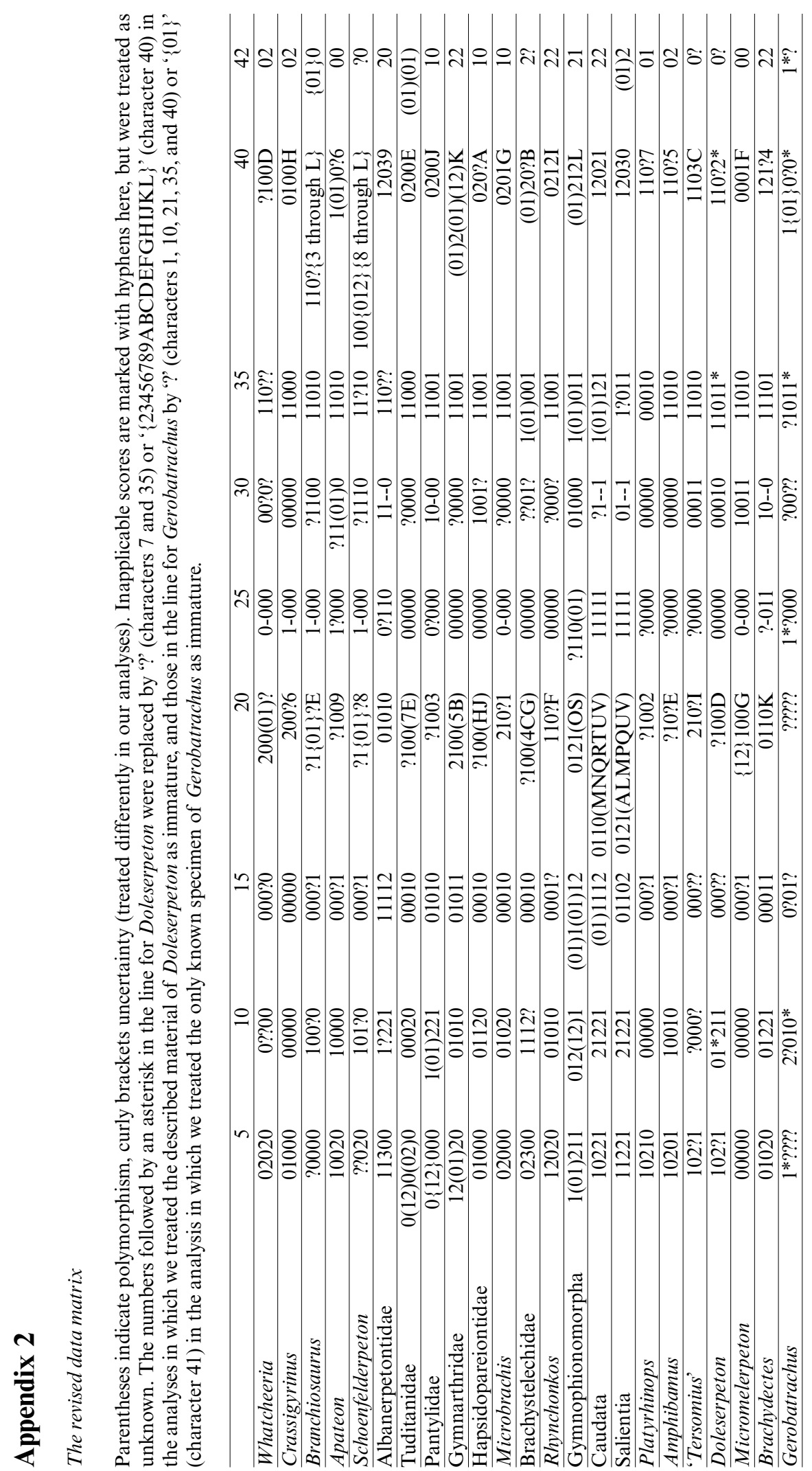




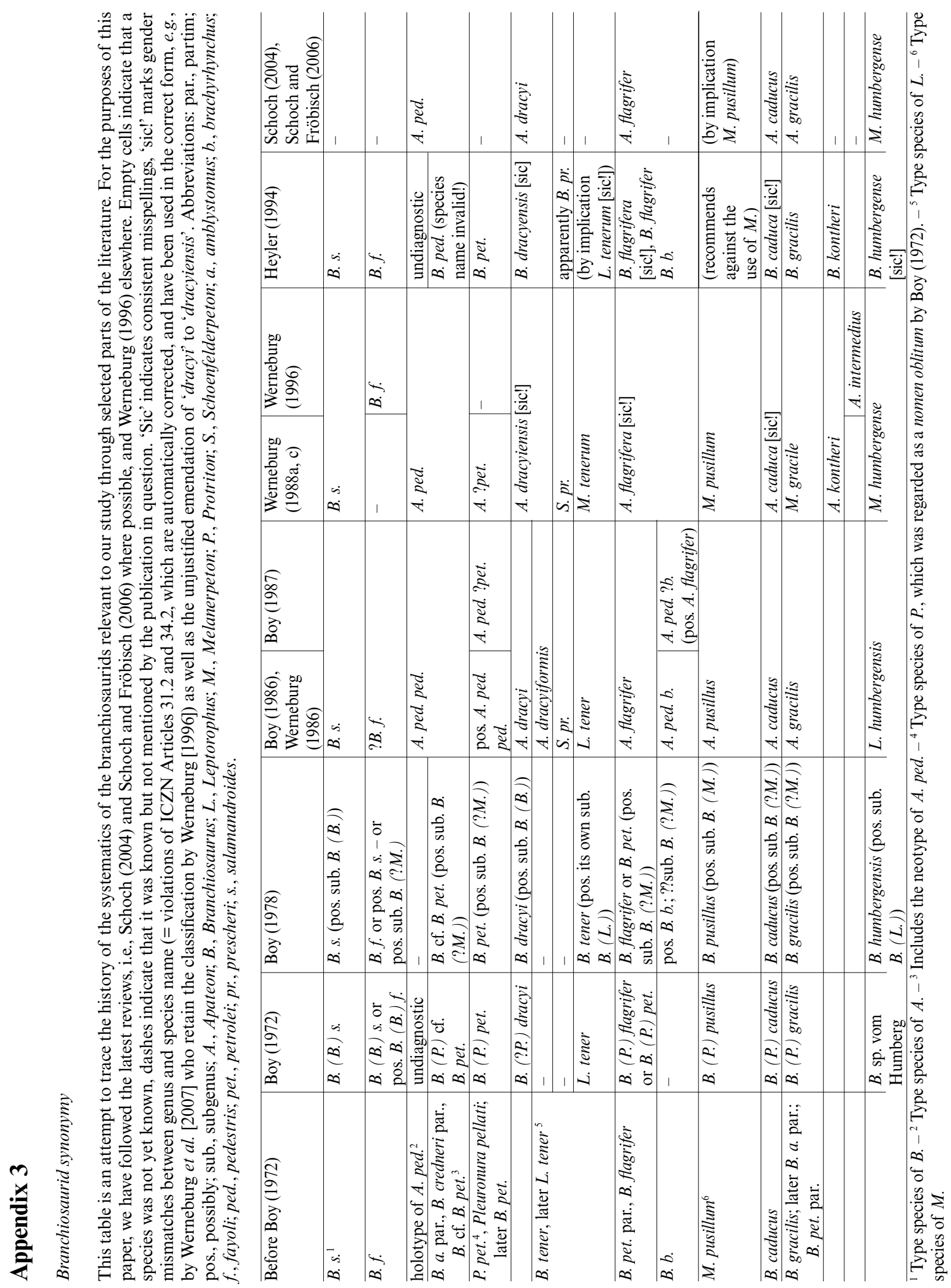

